
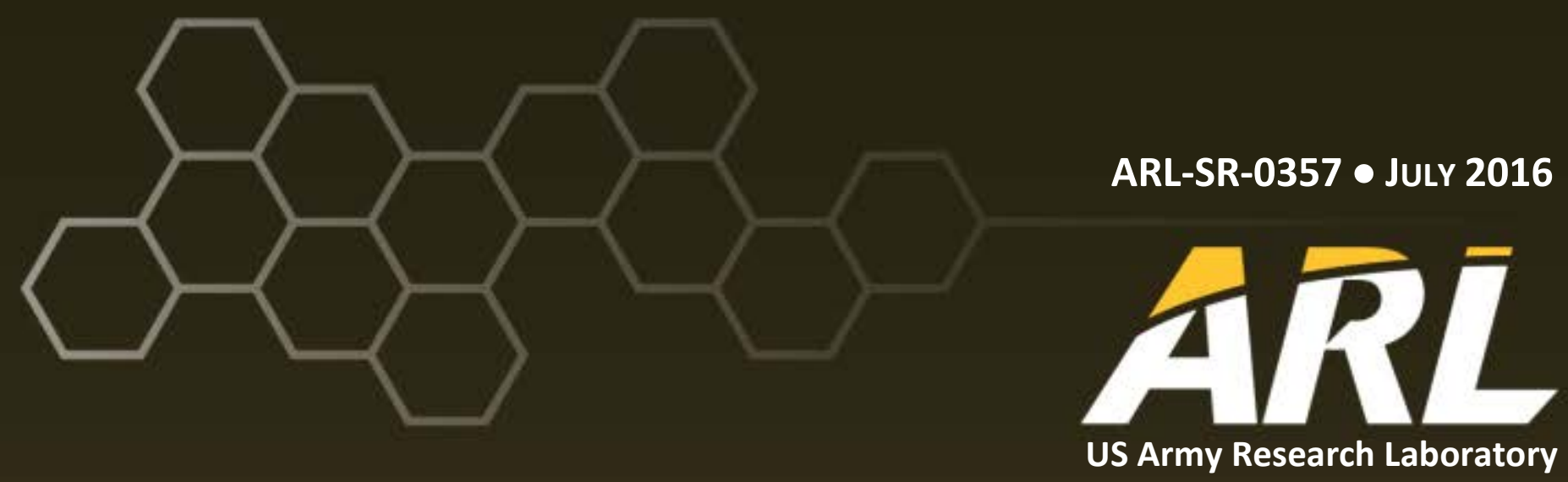

\title{
Advances in Additive Manufacturing
}

\author{
Compiled by Marc S Pepi
}

A Compilation of Presentations by Marc Pepi, Todd Palmer, Jennifer Sietins, Jonathan Miller, Dan Berrigan, and Ricardo Rodriquez 


\section{NOTICES}

\section{Disclaimers}

The findings in this report are not to be construed as an official Department of the Army position unless so designated by other authorized documents.

Citation of manufacturer's or trade names does not constitute an official endorsement or approval of the use thereof.

Destroy this report when it is no longer needed. Do not return it to the originator. 
ARL-SR-0357 • JULY 2016

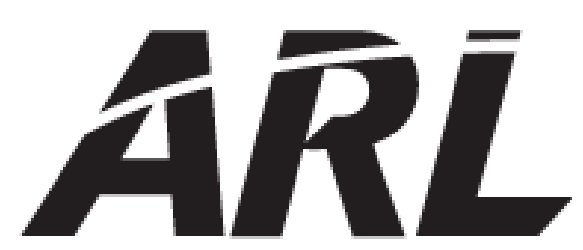

US Army Research Laboratory

\title{
Advances in Additive Manufacturing
}

\author{
Compiled by Marc S Pepi
}

A Compilation of Presentations by Marc Pepi, Todd Palmer, Jennifer Sietins, Jonathan Miller, Dan Berrigan, and Ricardo Rodriquez 


\begin{tabular}{|c|c|c|c|c|c|}
\hline \multicolumn{5}{|c|}{ REPORT DOCUMENTATION PAGE } & $\begin{array}{l}\text { Form Approved } \\
\text { OMB No. 0704-0188 }\end{array}$ \\
\hline \multicolumn{6}{|c|}{$\begin{array}{l}\text { Public reporting burden for this collection of information is estimated to average } 1 \text { hour per response, including the time for reviewing instructions, searching existing data sources, gathering and maintaining the } \\
\text { data needed, and completing and reviewing the collection intormation. Send comments regarding this burden estimate or any other aspect of this collection of information, including suggestions for reducing the } \\
\text { burdent to Department of Defense, Washington Headquarters Services, }\end{array}$} \\
\hline \multirow{2}{*}{\multicolumn{2}{|c|}{$\begin{array}{l}\text { 1. REPORT DATE (DD-MM-YYYY) } \\
\text { July } 2016\end{array}$}} & \multicolumn{3}{|l|}{ 2. REPORT TYPE } & 3. DATES COVERED (From - To) \\
\hline & & \multicolumn{3}{|l|}{ Special Report } & 1-31 May 2015 \\
\hline \multirow{3}{*}{\multicolumn{5}{|c|}{$\begin{array}{l}\text { 4. TITLE AND SUBTITLE } \\
\text { Advances in Additive Manufacturing }\end{array}$}} & 5a. CONTRACT NUMBER \\
\hline & & & & & \\
\hline & & & & & 5c. PROGRAM ELEMENT NUMBER \\
\hline \multirow{2}{*}{\multicolumn{5}{|c|}{$\begin{array}{l}\text { 6. COMPILER(S) } \\
\text { Marc S Pepi }\end{array}$}} & 5d. PROJECT NUMBER \\
\hline & & & & & \\
\hline \multirow{2}{*}{\multicolumn{5}{|c|}{ Marc S Pepi }} & 5e. TASK NUMBER \\
\hline & & & & & 5f. WORK UNIT NUMBER \\
\hline \multicolumn{5}{|c|}{ 7. PERFORMING ORGANIZATION NAME(S) AND ADDRESS(ES) } & 8. PERFORMING ORGANIZATION REPORT NUMBER \\
\hline \multicolumn{5}{|c|}{$\begin{array}{l}\text { US Army Research Laboratory } \\
\text { ATTN: RDRL-WMM-D } \\
\text { Aberdeen Proving Ground, MD 21005-5069 }\end{array}$} & ARL-SR-0357 \\
\hline \multirow{2}{*}{\multicolumn{5}{|c|}{ 9. SPONSORING/MONITORING AGENCY NAME(S) AND ADDRESS(ES) }} & 10. SPONSOR/MONITOR'S ACRONYM(S) \\
\hline & & & & & 11. SPONSOR/MONITOR'S REPORT NUMBER(S) \\
\hline \multicolumn{6}{|c|}{ 12. DISTRIBUTION/AVAILABILITY STATEMENT } \\
\hline \multicolumn{6}{|c|}{ Approved for public release; distribution is unlimited. } \\
\hline \multicolumn{6}{|c|}{ 13. SUPPLEMENTARY NOTES } \\
\hline \multicolumn{6}{|l|}{ 14. ABSTRACT } \\
\hline \multicolumn{6}{|c|}{$\begin{array}{l}\text { This special report is a compilation of the presentations provided at the } 2016 \text { Society for Machinery Failure Prevention } \\
\text { Technology conference in Dayton, OH, on 23-26 May 2016. These } 6 \text { briefs were presented in the Additive Manufacturing } \\
\text { session and provide a summary of work being performed in additive manufacturing by the Army, Air Force, and academia } \\
\text { (Penn State University). }\end{array}$} \\
\hline \multicolumn{6}{|c|}{ 15. SUBJECT TERMS } \\
\hline \multirow{2}{*}{\multicolumn{3}{|c|}{ 16. SECURITY CLASSIFICATION OF: }} & 17. LIMITATION & 18. NUMBER & 19a. NAME OF RESPONSIBLE PERSON \\
\hline & & & OF & OF & Marc S Pepi \\
\hline a. REPORT & b. ABSTRACT & c. THIS PAGE & & PAGES & 19b. TELEPHONE NUMBER (Include area code) \\
\hline Unclassified & Unclassified & Unclassified & UU & 110 & $410-306-0848$ \\
\hline
\end{tabular}




\section{Contents}

Acknowledgments

1. Introduction

2. Agile Additive Manufacturing in Austere Environments (Marc Pepi, Army Research Laboratory, Weapons and Materials Research Directorate)

3. Role of Processing-Structure-Property Relationships in Developing Certification Protocols for Ti-6Al-4V Components (Todd Palmer, Pennsy/vania State University, Applied Research Laboratory)

4. Additive Manufacturing Characterization Utilizing X-ray Computed Tomography (Jennifer Sietins, Army Research Laboratory, Weapons and Materials Research Directorate)

5. Quality Assurance Methods for Additive Manufacturing Processes: Motivation, Challenges, and Opportunities (Jonathan Miller, Air Force Research Laboratory/Metals Branch)

6. Air Force Vision and Challenges for Additive Manufacturing of Functional and Soft Matter Materials (Dan Berrigan, Air Force Research Laboratory/Metals Branch)

7. Army Research Laboratory's Additive Manufacturing for the Future Expeditionary Force (Ricardo Rodriguez, Army Research Laboratory, Weapons and Materials Research Directorate)

List of Symbols, Abbreviations, and Acronyms101

Distribution List 


\section{Acknowledgments}

The following personnel were instrumental in providing contributions to the briefs herein:

Army Research Laboratory, Weapons and Materials Research Directorate

- $\quad$ Raymond Wildman

- $\quad$ Nicole Zander

- Margaret Gillan

- Andrew Gaynor

- William Green

- $\quad$ Larry Holmes

Pennsylvania State University, Applied Research Laboratory

- $\quad$ Rich Martukanitz

- Ken Meinert

- Ted Reutzel

- Jay Keist

- Griffin Jones

- Jay Tressler

- Ed Good

- Pan Michaleris

- Michael Gouge

- Erik Denlinger

- Jarred Heigel

- Dennis Krizcky

- T DebRoy

- Long-Qing Chen

- Ashwin Raghavan 
- B Carroll

- Allison Beese

- $\quad$ Patrick Hricko

- Huiliang Hue

- Reggie Hamilton

- Beth Bimber

Air Force Research Laboratory, Metals Branch

- Eddie Schwalbach

- Mike Groeber

- Benjamin Leever

- James Hardin

- $\quad$ Phillip Buskohl

- Abby Juhl

- Ryan Kohlmeyer

- Aaron Blake

- Ming Shao

- Jason Wilkinson

- Giorgio Bazzan

- Michael Durstock

Rutgers University

- Rik Riman 
INTENTIONALLY LEFT BLANK. 


\section{Introduction}

The Society of Machinery Failure Prevention Technology (MFPT) held its first session in additive manufacturing (AM) at the 2016 conference in Dayton, Ohio, on May 24th, 2016. The presentations included work being performed within the Department of Defense (Army Research Laboratory [ARL] and Air Force Research Laboratory [AFRL]) as well as academia (Penn State University's Applied Research Laboratory) in the area of AM, with a focus on the technologies that the MFPT community could provide assistance with in this area (nondestructive testing and inspection, prognostics, diagnostics, structural health monitoring, failure analysis, data management, and sensors). This report includes all 6 of the presentations briefed at the conference.

Additive manufacturing is an emerging and disruptive technology that is transforming the manufacturing industry by allowing the designer to convert a computer model to a finished product in a few steps while overcoming the constraints associated with traditional manufacturing. There are many different technologies that comprise additive manufacturing, with the ability of utilizing polymer materials, metals, ceramics, fibers, and combinations therein.

Marc Pepi (Team Leader, Near-Net Shape Processing Team, ARL) briefed the status of an ARL program titled "On-Demand Manufacturing of Recycled, Reclaimed and Indigenous Materials”. Mr Pepi indicated that AM on the battlefield could provide a logistical and tactical advantage for the Warfighter. This research focuses on 3 different aspects of additive manufacturing on the battlefield: 1) researching the formation of AM-grade metal powder from battlefield scrap and operating base waste, 2) potential of 3-D printing with sand to make casting molds for traditional casting processes on the battlefield, and 3) the use of recycled polymeric materials as feedstock for 3-D printers already on the battlefield within the Army Rapid Equipping Force Expeditionary Laboratory. Todd Palmer (Senior Research Associate and Associate Professor, Pennsylvania State University, Applied Research Laboratory) subsequently briefed his presentation "Role of Processing-Structure-Property Relationships in Developing Certification Protocols for Ti-6Al-4V Components”, stressing that AM certification requires an understanding of the processing-structure-property relationships of the materials used for AM. He showed the importance of locking down the manufacturing process steps for repeatability in structure and properties of Ti-6Al-4V. Jennifer Sietins (Materials Engineer, ARL) then briefed "Additive Manufacturing Characterization Utilizing X-ray Computed Tomography”, which showed the impact of X-ray computed tomography (CT) in the nondestructive inspection of 
AM parts for quality control, dimensional tolerance, and microstructural characterization.

The second AM session at the conference commenced with Jonathan Miller (AM Lead for Materials and Manufacturing Directorate, AFRL) presenting “Quality Assurance Methods for Additive Manufacturing Processes: Motivation, Challenges and Opportunities”, summarizing the importance of understanding the many implicit details of AM processing that affect the final structure and properties of the built component. Dan Berrigan (Program Manager and Research Scientist, AFRL) followed with a presentation titled "Air Force Vision and Challenges for Additive Manufacturing of Functional and Soft Matter Materials”, focusing on flexible hybrid electronics. He highlighted a few projects in additively manufactured electronics (e.g., batteries, capacitors, antennas) that span bench-level research to engineered solutions. In addition, he discussed the path forward as AFRL begins to explore the fundamental materials and processing challenges associated with pattern stimuli responsive materials and design of soft mechanical structures/actuators. The final paper was presented by Ricardo Rodriguez (Materials Engineer, ARL), entitled “ARL's Additive Manufacturing for the Future Expeditionary Force”. This brief summarized the impact AM will have as the Army changes its focus from a traditional force into a more expeditionary force and hybrid AM techniques developed at ARL. 


\section{Agile Additive Manufacturing in Austere Environments}

\section{Marc Pepi}

(Army Research Laboratory, Weapons and Materials Research Directorate)

Additive manufacturing provides many cost-saving advantages to industry and the ability to manufacture complex and unique designs and geometries in a timely fashion. It also provides a more environmentally friendly means of production (leads to less waste than subtractive manufacturing). The Department of Defense is now interested in additive manufacturing as a means of being able to produce parts “on-demand” in extreme environments, such as on a ship or on a forward-operating base. However, there are technical challenges that need to be overcome to fully achieve this capability in the future. One such challenge is part quality, and the qualification and certification of parts produced in this manner to ensure the parts will not fail in service. This paper will discuss this and other challenges in more detail, and will provide a lead for other briefs on additive manufacturing to be featured in the same session. 

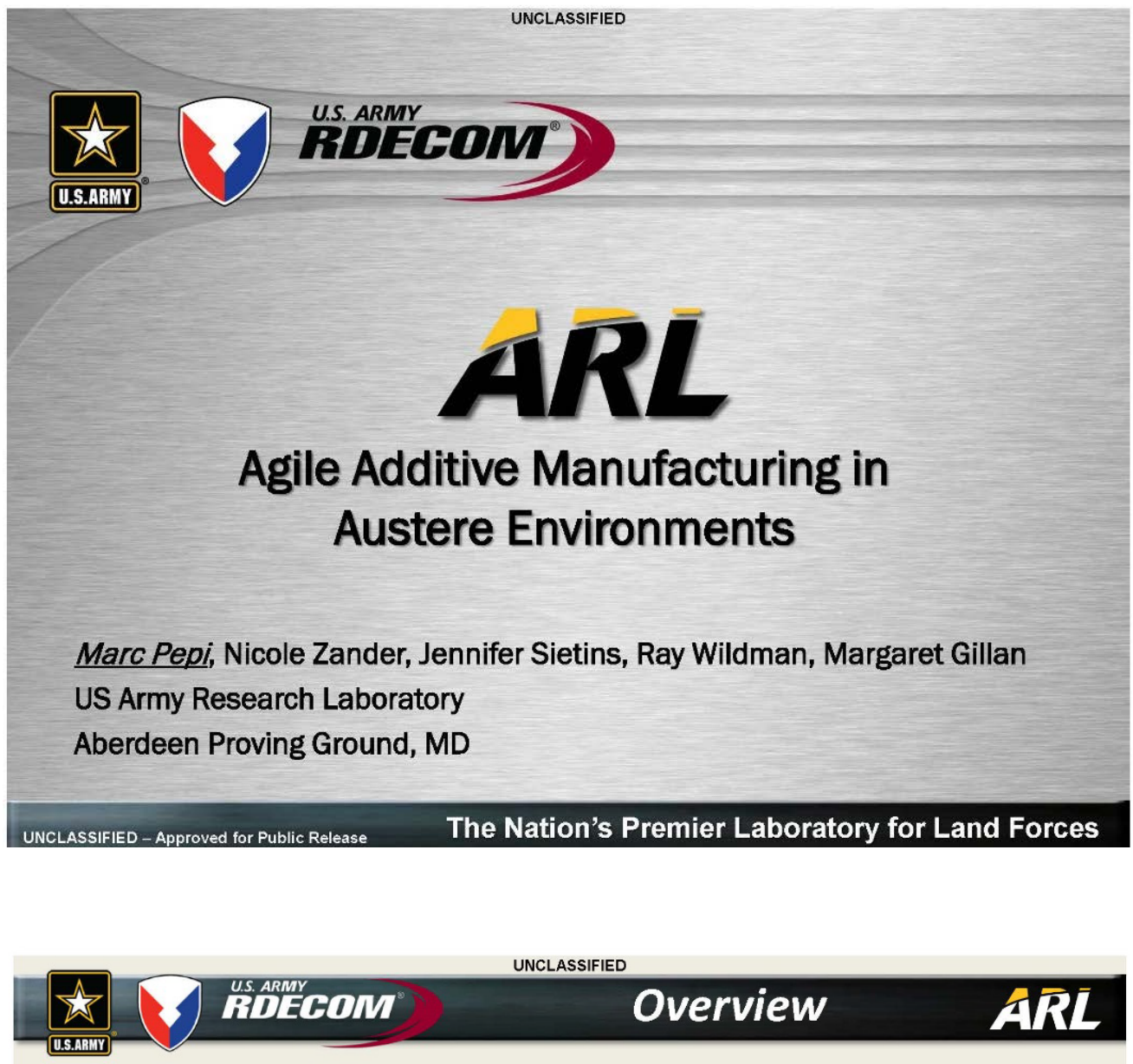

- What is "Additive Manufacturing"?

- How can Additive Manufacturing help the DoD?

- Additive manufacturing on the battlefield...ARLs current work with:

$\checkmark$ Metal AM

$\checkmark$ Sand + Binder AM with traditional foundry methods

$\checkmark$ Polymeric 3D printing

- Conclusions

General Dwight D. Eisenhower noted, “ You will not find it difficult to prove that battles, campaigns, and even wars have been won or lost primarily because of logistics." 
UNCLASSIFIED

\section{WIDECOM What is Additive Manufacturing? A $\bar{A} \overline{\mathbf{R}}$}

Definition ${ }^{1,2}$ :

- Additive manufacturing is a process of joining materials to make objects from 3D model data, usually layer upon layer, as opposed to subtractive manufacturing methodologies.

- 3D printing is the fabrication of objects through the deposition of a material using a print head, nozzle or other printer technology.

Eight processing steps common to additive manufacturing ${ }^{3}$ :

- conceptualization and Computer-Aided Design (CAD)

- conversion to STereoLithography (STL) / Additive Manufacturing Format (AMF)

- transfer and manipulation of STL file on AM machine

- machine setup

- build product

- part removal and cleanup

- post-processing of part

- application of printed part

${ }^{1}$ Additive Manufacturing Challenges and Opportunities for Military Applications, Joseph Hazeltine, RIAC TAT: RI-13-RMS\#690/DO\#290, November 2013

2 ASTM-F2792-12a, "Standard Terminology for Additive Manufacturing Technologies", ASTM, West Conshohocken, PA, 2012.

${ }^{3}$ Naval Postgraduate School Monterey, California Thesis, Additive Manufacturing In The Marine Corps, by Luke J. McLearen, June 2015.

UNCLASSIFIED

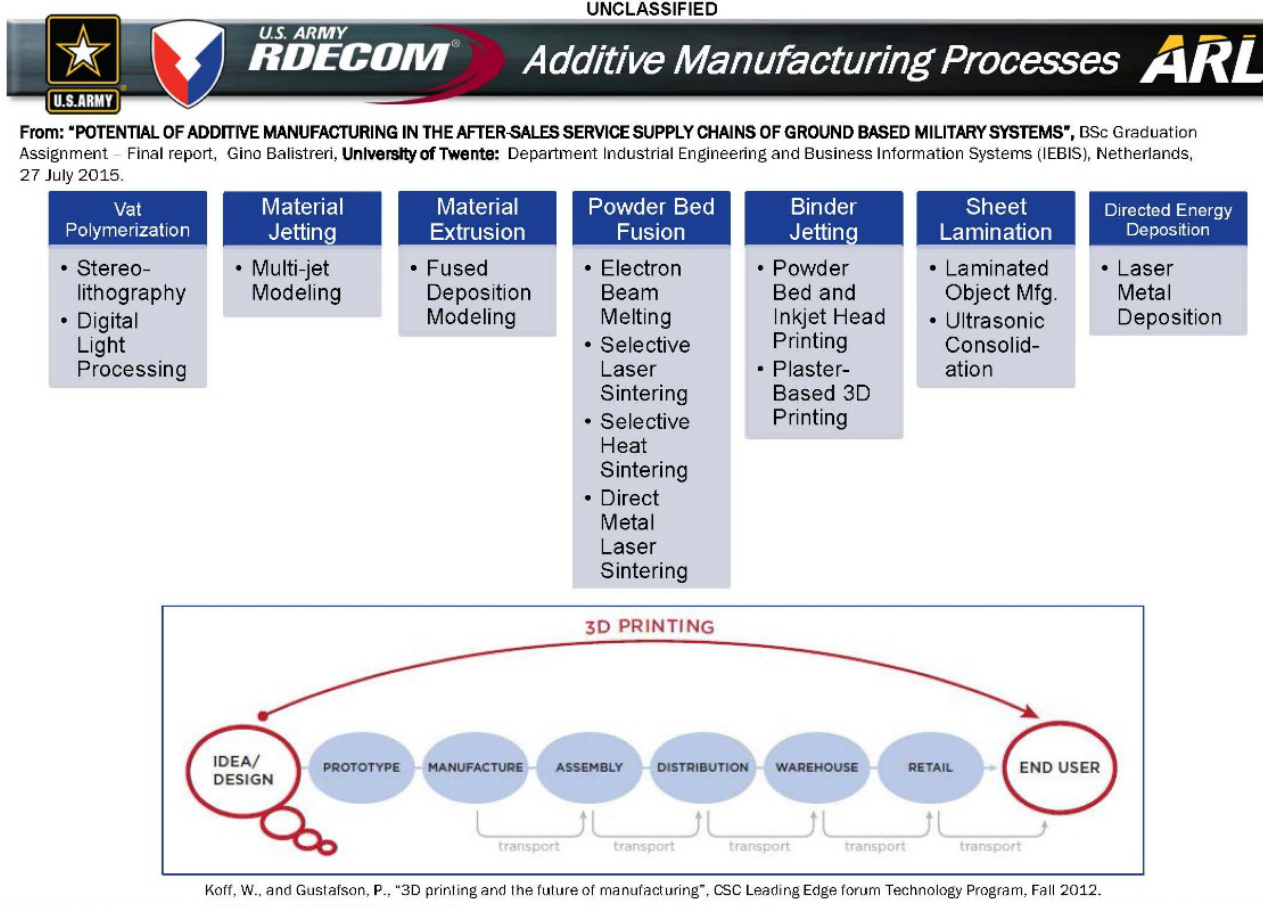


Key AM applications with high potential significance to DoD, now and in the future:

- Prototyping / Modeling

$>$ Intended to improve an existing design

- Tooling / Support Aids / Direct Part Production

$>$ Offers design flexibility, lighter weight, increased complexity, modularity, cost efficiency

- Maintenance and Repair

> On-demand spare parts production, and field repairs (so far, better suited for

- Medical depot level versus field-level)

- Food

Even after a decade of combat operations in Iraq and Afghanistan, parts requisitioning was a long process. Every day a piece of equipment is inoperable because of a repair part is another day that a unit's overall capability is degraded.

*Additive Manufacturing Challenges and Opportunities for Military Applications, Joseph Hazeltine, RIAC TAT: RI-13-RMS\#690/DO\#290, November 2013.

*Naval Postgraduate School Monterey, California Thesis, Additive Manufacturing In The Marine Corps, by Luke J. McLearen, June 2015. UNCLASSIFIED - Approved for Public Release The Nation's Premier Laboratory for Land Forces

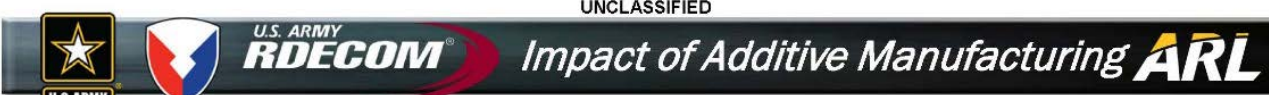

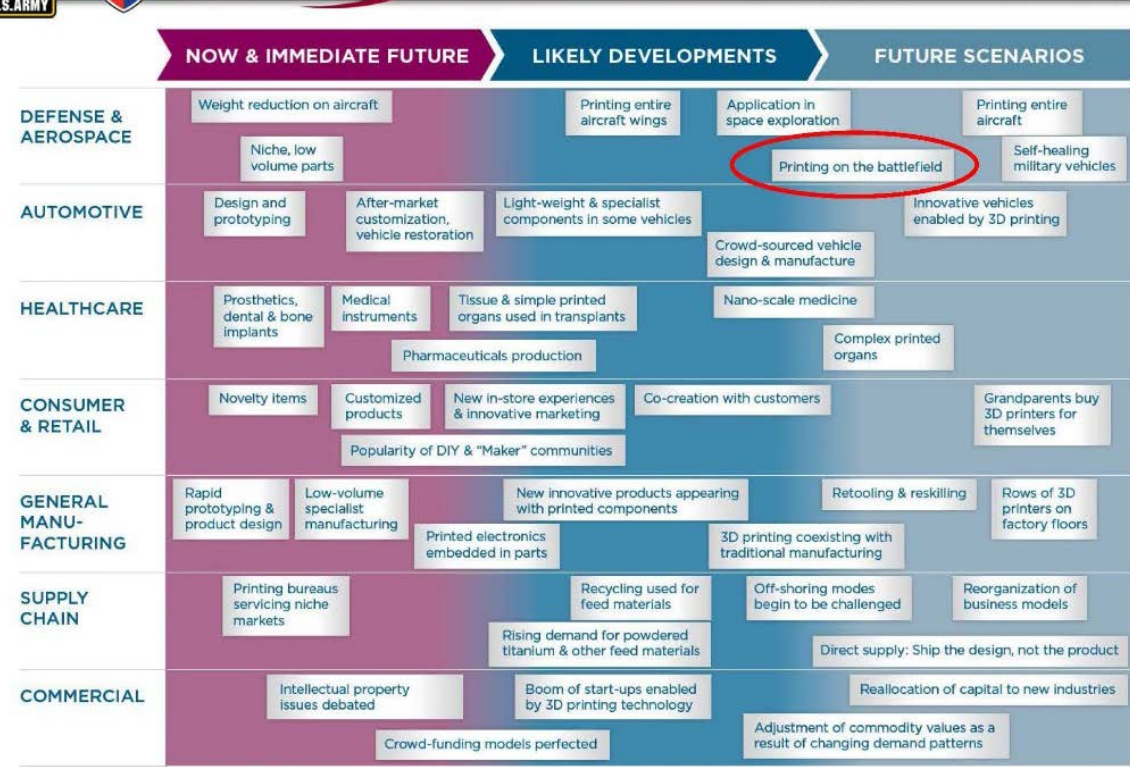

From: Koff, W., and Gustafson, P., "3D printing and the future of manufacturing”, CSC Leading Edge forum Technology Program, Fall 2012.

UNCLASSIFIED - Approved for Public Release The Nation's Premier Laboratory for Land Forces 

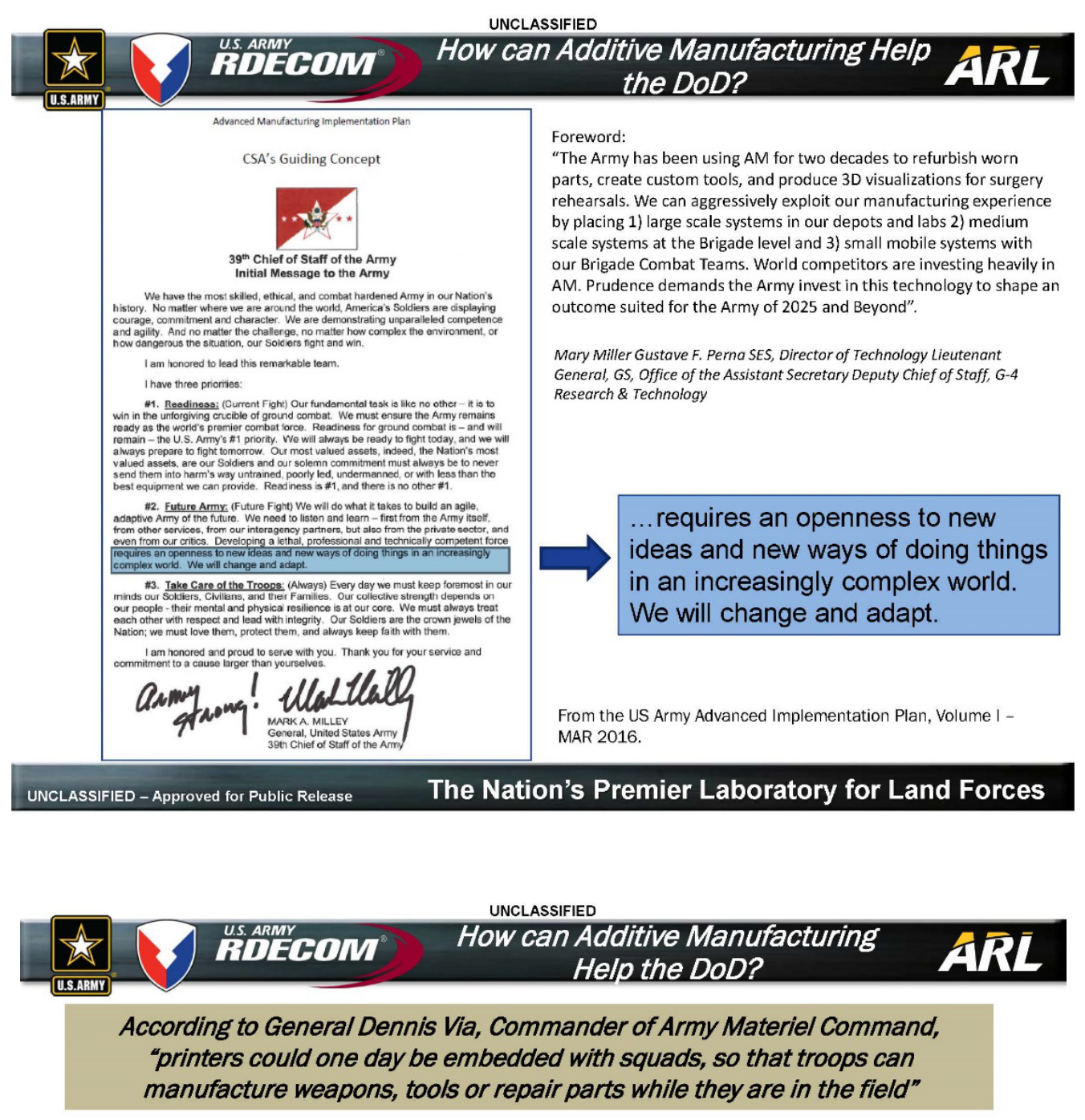

Logistical

Additive Manufacturing (AM), presents a significant opportunity for the U.S. Department of Defense (DoD) to enhance warfighter capability and reduce the current logistical footprint and total life cycle costs of numerous systems. AM offers the potential to reduce production time/costs for low-volume/high-value/complex-shaped components and the opportunity to manufacture in atypical, remote environments - such as forward operating bases (battlefield). AM may help DoD overcome a burdensome acquisition cycle requiring a great amount of cost, time, security, and storage space.

\section{Tactical}

With our enemies forced to innovate rapidly to survive, it's become increasingly important for the U.S. military to improve its own agility and flexibility. With additive manufacturing, parts could be produced where they're needed, when they're needed.

UNCLASSIFIED - Approved for Public Release The Nation's Premier Laboratory for Land Forces 
Imagine a company or brigade able to produce repair parts on the battlefield. The Army alone spends billions of dollars buying parts every year. Every Army unit carries large parts stockpiles to keep rolling. This is costly and adds a huge burden to a unit as it deploys and in moving around the battlefield. A unit can't carry everything, and it's very difficult to predict what parts will be needed, so the Army uses various methodologies to figure out the most important ones on hand, balancing against cost and bulk. When a unit needs a part it doesn't have, equipment can sit for weeks until a replacement part is shipped all the way from a depot or the manufacturer. Worse yet, sometimes the part isn't available at all, triggering a potentially lengthy acquisition process. This problem has increasingly plagued the US military. Fewer manufacturers are interested in producing small batches of specialized military items for the fleets that have dwindled from their Cold War expanse. The explosion of unique, constantly evolving low-density equipment used in Iraq and Afghanistan has exacerbated this issue.

From:

*http://breakingdefense com/2014/01/3d-printing-imagine-a-brigade-producing-parts-on-battlefield/

UNCLASSIFIED - Approved for Public Release The Nation's Premier Laboratory for Land Forces

UNCLASSIFIED

When dealing with safety concerns, it's also important to consider additive manufacturing as a supplier of temporary parts rather than final replacement parts. If a part breaks in the field, vital equipment may be down until the replacement part can be secured. This can sometimes require great time, great money, or both. But with additive manufacturing supplying a temporary part, equipment can remain operational until the actual replacement arrives. Because the temporary part is not intended to be the final replacement part, it doesn't need to meet the same stringent operating requirements. The additive manufactured part can bridge the gap, much like a spare tire on a car miles from an auto shop.

From: “Additive Manufacturing: Production on Demand”, James Barkley, http://www.mitre.org/publications/project-stories/additivemanufacturing-production-on-demand, referenced 10/14/15

UNCLASSIFIED - Approved for Public Release The Nation's Premier Laboratory for Land Forces 
ARL is investigating how to bring AM capabilities to the battlefield:

1) Metal AM

- Must overcome many challenges. Can we make powder in-theater from battlefield scrap, and FOB waste?

2) Sand/binder AM with traditional foundry capabilities

- Can use recycled/reclaimed/scrap materials

3) Polymeric AM using recycled materials

- Must overcome issue of dedicated OEM feedstock materials

- Improved sustainment

- Maximized operational readiness

- Enhanced supply logistics

\section{Resource/Material/Process/Application Map for Battlefield AM}

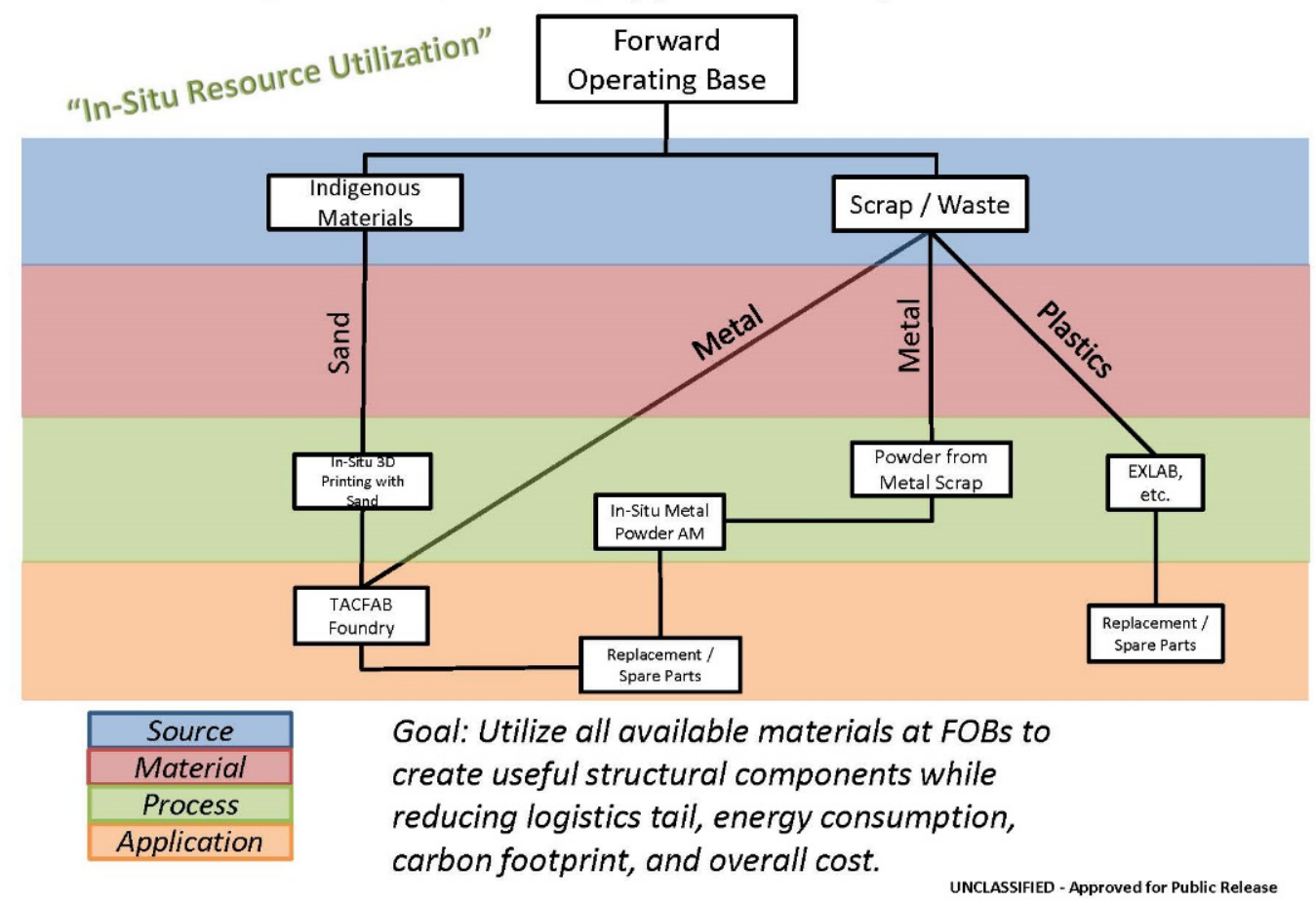


- SBIR Phase I Topic A16-023, "Processing of Metallic Scrap Materials for Battlefield Additive Manufacturing" approved. Proposals received include the following technologies for AM Grade metallic powder production in-theater:

> Melting + Lorenz Force Projection

> Metal carbonyl process

$>$ Spark erosion

- Atomization in mobile foundry

$>$ Rotating electrode wire/rod process -REP

> Centrifugal Atomization or Plasma Rotating Electrode Process (REP)

- Received actual foreign metallic battlefield scrap from NGIC. Chemistry results based on hand-held LIBS analysis.
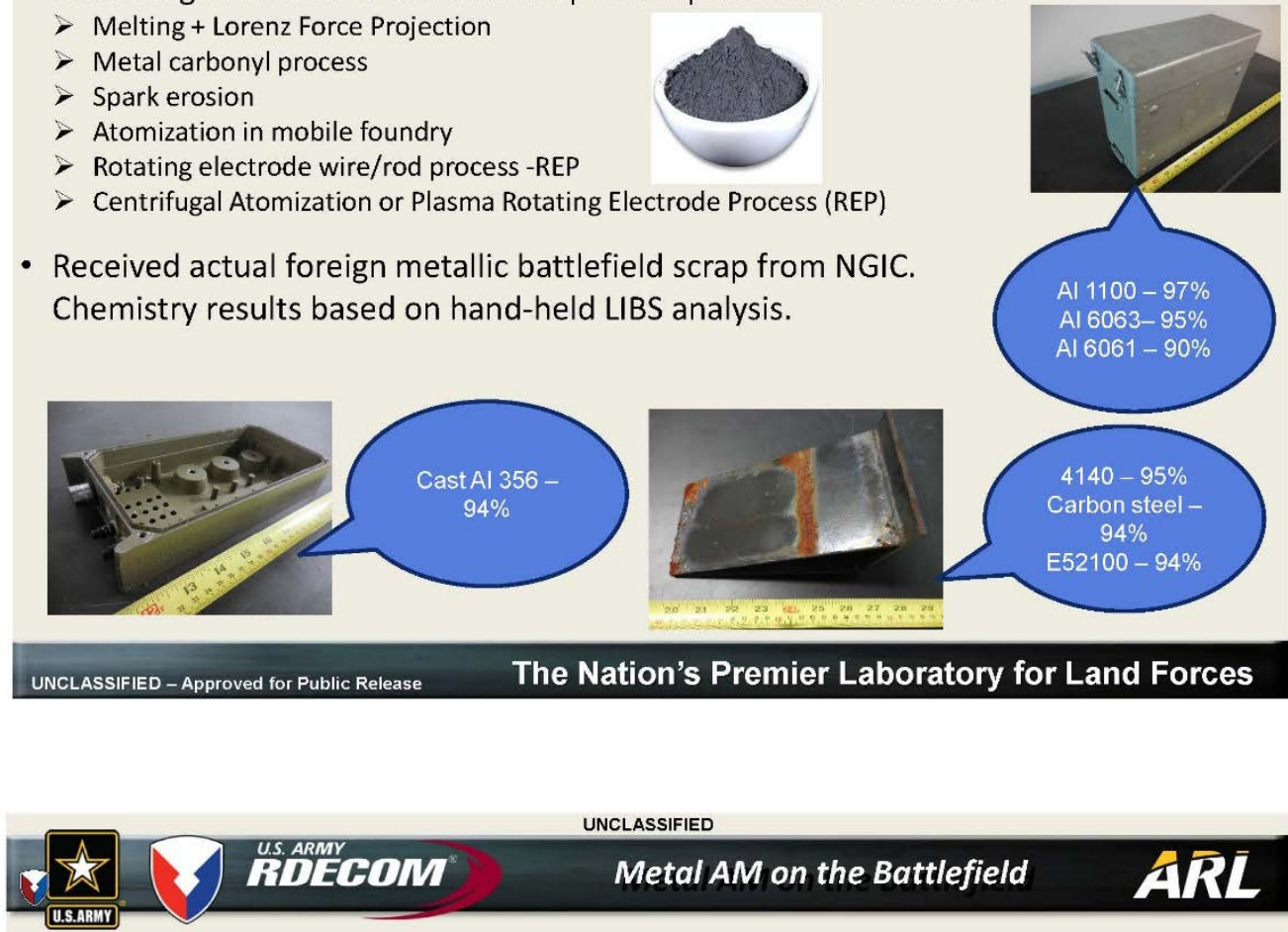

Typical waste on a Forward Operating Base:

This list is by no means exhaustive, but it was all present on the last FOB I operated from in RC-E this past fall.

1. MRE Trash: plastic bags of varying materials, cardboard boxes, cardboard food trays. 2. Clear plastic water bottles.

3. Cardboard boxes, cellophane and Styrofoam packing boxes from spare parts.

4. Used oil \& air filters from vehicles and aircraft.

5. Used (waste) motor oil, used gear oil, used trans fluid and the 1qt - 55 gal metal containers these fluids are shipped in.

6. Ammunition dunnage: This includes cardboard packing, wooden crates, wooden pallets, Styrofoam packing, individual metallic round shipping containers (for grenades \& artillery rounds) empty brass cartridge casings ranging in size from 9 to $105 \mathrm{~mm}$, expended AT-4 tubes (I believe they're fiberglass or some type of composite) and metallic links.

7. Medical waste, human fecal waste.

8. Used batteries; mostly sizes AA (lithium), BA-5590 (lithium), and $24 \mathrm{~V}$ automotive. 9. Used steel-belted off-road tires. If the FOB is utilized by an Armored

Brigade, they will also have some used steel track on hand though not much.

The amounts of these waste materials present will vary with the pace of operations being conducted from that particular FOB as well. I hope this helps, but feel free to give me a call with any questions or if there's anything specific you're trying to determine if it's available or not.

$\mathrm{v} / \mathrm{r}$,

CPT, USA
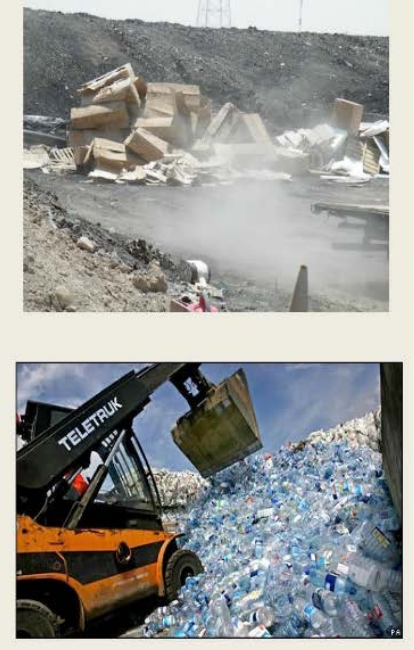
UNCLASSIFIED

\section{Challenges/gaps associated with metal powder additive manufacturing on the battlefield...}

- Cost of equipment

- Footprint of equipment

- Weight of equipment

- Power needs

- Transport and storage of metal powders

- EDM equipment generally needed to remove parts from build plate

- Need for post-processing equipment

- Equipment supportability

...and what about...

- IP of parts being made in the field?

- Inspection / validation / verification?

UNCLASSIFIED - Approved for Public Release The Nation's Premier Laboratory for Land Forces

UNCLASSIFIED

\section{US.AREVEOM}

AR̃L

AM Grade metallic powder production on an operating base would reduce our logistics tail, and support operational readiness, by enabling component repair via gas dynamic cold spray or laser powder deposition technology.

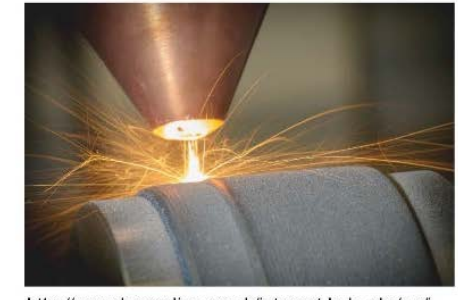

http://www.boconline.co.uk/internet.lg.lg.gbr/en/ mages/20151005_95572_2333410_176194.jpg

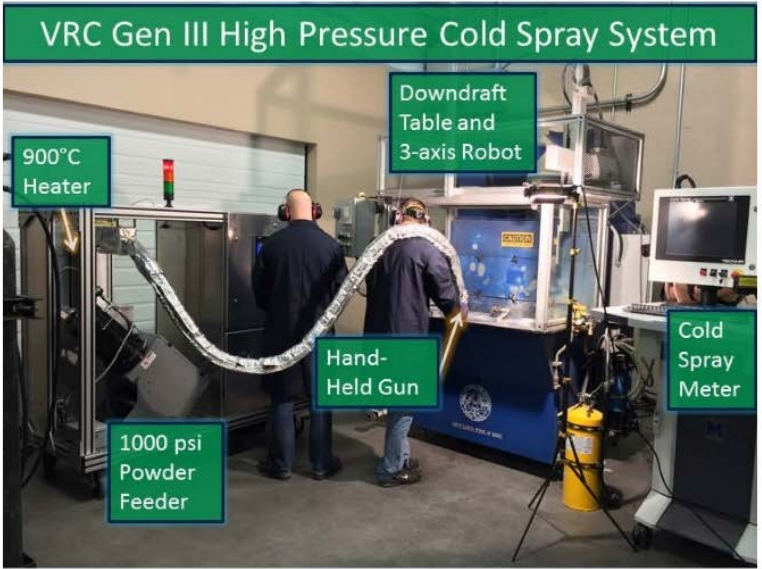

http://www.vrcmetalsystems.com/images/NRC\%20Gen\%20II\%20Cold\%20Spray\% 20System.jpg 


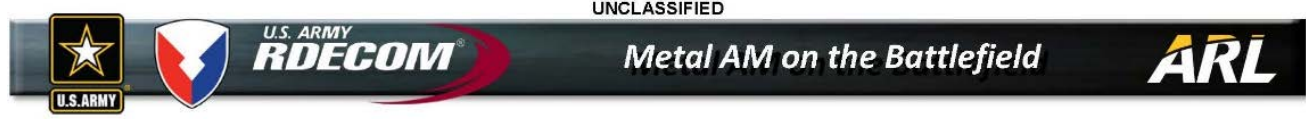
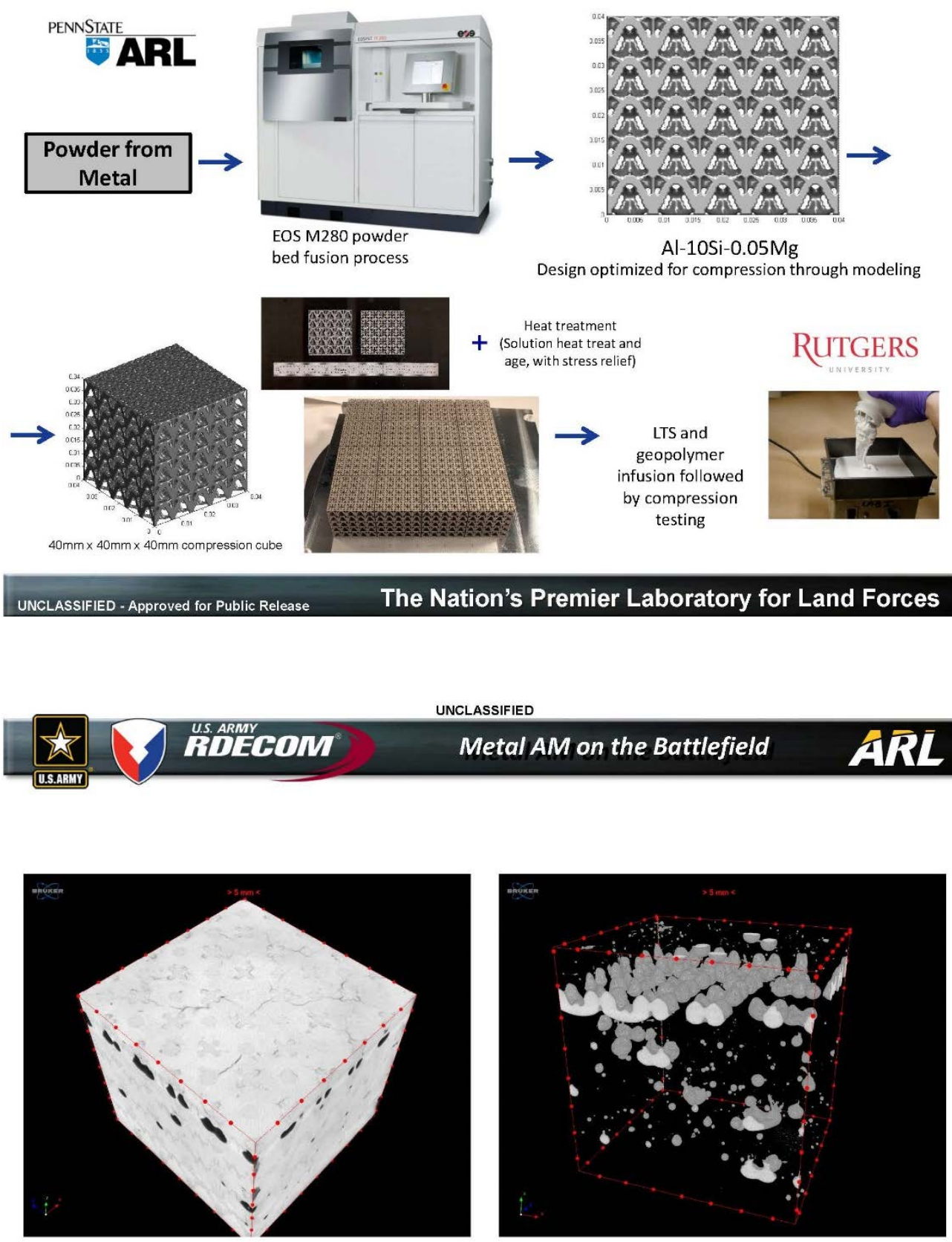

Micro-CT inspection of LTS-infused truss 
UNCLASSIFIED

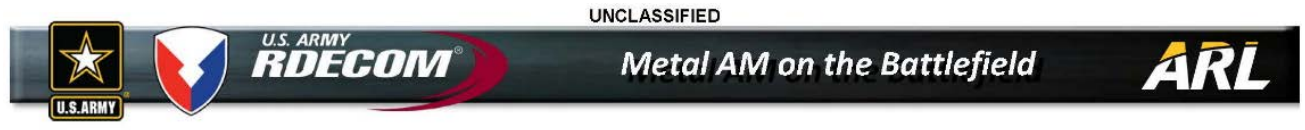

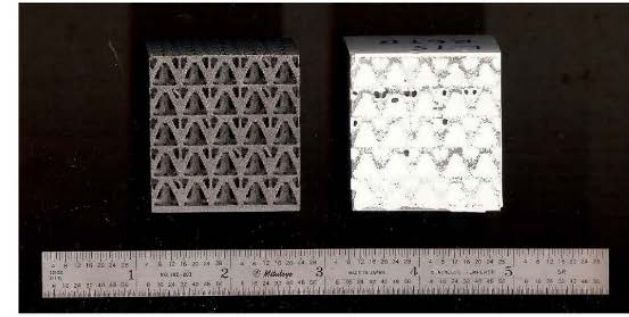

Aluminum truss made from EOS M280 powder bed fusion process (above, left), and similar truss infused with low-temperature solidified ceramic (above, right). Future protection of soft FOB shelters (right)?

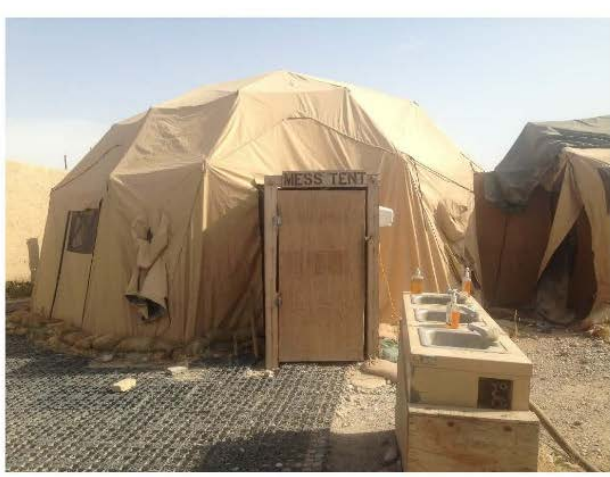

From: http://battlerattle.marinecorpstimes.com/2014/05/12/on-theground-in-afghanistan-the-last-days-of-a-fob/
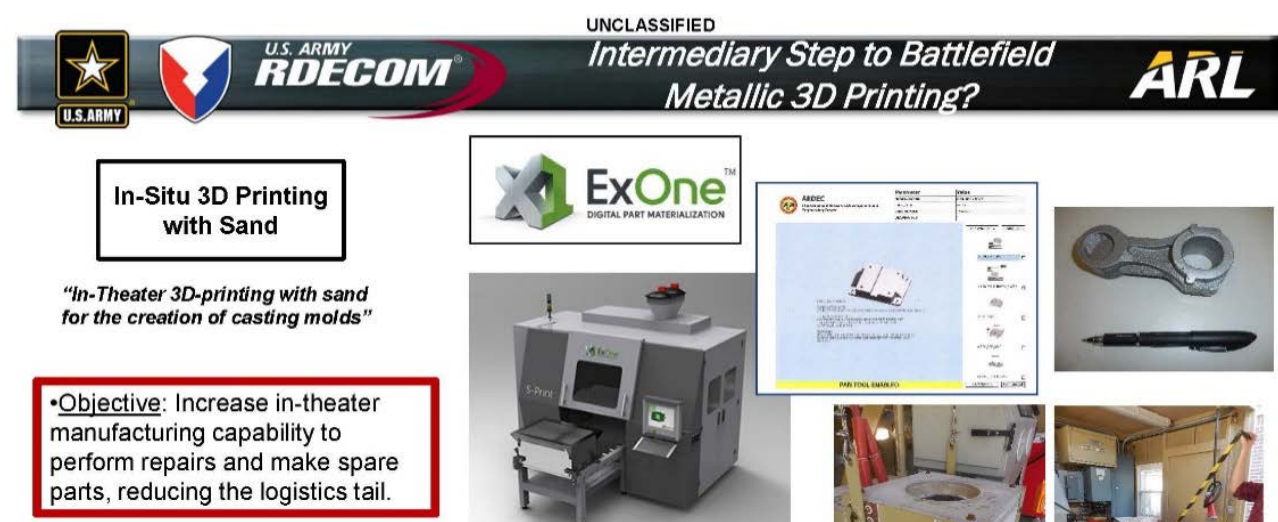

"In-Theater 3D-printing with sand

Objective: Increase in-theater manufacturing capability to

parts, reducing the logistics tail.

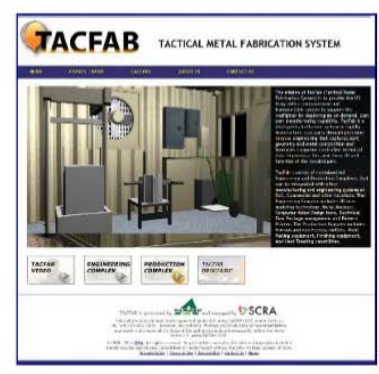

UNCLASSIFIED - Approved for Public Release
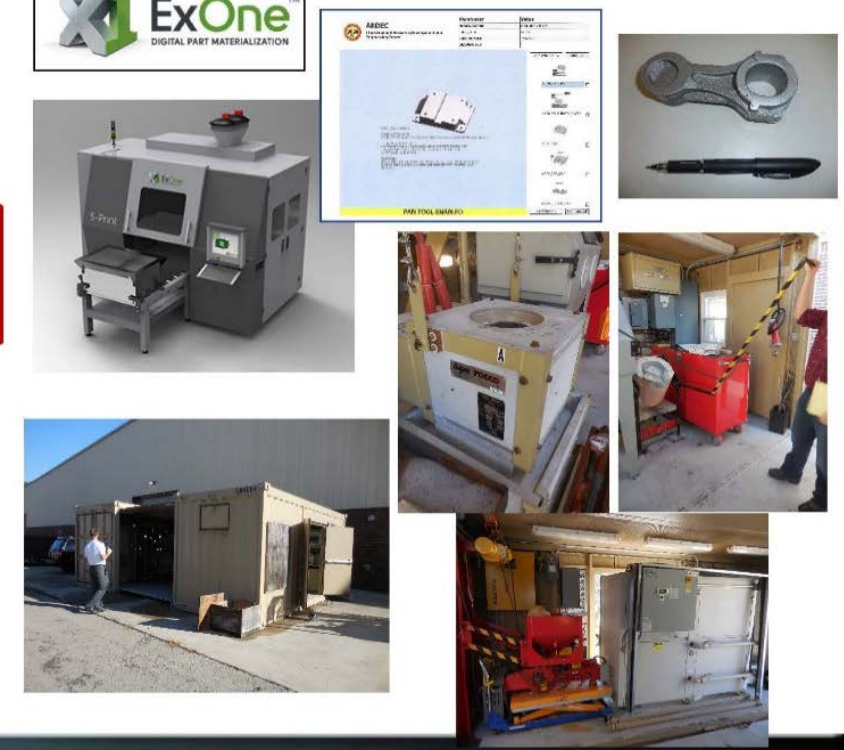

The Nation's Premier Laboratory for Land Forces 

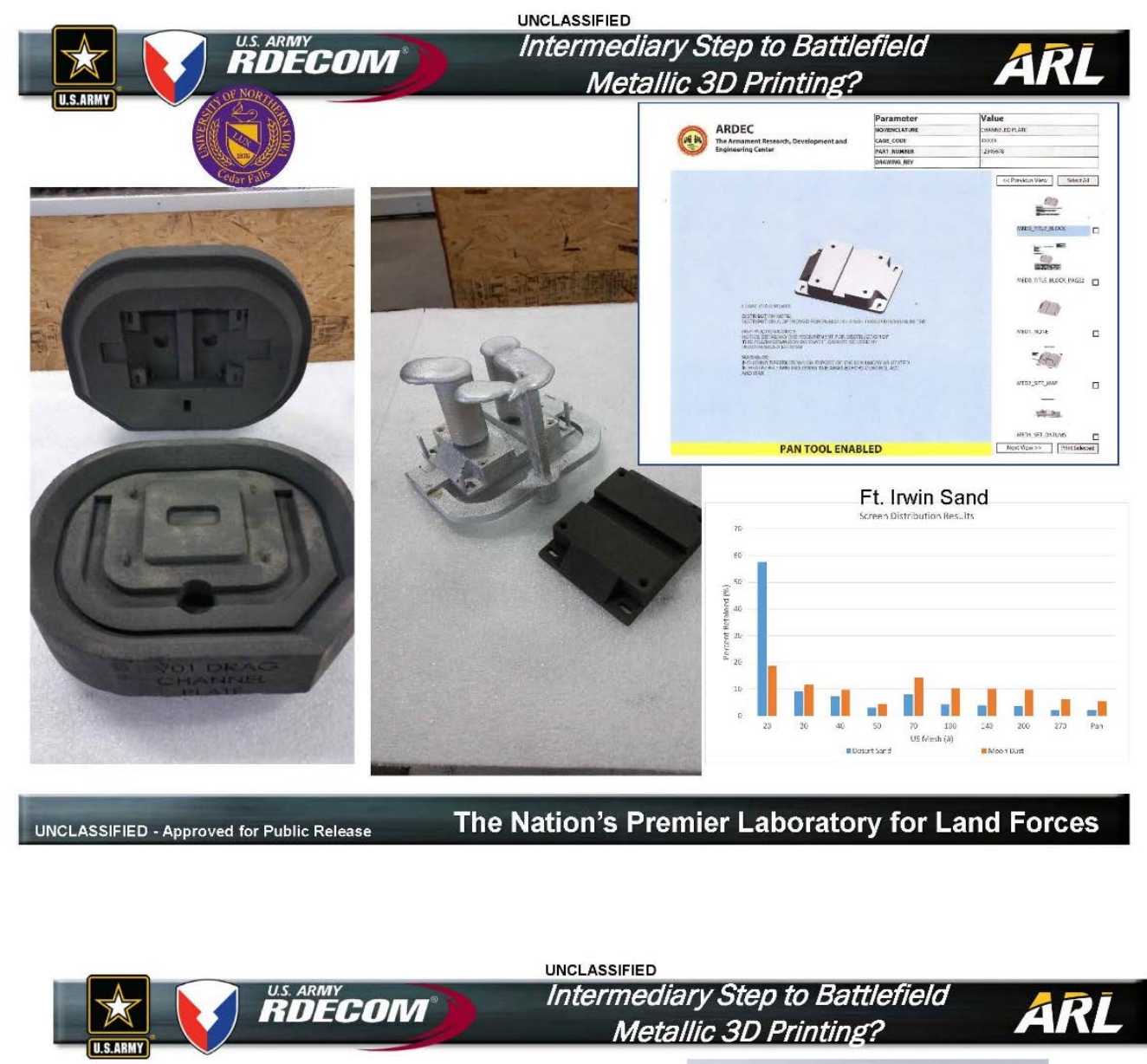

- Alternative approach to metallic 3D printing, sand printing

- Othermill allows for precision 3D milling (positional accuracy to within 0.001 inch)

- Scrap metals (aluminum, brass, copper) will be cast into simple molds and milled to shape

- Limited to thin parts (<1.25 in)
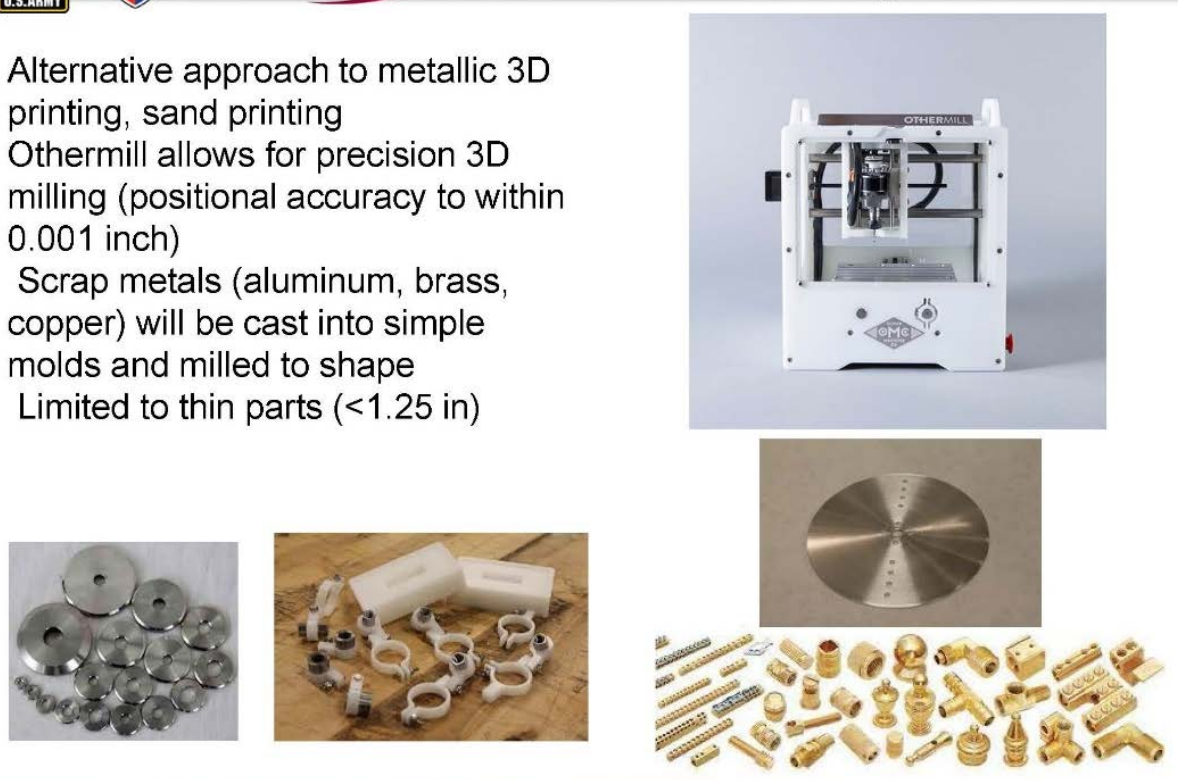
UNCLASSIFIED

U.S.ARMY

Ground vehicle parts that might be technologically feasible through additive manufacturing:

Brake levers

Brake shoes

(Front axle) casings

Cross pieces

Exhaust manifolds

Fan clutches

Flanges

(Metal/plastic) gaskets

Guide carriages

Hoods
Levers

(Mirror) mounts

Specific rings

Steering wheels

Tow bars

Universal joints

Vent valves

Thrust collars

Locking levers

Filler necks

*From “POTENTIAL OF ADDITIVE MANUFACTURING IN THE AFTER-SALES SERVICE SUPPLY CHAINS OF GROUND BASED MILITARY SYSTEMS", BSc Graduation Assignment - Final report, Gino Balistreri, University of Twente: Department Industrial Engineering and Business Information Systems (IEBIS), Netherlands, 27 July 2015.

\section{USARENEOM}

UNCLASSIFIED

\section{Army Rapid Equipping Force (REF)} Expeditionary Laboratory (ExLab III)

- Contains a polymeric fused deposition modeling (FDM) 3D printer; a Stratasys Fortus 250.

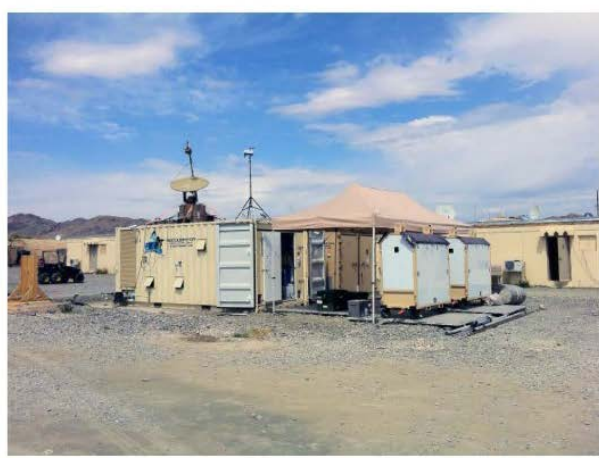

http://www.rapidreadytech.com/2012/08/u-s-army-brings-3dprinting-to-the-front-lines/

\section{Polymer AM on the Battlefield $\bar{A} \bar{R} \bar{L}$}

The Nation's Premier Laboratory for Land Forces

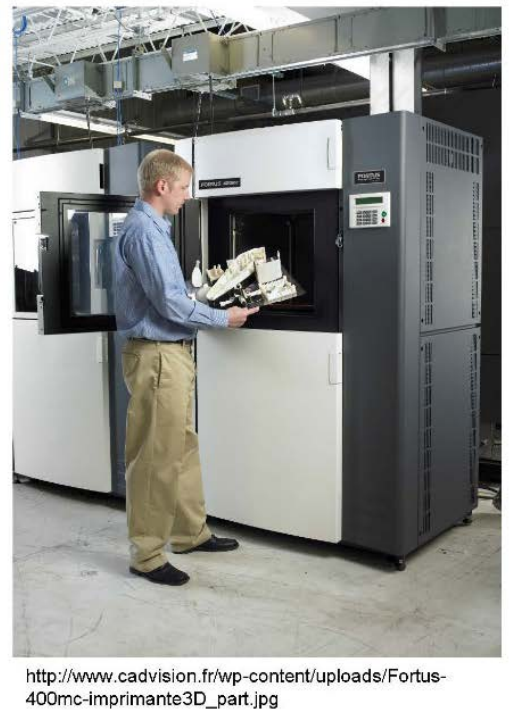

400mc-imprimante3D_part.jpg 

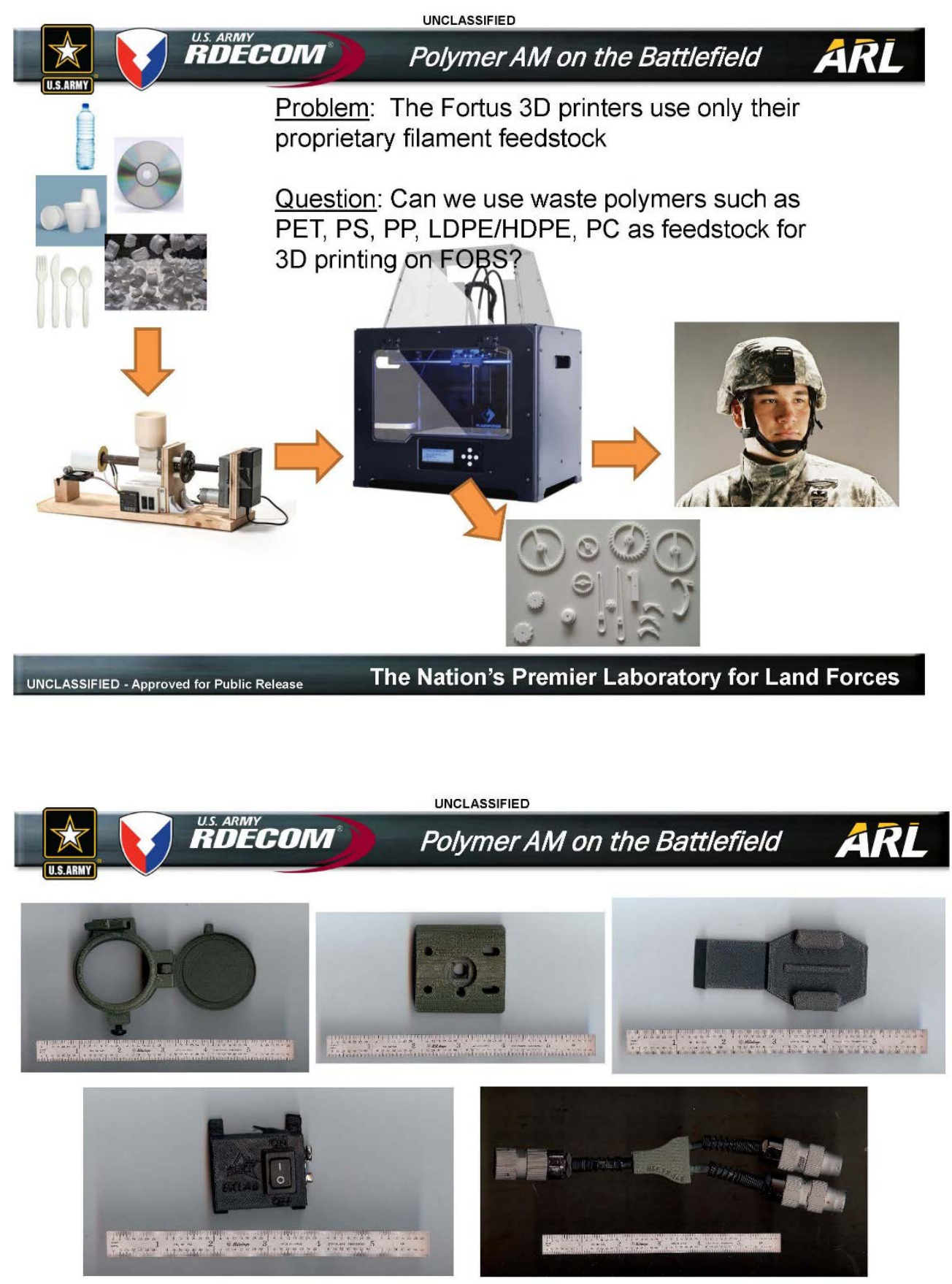

The Army REF furnished ARL with 3D printed parts from the battlefield, made from $A B S$ for comparison to these parts made of recycled materials. 
ARL has successfully made 3D printing filament feedstock from waste MRE bags. nScrypt Ex31:3 fused deposition modeling (FDM) equipment successfully converted the filament into a simple shape.
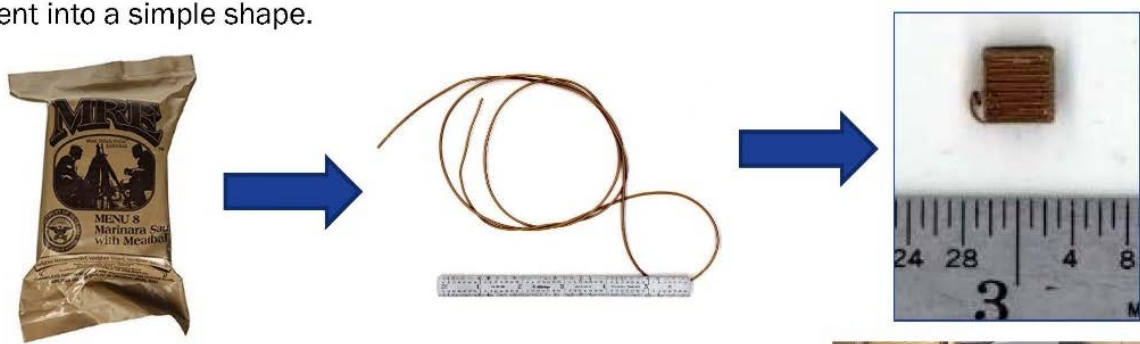

Filaments also made from water bottles (PET), Styrofoam, scrap polystyrene, polypropylene and HDPE.

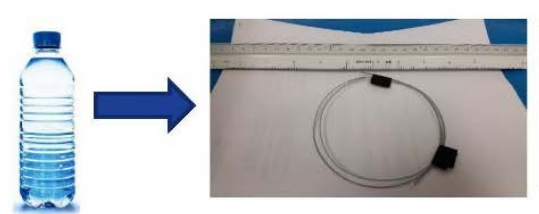

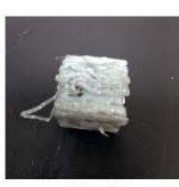

rPET

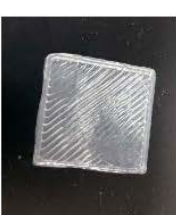

rPS

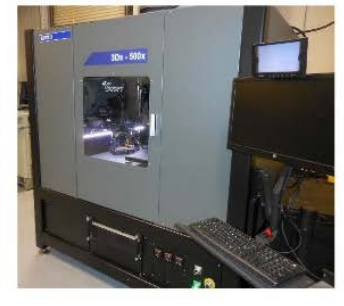

The Nation's Premier Laboratory for Land Forces

UNCLASSIFIED

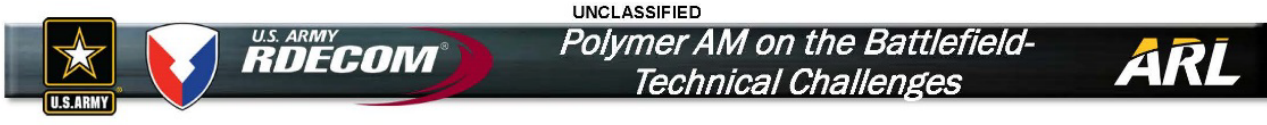

- PET extrusion difficult due to low viscosity of polymer, filament diameter too small- modification to extruder needed (larger nozzle, filament winder and speed controller ordered). Collaborator making PET filament in meantime

- PP filament diameter not consistent- winder should help solve problem

- Styrofoam filaments too brittle- switch focus to high-density polystyrene

- MRE (outer bag) print layers have poor adhesion- working on drying filament, changing bed and printing parameters, work planned also using inner bags (polypropylene) 


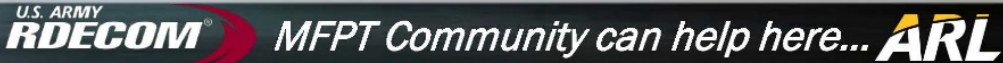
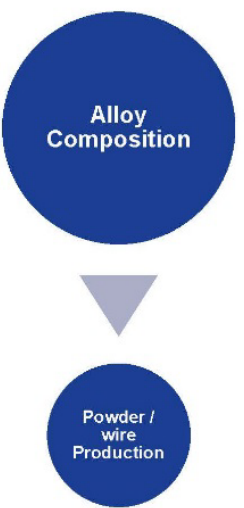

3

In-situ and/or final non-destructive inspection
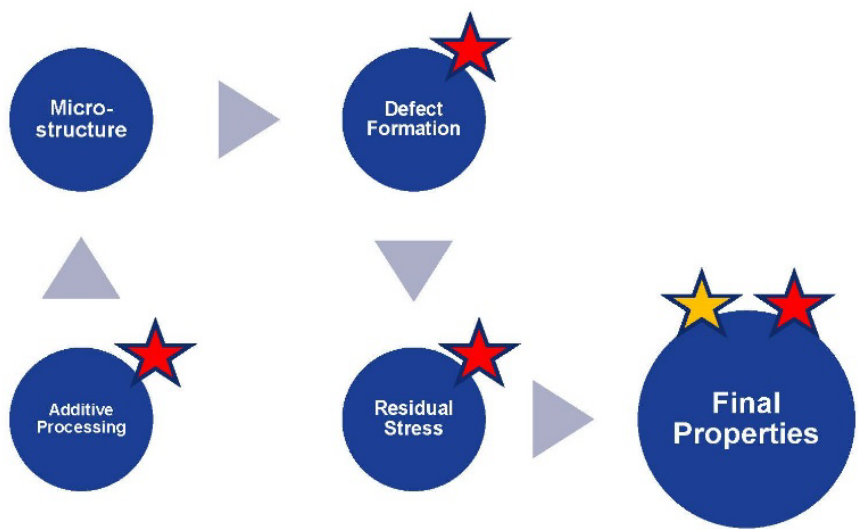

From: http://www.amaze-project.eu/10

Sensors, diagnostics, prognostics if/when part placed into service

UNCLASSIFIED

- Additive manufacturing (polymer 3D printing) is already on the battlefield

- ARLs current work is hoping to prove out the following:

- Metal AM powder production on the battlefield

- Sand + Binder AM with traditional foundry methods on the battlefield

- Polymeric 3D printing using recycled, reclaimed, and scrap materials as feedstock on the battlefield 


\section{Role of Processing-Structure-Property Relationships in Developing Certification Protocols for Ti-6Al-4V Components}

Todd Palmer

(Pennsylvania State University, Applied Research Laboratory)

A fundamental understanding of processing-structure-property relationships is a key prerequisite to the eventual development and implementation of a certification protocol for additively manufactured (AM) components. One unique aspect of the AM process is the role that geometry plays on these relationships and how it can be integrated into certification. These relationships are defined here for specific directed energy deposition AM processing conditions in Ti-6Al-4V by correlating microstructural features with the resulting static mechanical properties. By concentrating on simple geometries, we can characterize variations in the resulting microstructures and mechanical properties at all locations within the Ti-6Al-4V builds. As a result, the relationships between the processing conditions and the resulting structure and properties of the build are quantified and used in the selection of processing conditions that ensure adequate mechanical properties and performance in the final design. Based on these results, a methodology that establishes fundamental relationships between the AM processing conditions, the microstructural features, and the mechanical properties is under development. As part of this effort, an analysis of the uncertainty in mechanical property data for Ti$6 \mathrm{Al}-4 \mathrm{~V}$ AM components and a methodology for identifying minimum design values is being developed. 
Role of

Processing-Structure-Property

Relationships in Developing Certification

Protocols for Ti-6Al-4V Components

\author{
T.A. Palmer
}

Applied Research Laboratory

Department of Materials Science and Engineering

Pennsylvania State University

\title{
Acknowledgements
}

Center for Innovative Materials Processing through Direct Digital Deposition G|MP-3]
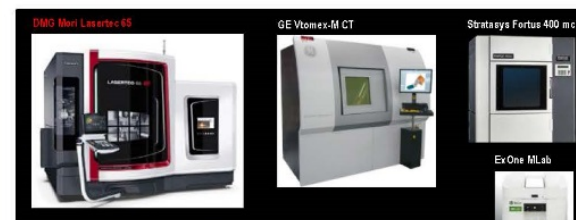

Optomac Lens

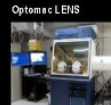

G.WPII

was

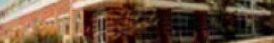

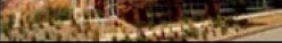

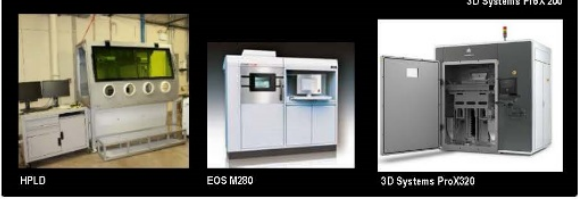

PennState

GIMP.30
Dr. Rich Martukanitz (Director)
Dr. Ted Reutzel

Mr. Griffin Jones

Mr. Jay Tressler

Department of Mechanical and Nuclear Engineering

Prof. Pan Michaleris

Dr. Michael Gouge

Dr. Jarred Heigel

Dr. Erik Denlinger Mr. Dennis Krizcky
Department of Materials Science and Engineering Prof. T. DebRoy

Prof. Long-Qing Chen

Dr. Ashwin Raghavan

Prof. Allison Beese

Ms. B. Carroll

Mr. Patrick Hricko

Mr. Huiliang Hue

Department of Engineering Science and Mechanics

Prof. Reggie Hamilton Ms. Beth Bimber 


\section{Agenda}

Challenges in Certification of Titanium Components

Developing Process-Structure-Property Relationships in Titanium Alloys

Impact of Post Processing

Inspection of AM Components

Path Forward

\section{Challenges in Certification of Titanium Components}




\section{Accelerated AM Implementation}

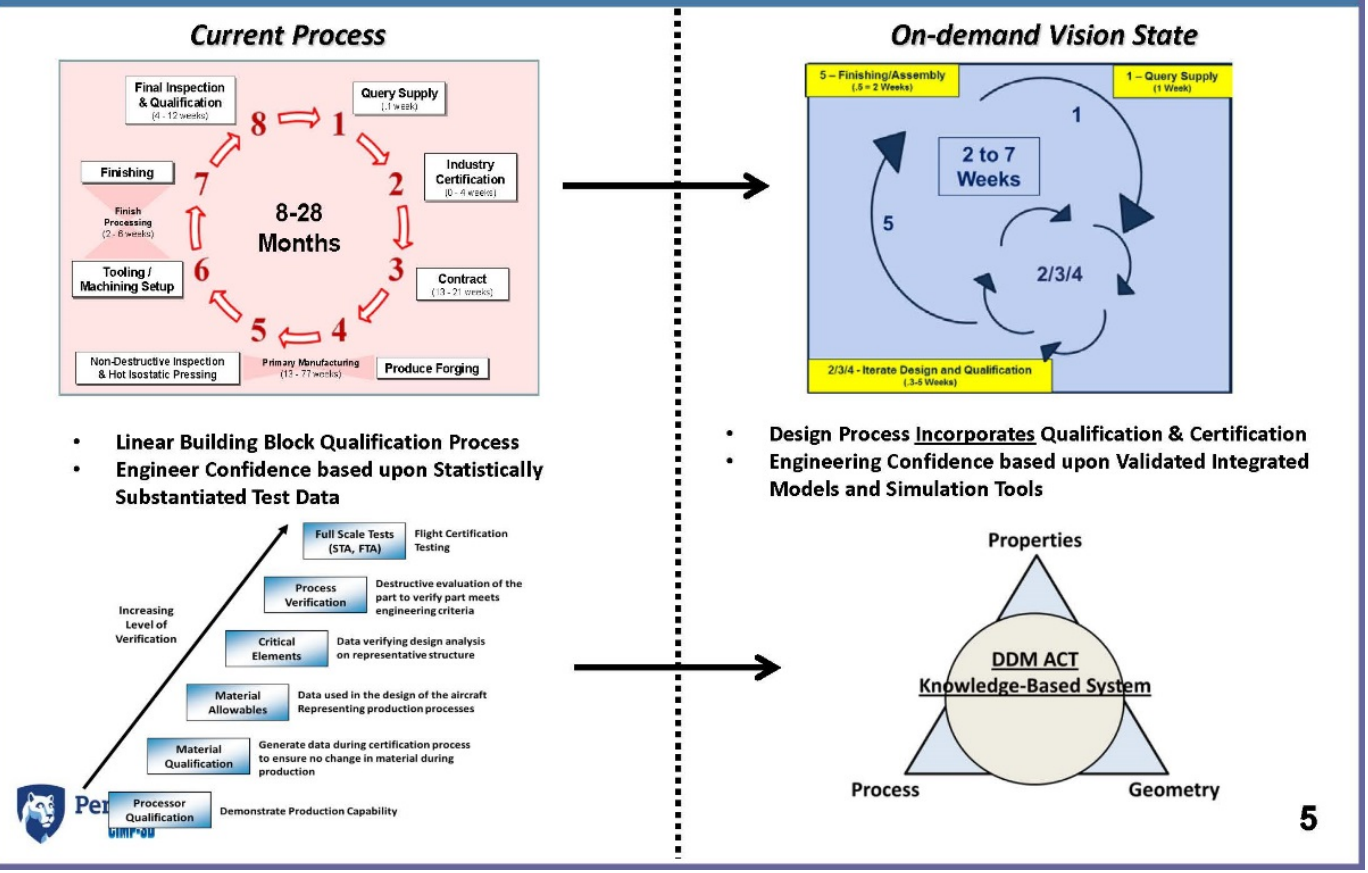

PennState

Applied Research

Laboratory

\section{Designers Rely on MMPDS}

- Various processes

- Die forging

- Extrusion

- Sheet

- Bar

- Casting

- Post processing

- Includes various information beyond tensile properties

- Fatigue behavior

- Creep behavior

- Properties versus temperature

PennState
UTS

Yield

Elong

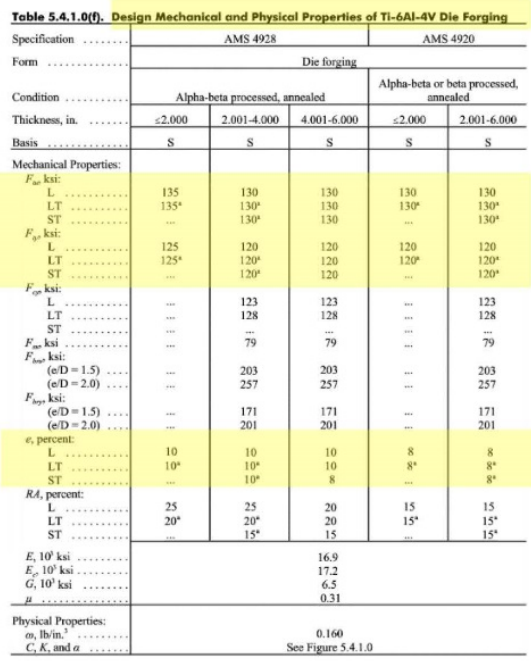

Example table from Metallic Materials Properties Development and Standardization (MMPDS) 


\section{AMS4999A Uses an Extensive Material Property Database}

Laser Additive Manufacturing (LAM) process developed by AeroMet

High-power laser powder deposition process (18 kW CO

Until 2005, AeroMet manufactured parts for the aerospace industry
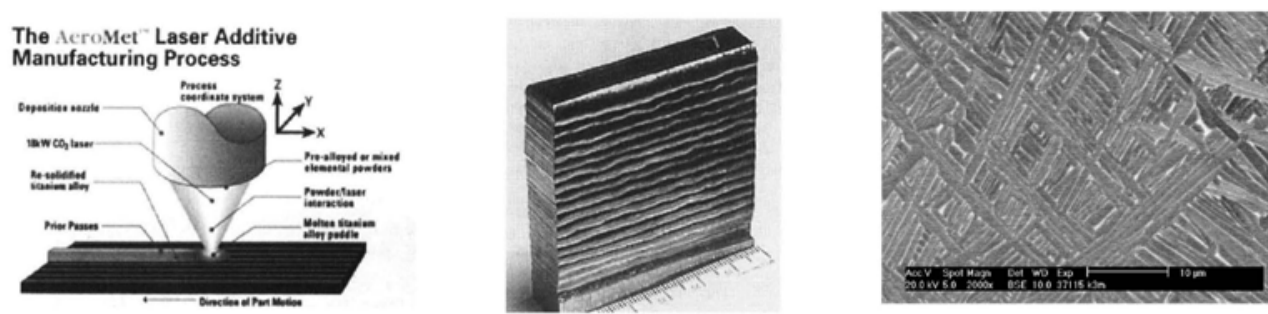

Materials specification with chemistry, heat treatment, and quality assurances Minimum tensile properties requirements

Qualification of the process and supplier and process parameters

PennState

Applied Research

Laboratory
Lablied Resear

\section{Current AM Allowables are Generally Below Forged Properties}

Minimum tensile properties from AMS4999A specification for Ti-6Al-4V AM components

\begin{tabular}{|c|c|c|c|c|c|}
\hline & \multicolumn{2}{|c|}{ Tensile Strength } & \multicolumn{2}{|c|}{ Yield Strength } & \multirow{2}{*}{$\begin{array}{c}\text { Elongation } \\
(\%)\end{array}$} \\
\hline & (ksi) & (MPa) & (ksi) & (MPa) & \\
\hline $\begin{array}{c}\text { Direct } \\
\text { Deposited } X \\
\text { and } Y[1]\end{array}$ & 129 & 889 & 116 & 799 & 6 \\
\hline $\begin{array}{c}\text { Direct } \\
\text { Deposited } \\
Z^{[1]}\end{array}$ & 124 & 855 & 111 & 765 & 5 \\
\hline $\begin{array}{l}\text { Forged Bars and } \\
\text { Billets [2] }\end{array}$ & 130 & 895 & 120 & 828 & 10 \\
\hline
\end{tabular}

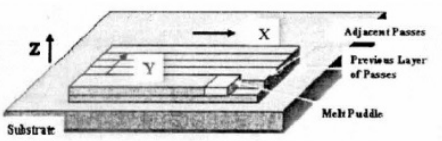

Specimen orientation for direct deposited Ti-6Al-4V [1]

[1] Aerospace Material Specification AMS4999 Rev. A. Titanium Alloy Direct Deposited Products 6AI - 4V Annealed

${ }^{[2]}$ ASTM B348-13. Standard Specification for Titanium and Titanium Alloy Bars and Billets 
Wide range of mechanical properties reported for AM fabricated Ti-6AI-4V.

PBF and DED Processes

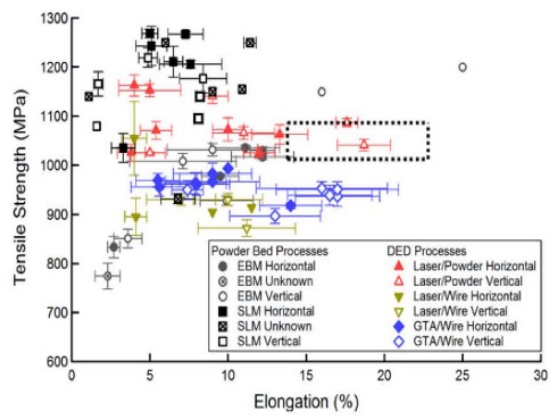

DED Processes

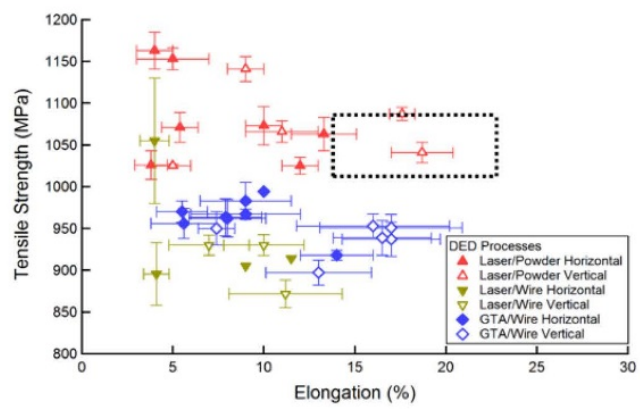

Even with nominally similar processing conditions, mechanical properties reported for AM fabricated Ti-6AI-4V still vary, particularly for elongation. 


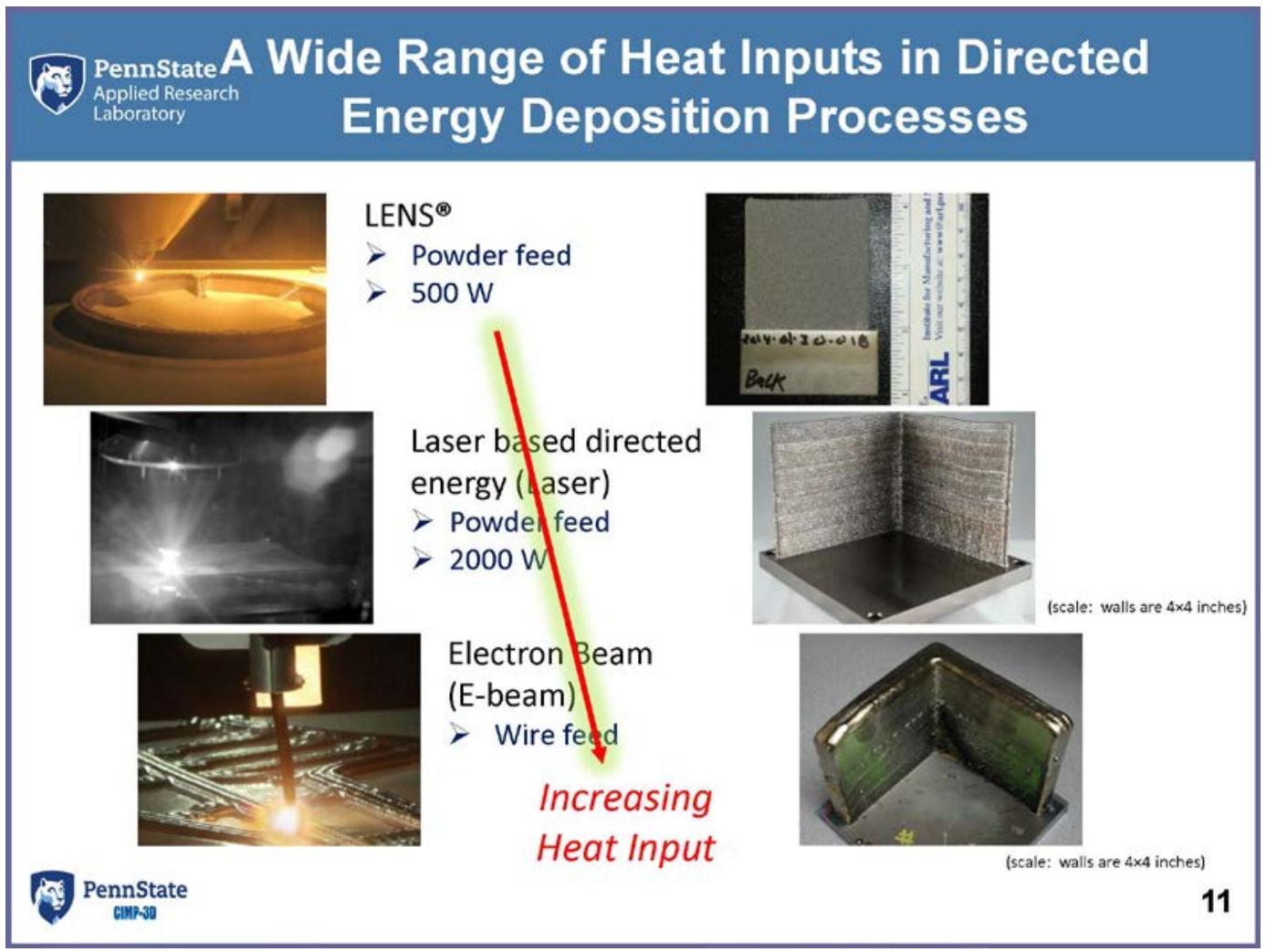

Pennstate

Applied Research

Applied Resear
Laboratory

\section{Overview of Single Geometry Laser Builds}

Fabrication of eight geometries using the laser deposition process has been completed.

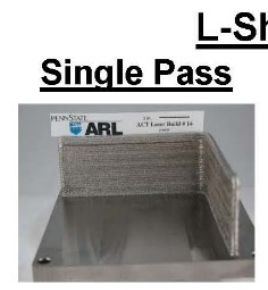

L-Shapes
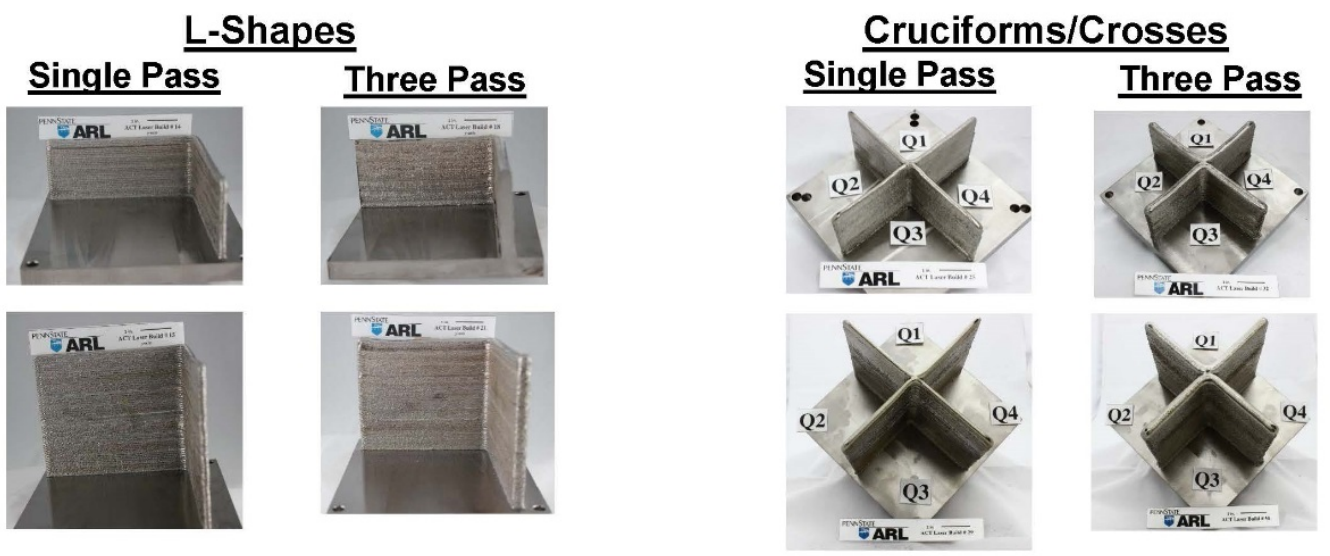

Three samples of each geometry were fabricated to provide samples for testing in the as-deposited and HIP conditions. 
PennState

Applied Research

Laboratory

\section{Sample Extraction from Single Geometry Laser Builds}

Tensile and metallographic specimens are removed at specific locations in each sample.

\section{L-Shapes \\ Single Pass}
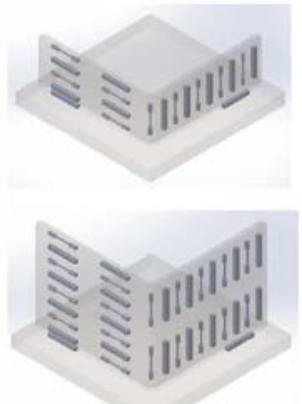

\section{Three Pass}

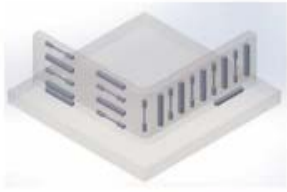

Cruciforms/Crosses Single Pass Three Pass

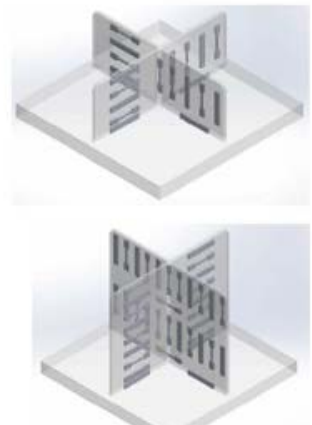

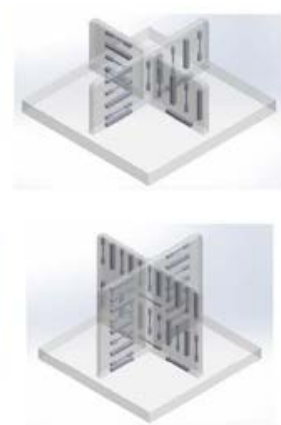

Same locations and orientations are tested for the as-deposited, heat treated, and HIP'd samples.

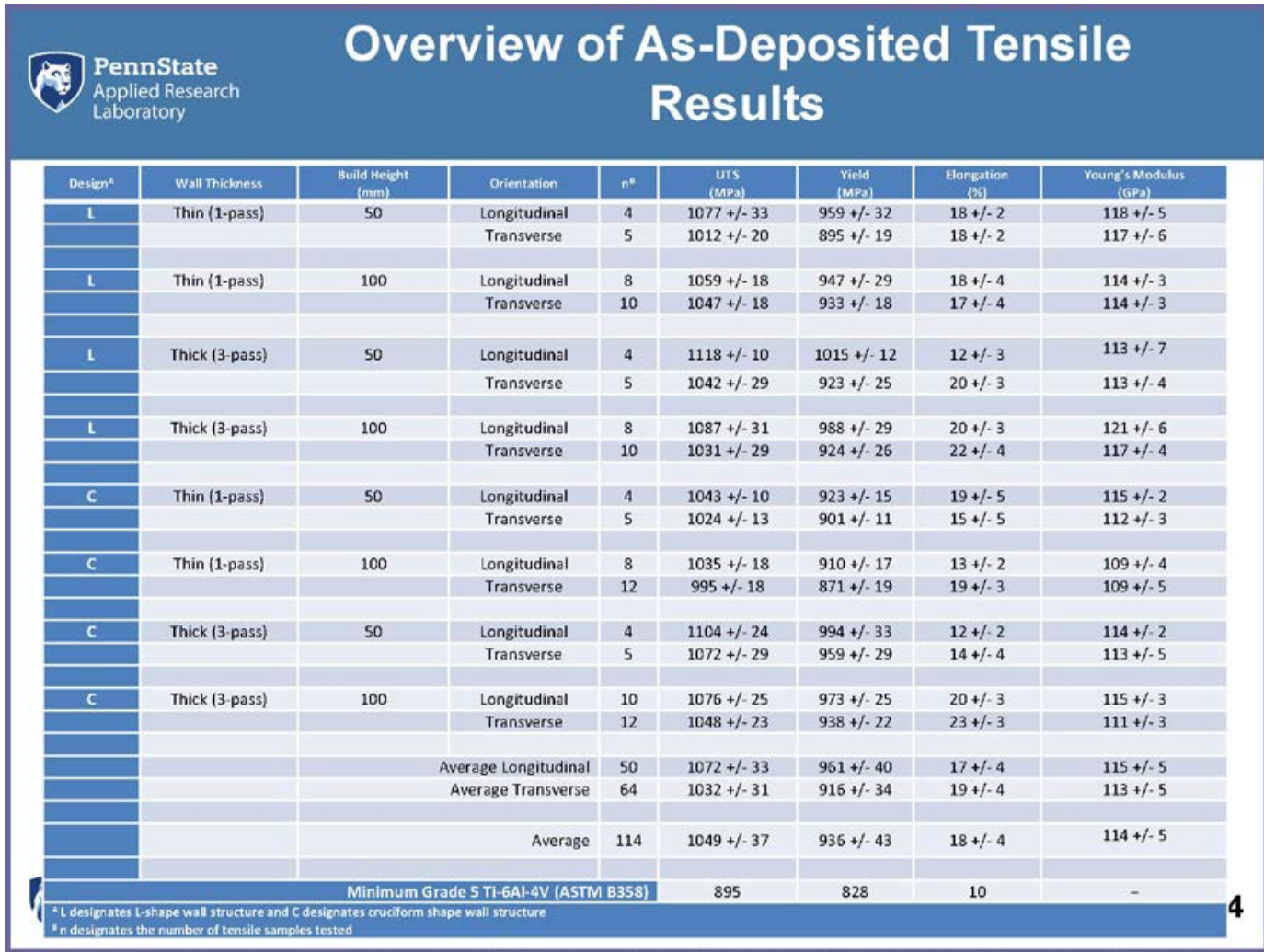




\section{Impact of Orientation on Mechanical Properties}
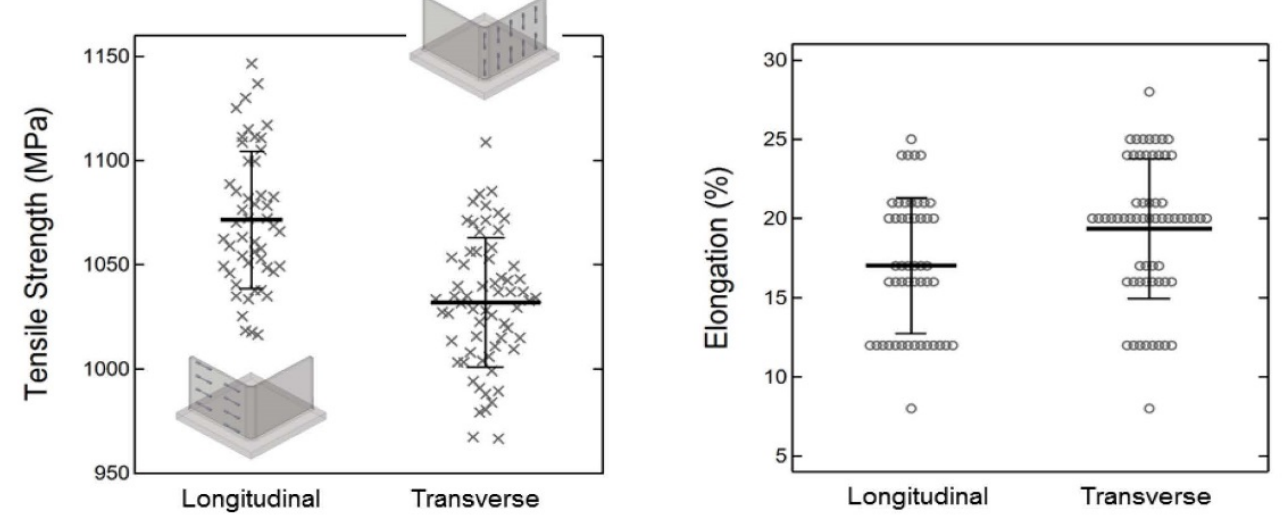

Longitudinally oriented samples exhibited significantly higher tensile strengths than transverse oriented samples.

\section{Impact of Wall Thickness on Mechanical Properties}
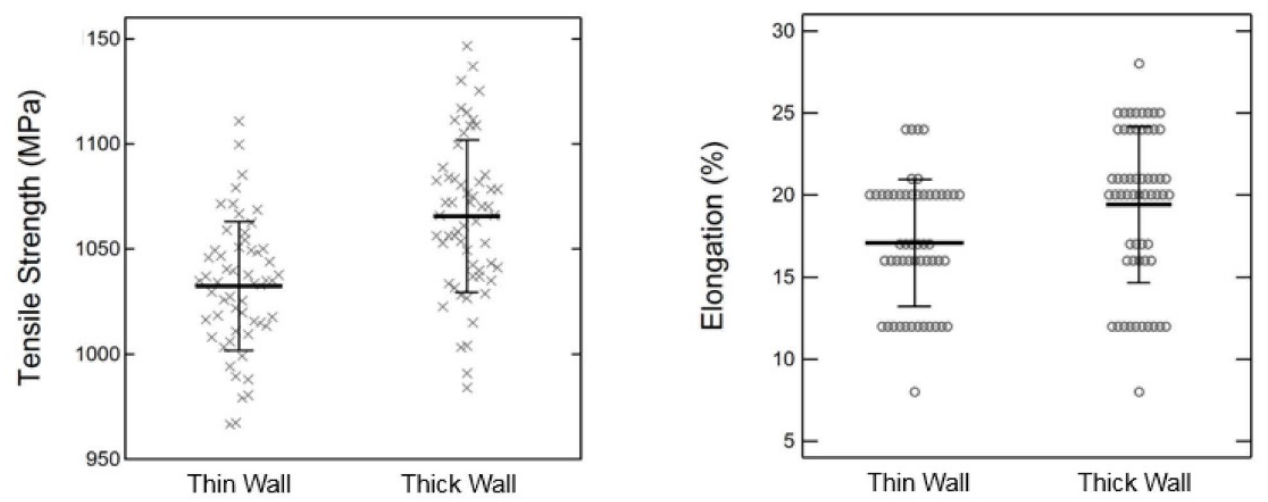

Tensile samples extracted from multi-pass thick wall structures exhibited significantly higher tensile strengths than samples extracted from single pass thin wall structures. 
PennState

Applied Research

Laboratory

\section{Impact of Geometry on Mechanical \\ Properties}
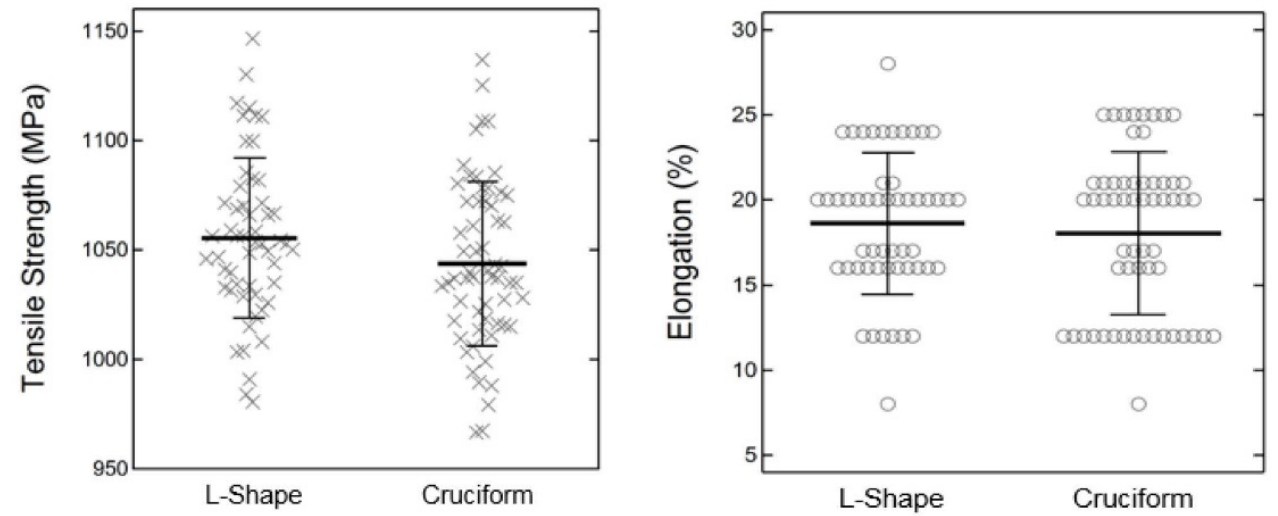

The wall shape was a significant parameter for the single pass thin wall structures. The thin wall L-shapes exhibited a higher tensile strength than the thin wall cruciform structures.

The resulting mechanical properties from the thick wall cruciform and thick Lshape structures, however, were statistically similar.

\section{Summary of Statistically Significant} Relationships

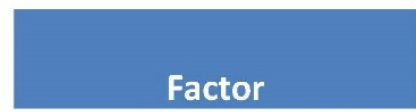

Wall Thickness

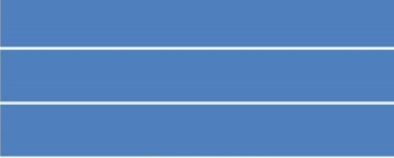

Design
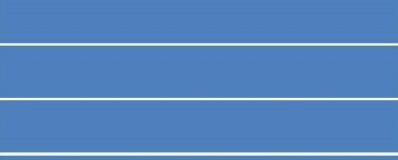

Thickness × Design

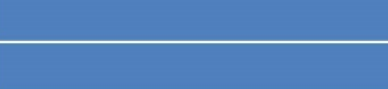

PennState 


\section{Primary Microstructural Features in AM Ti-6Al-4V}

Microstructural features

- $\alpha$ lath width

- $\alpha / \beta$ Phase volume fraction

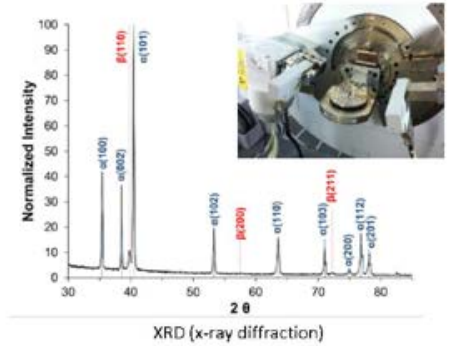

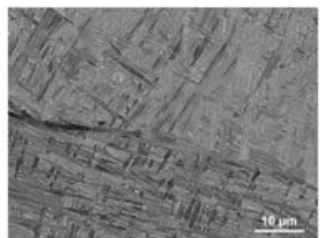

SEM microscopy - backscatter (Laser based directed energy)

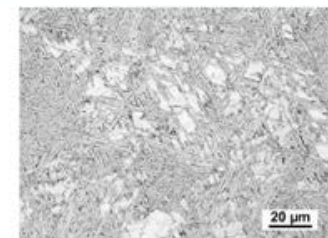

Optical microscopy (Laser based directed energy)

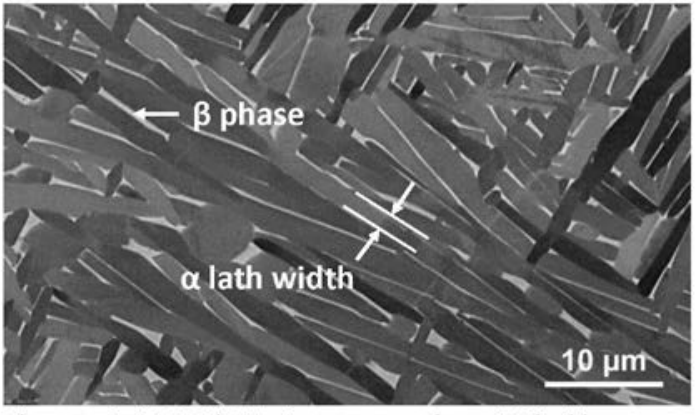

Characteristic Ti-6Al-4V microstructure from AM builds

PennstatDifferent Part Geometries Produce Different Applied Research
Laboratory Microstructures at Same Location

(a) - L-Shape Thin Wall

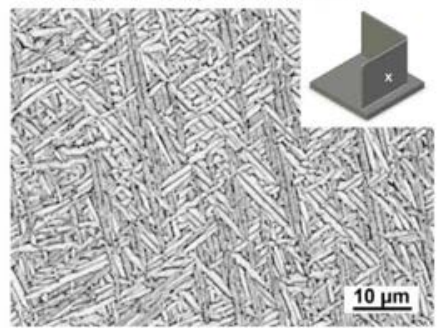

(c) - Cruciform Thin Wall

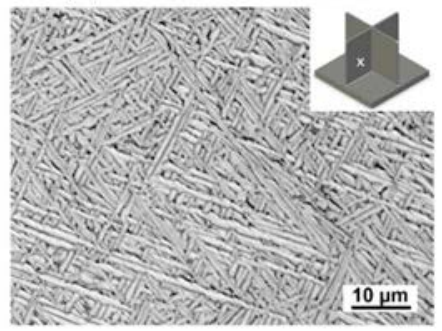

(b) - L-Shape Thick Wall

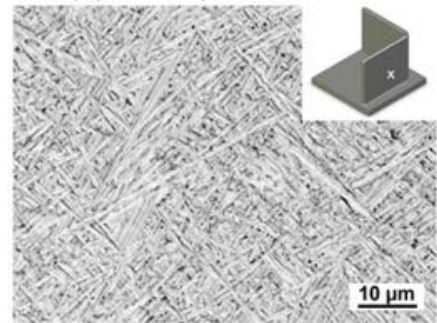

(d) - Cruciform Thick Wall

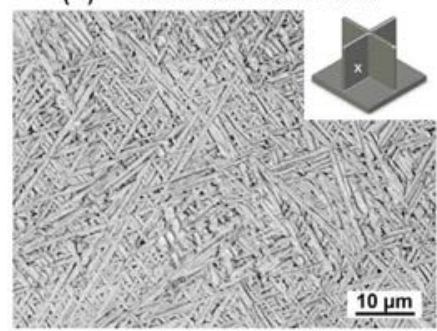


PennState

Applied Research Laboratory

\section{Alpha Lath Width Shows Little Change with Geometry}

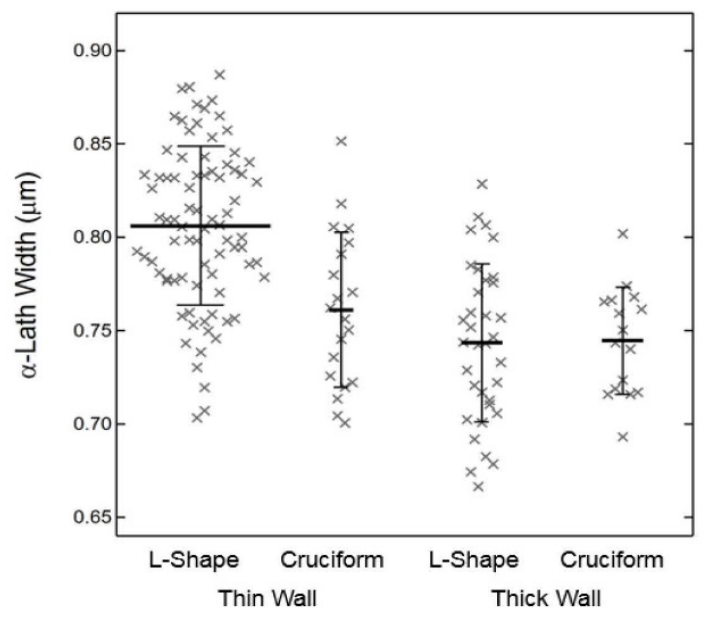

PennState

Applied Research Applied Resear
Laboratory

\section{Prior Beta Grain Structure Impacted by Changing Geometry}
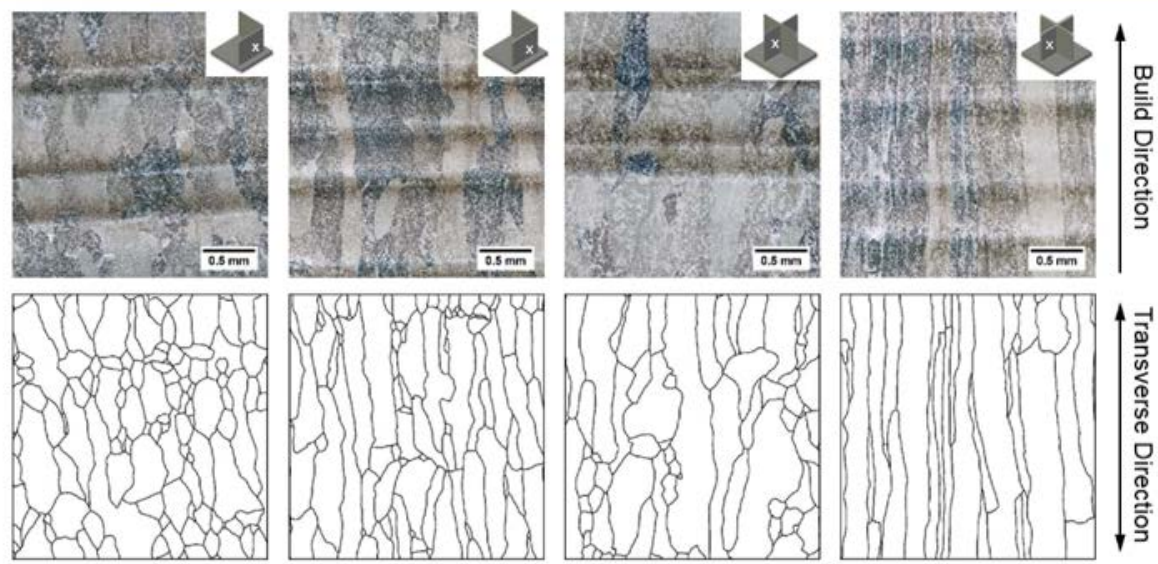

Longitudinal Direction

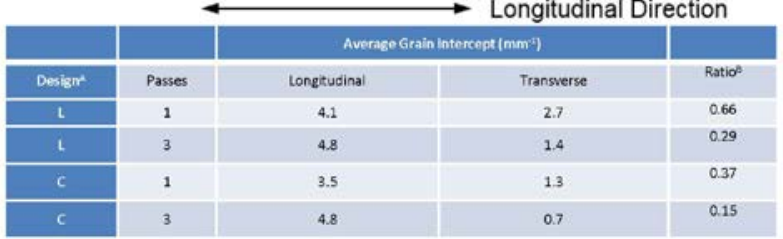




\section{Prior Beta Grain Measurements Show Trends With Tensile Strength}

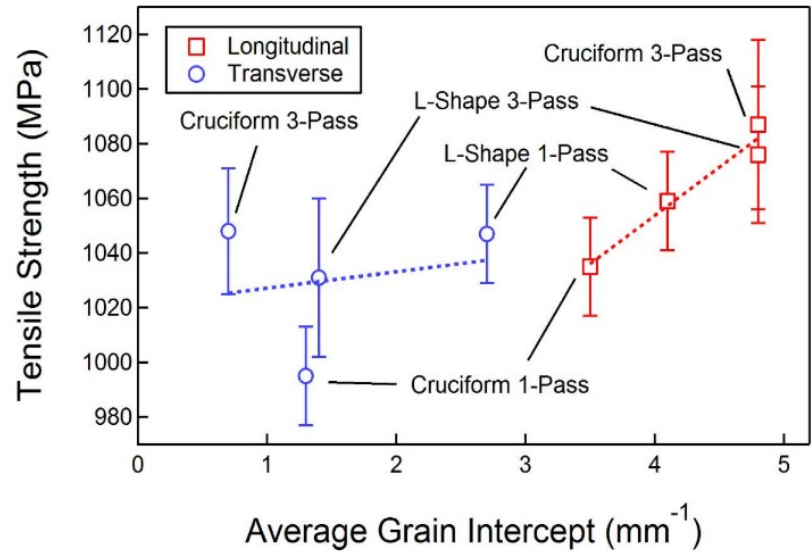

The impact of orientation, wall thickness and wall shape may be explained by the amount of boundary strengthening from the prior $\beta$ grain boundaries.

Higher tensile strengths were obtained from orientations and wall structures that exhibited a higher number of prior $\beta$ grain boundary intercepts.

PennState

Applied Research
Laboratory

\section{Location Dependence of Mechanical} Properties for Longitudinal Specimens
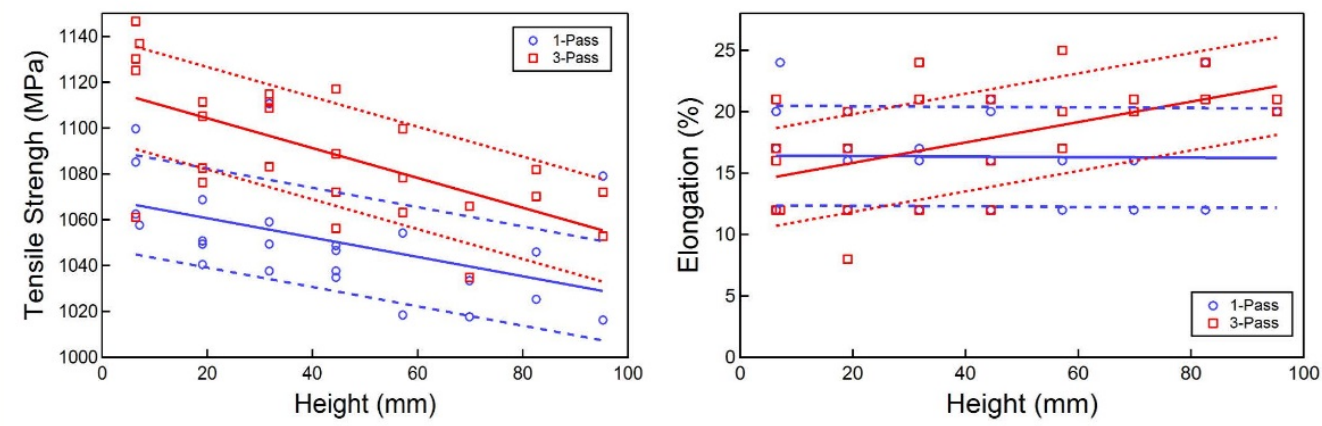

The tensile strengths decreased linearly with increasing height for all the wall structures and for both the longitudinal and transverse orientations.

The elongation measured from the longitudinal tensile samples extracted from the thick wall structures increased linearly with increasing height. 


\section{Changes in Microstructure with Height in a Thin Wall Specimen}
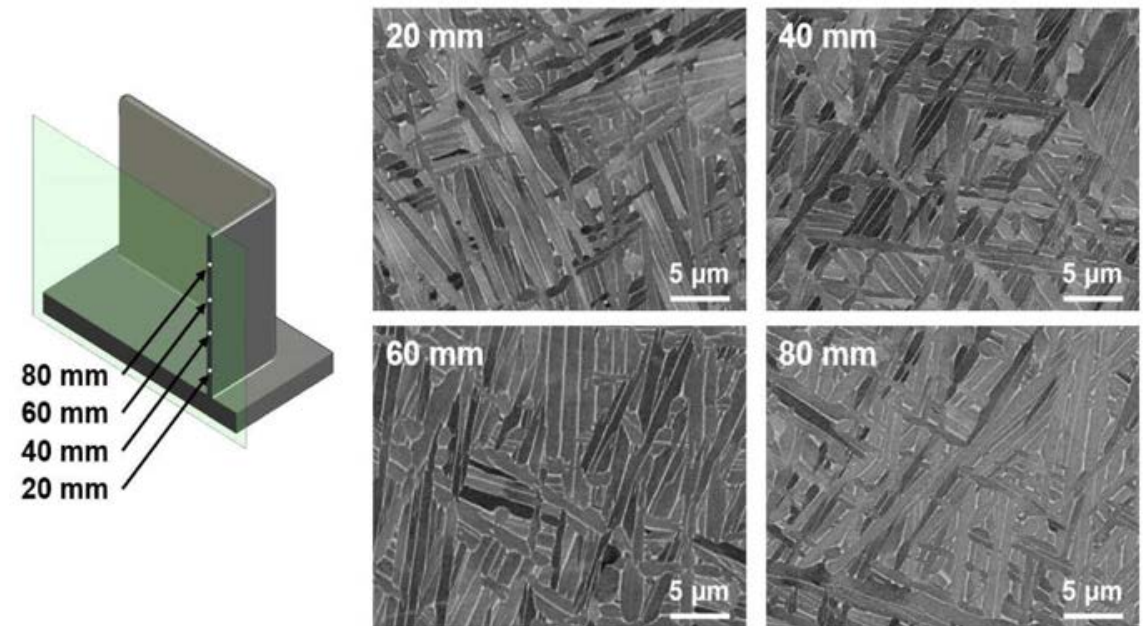

\section{Changes in Microstructure with Height in a Thick Wall Specimen}

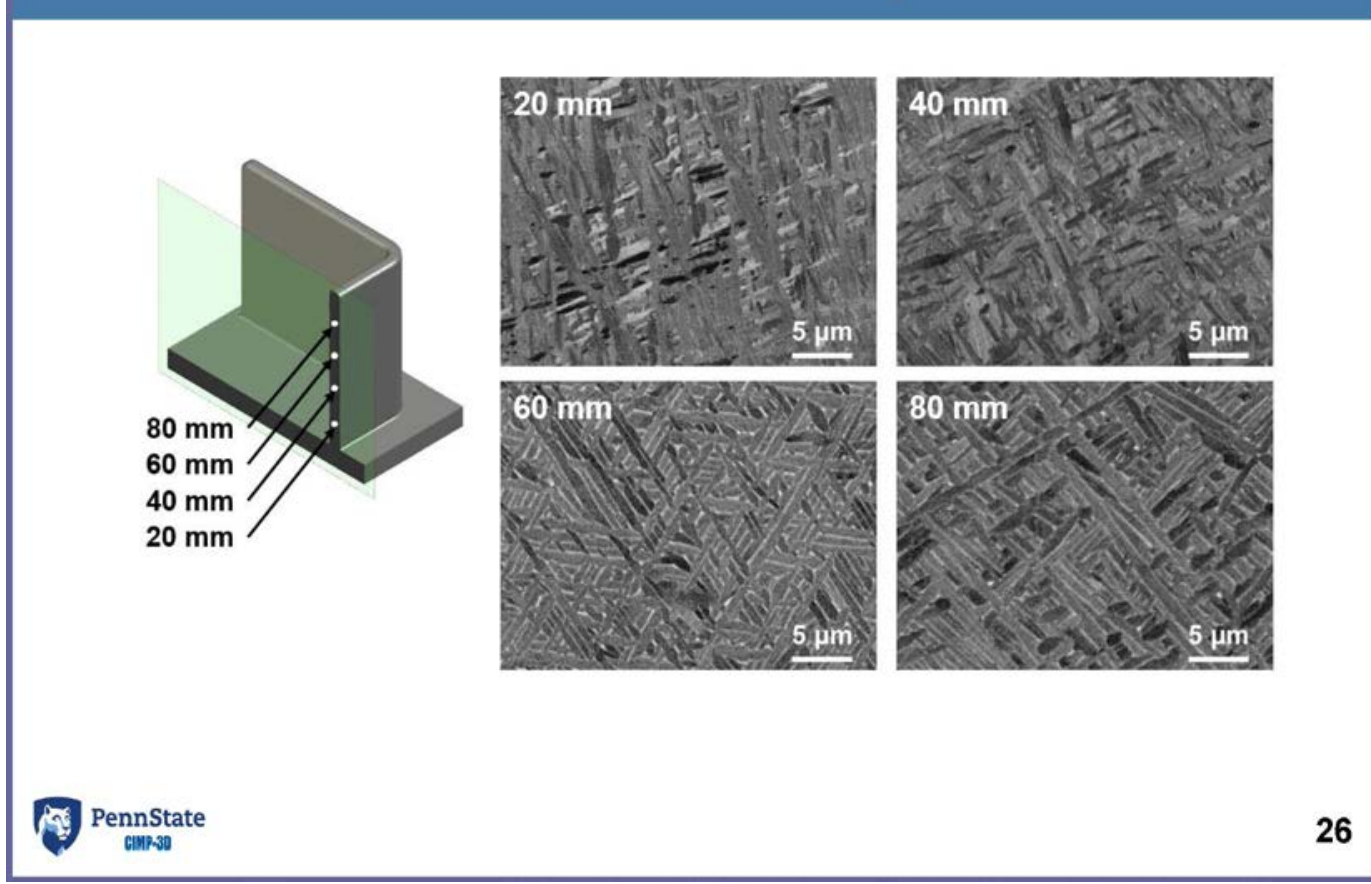


Pennstate Microstructural Features Demonstrate No

$\substack{\text { Applied Research } \\ \text { Laboratory }}$
Strong Dependence With Location

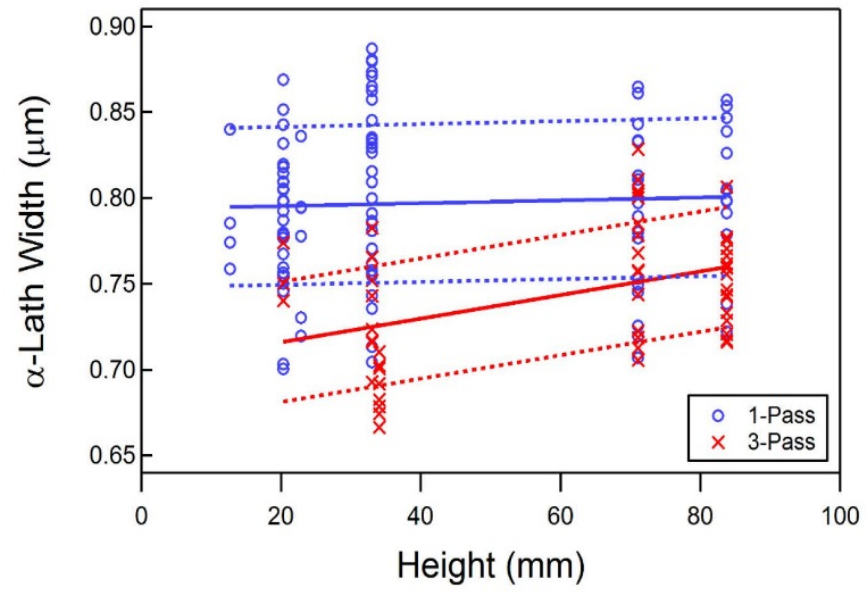

\section{Impact of Post Processing}



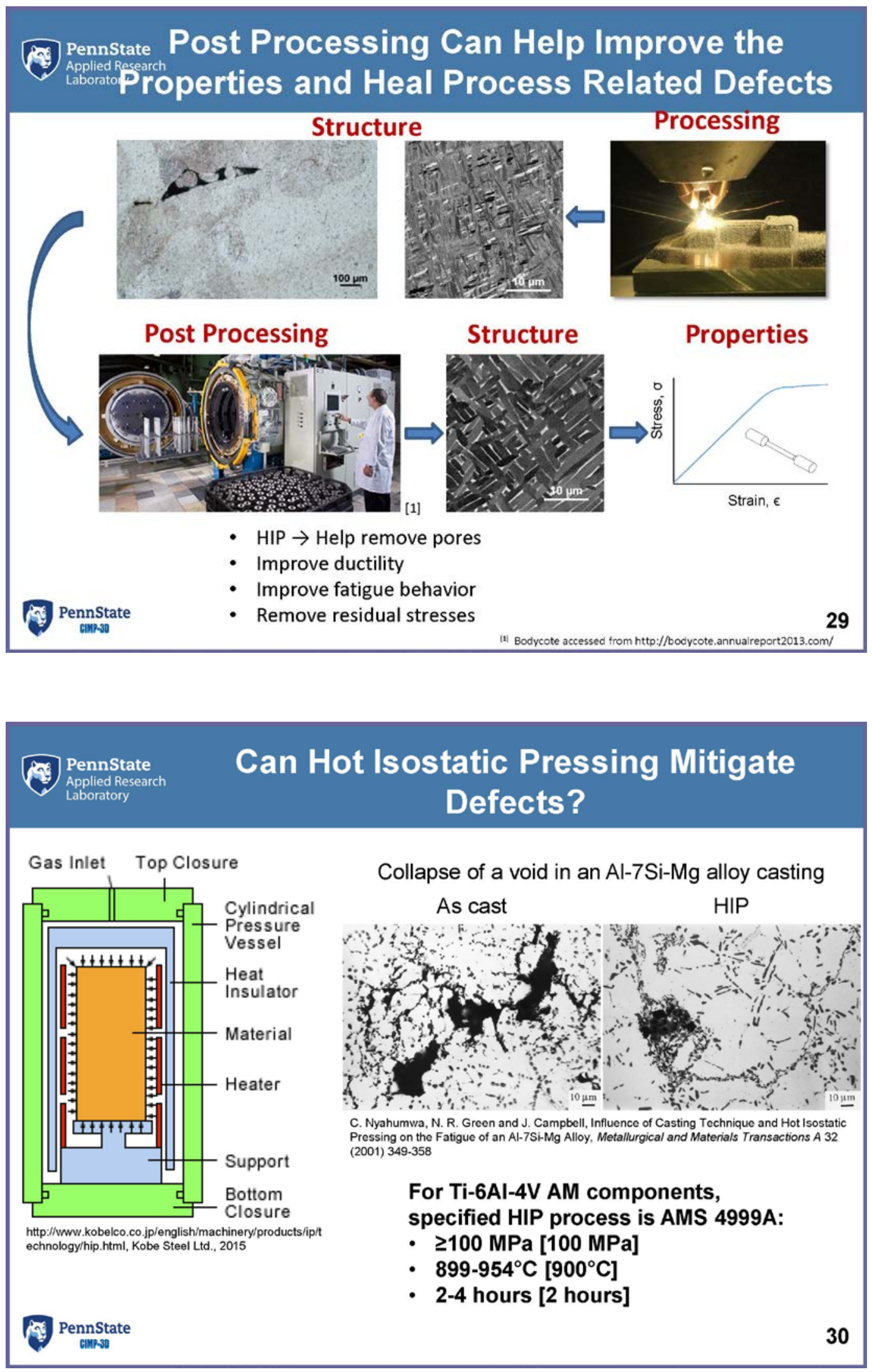
PennState Applied Research Laboratory

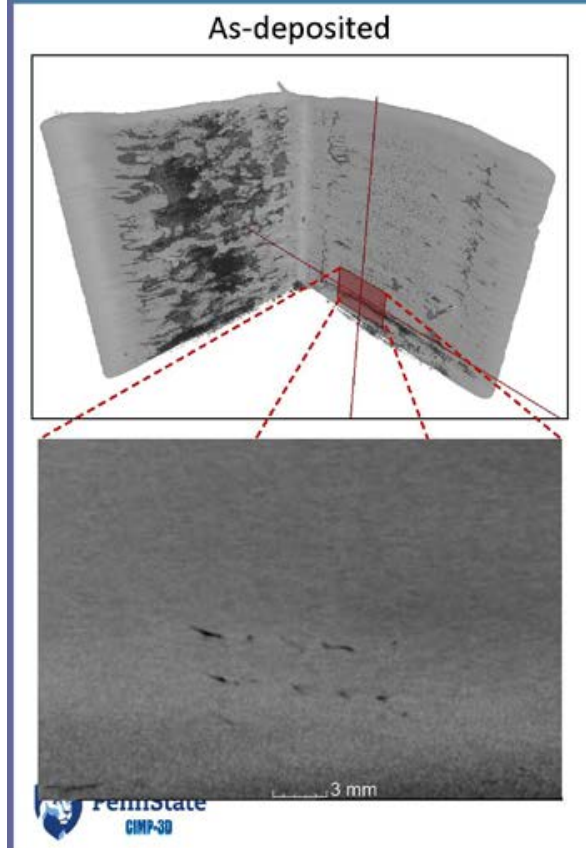

HIP

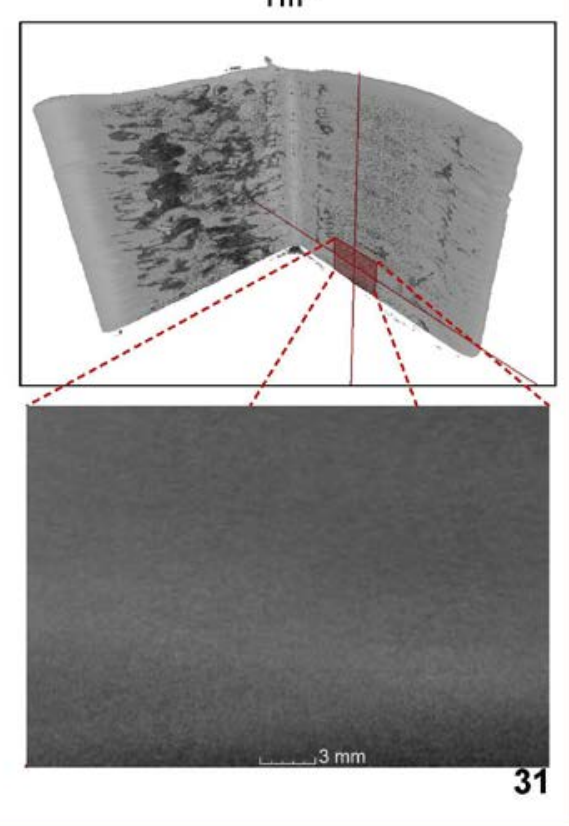

(3) Pennstate HIP has Improved Fatigue Life in AM Laboratory Components
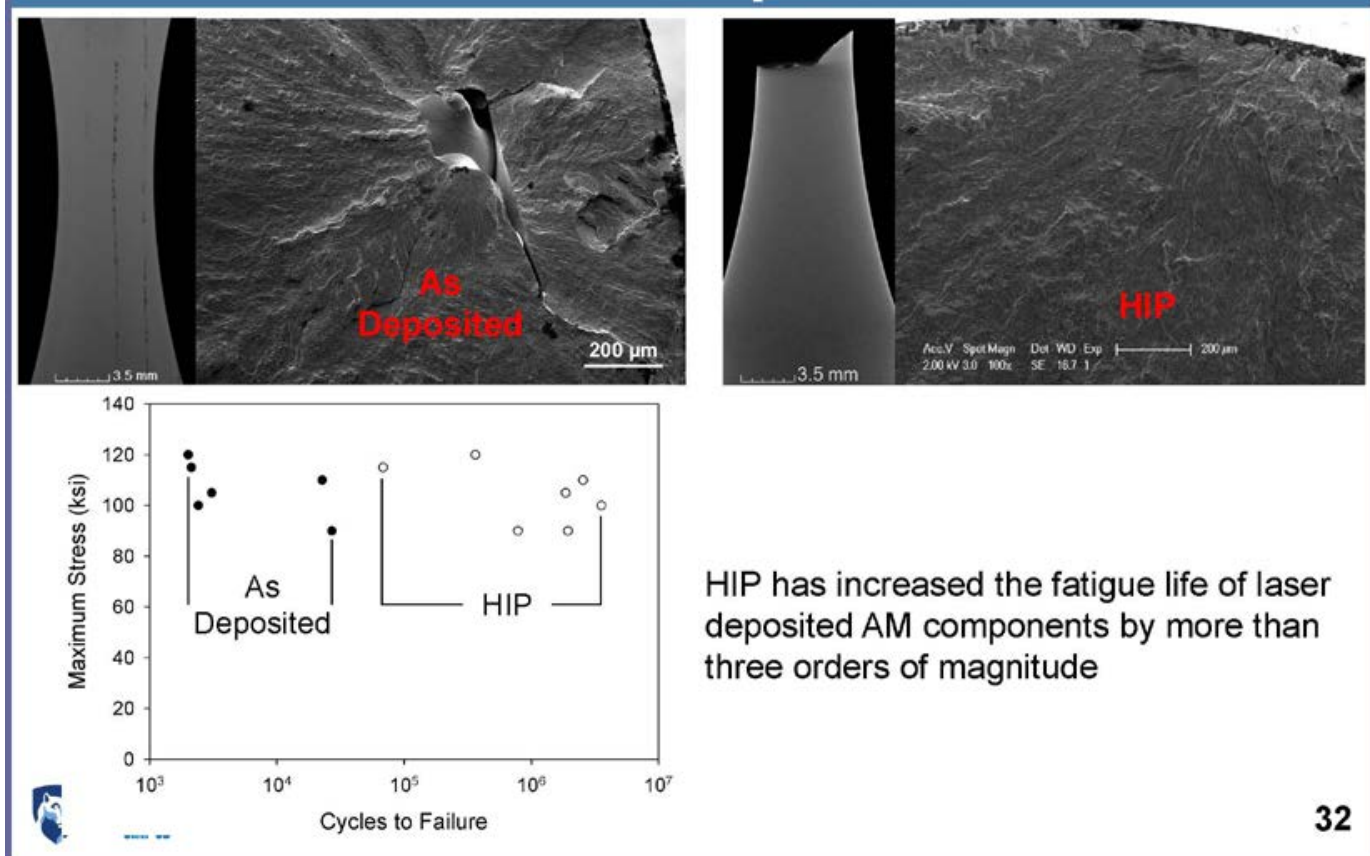

HIP has increased the fatigue life of laser deposited AM components by more than three orders of magnitude 


\section{Post Processing Results in Lower Tensile Strength and High Elongation}
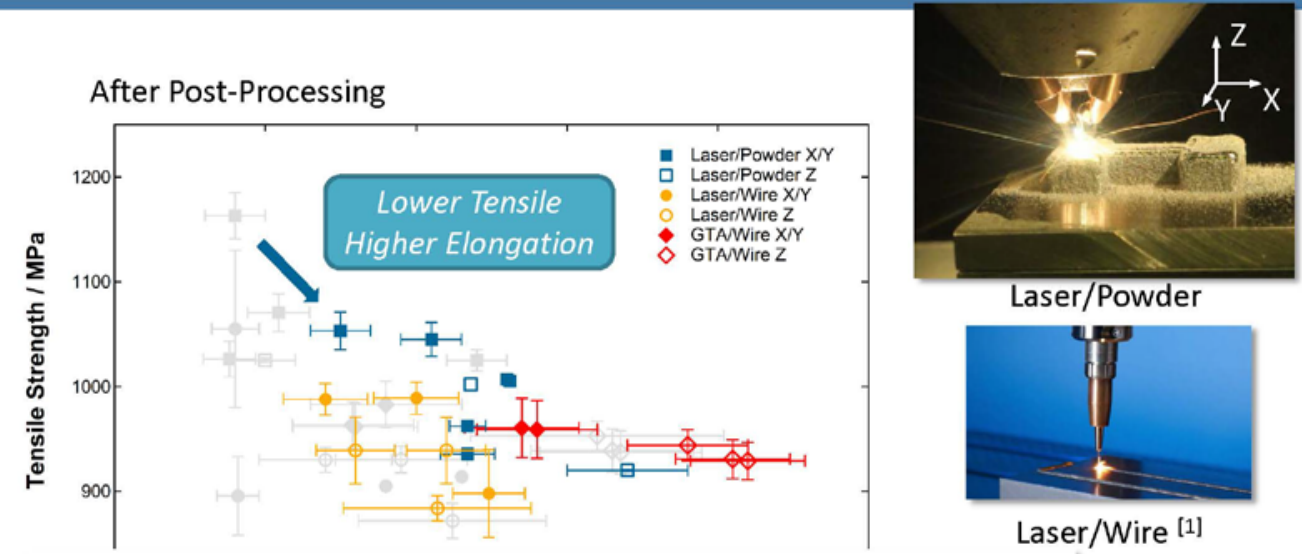

Laser/Wire ${ }^{[1]}$

1. Alcisto, J., et al. (2011). Journal of Materials Engineering and Performance 20(2): 203-212.

2. Baufeld, B., et al. (2011). Journal of Materials Processing Technology 211(6): 1146-1158.

3. Baufeld, B. and O. van der Biest (2009).Science and Technology of Advanced Materials 10(1).

4. Brandl, E., et al. (2010). Laser Assisted Net Shape Engineering 6, Proceedings of the Lane 2010, Part 25: 595-606.

5. Brandl, E., et al. (2011). Trends in Aerospace Manufacturing 2009 International Conference 26.

6. Dinda, G. P., et al. (2008). Metallurgical and Materials Transactions a-Physical Metallurgy and Materials Science 39A(12): 2914-2922.

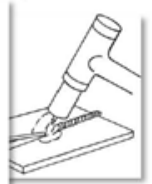

Kobryn, P. A. and S. L. Semiatin (2001). Solid Freeform Fabrication Symposium, Austin, TX

8. Qiu, C. L., et al. (2015). Journal of Alloys and Compounds 629: 351-361.

PennState Applied Researc Applied Researc
Laboratory

\section{Laser Builds Consistently Exhibit Higher} Tensile Strengths

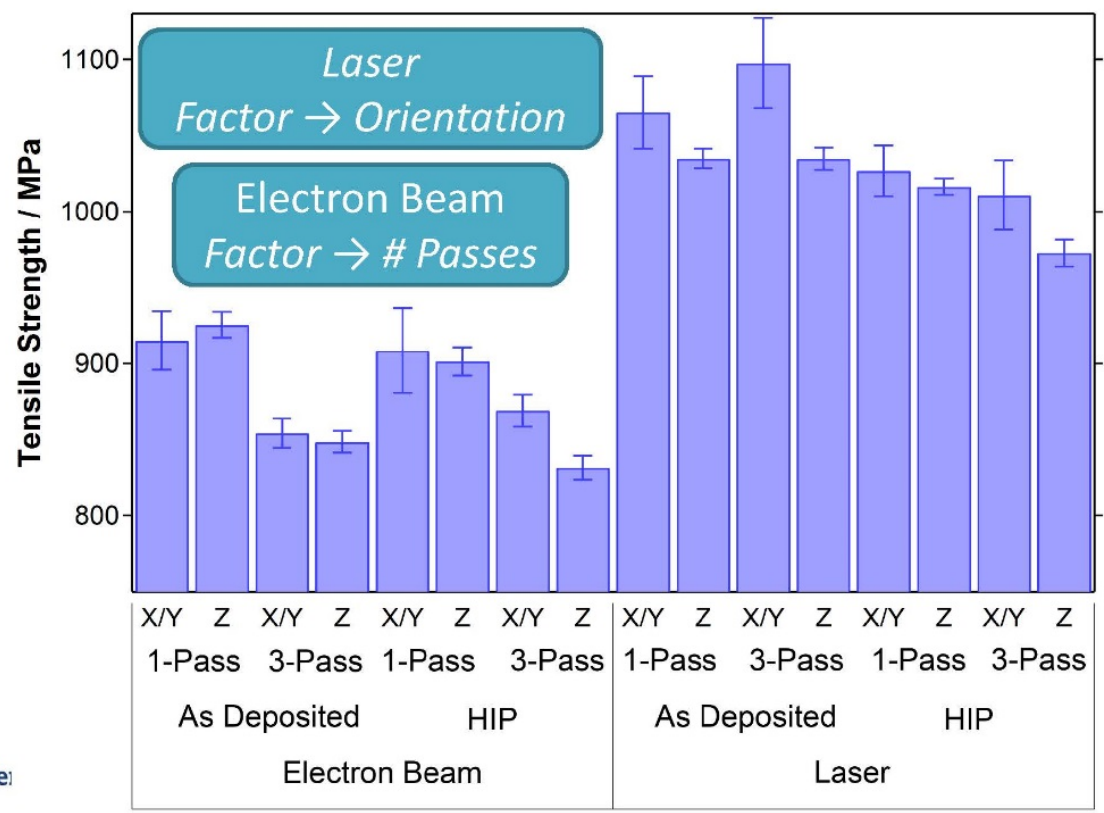



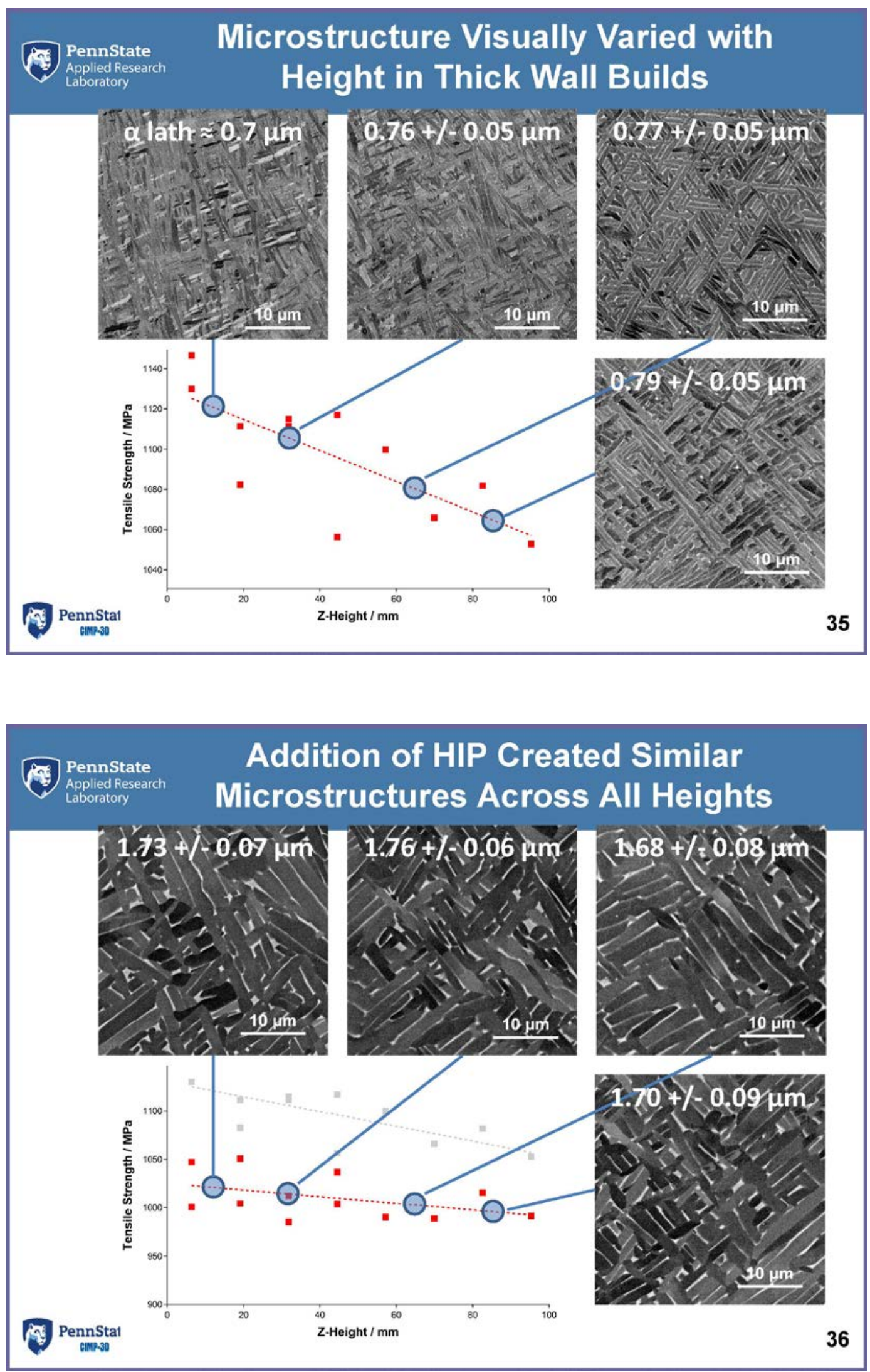


\section{Inspection of AM Components}

\section{Sources of Defects in Metal-Based Additive Manufacturing}

Layer-by-layer manner of the additive manufacturing process produces internal defects similar to those seen in welding and joining processes.

Common defects observed across all material types are process related and caused by changes in bead shape and improper selection and control of processing parameters.

\section{Lack of Fusion Defects}

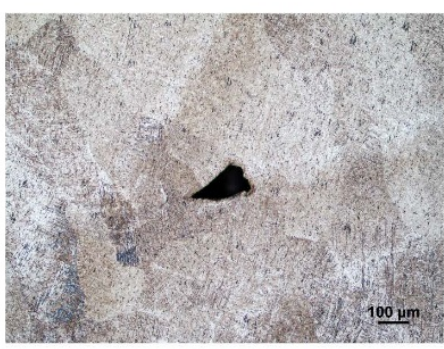

\section{Gas Porosity}

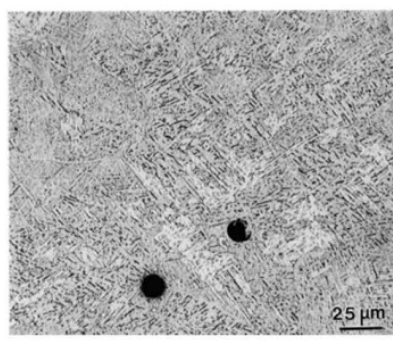

Keyhole Collapse

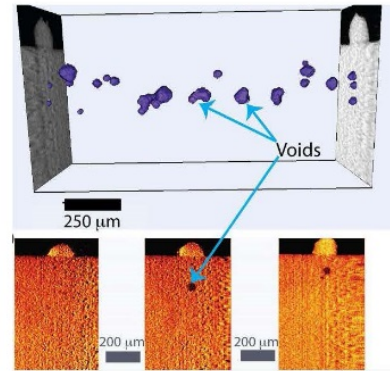

Other defects, i.e. cracking and gas porosity, can be material specific or specific to different processes. 
PennState

Applied Research

Laboratory

\section{Limitations to Traditional NDE Tools for AM Components}

Limiting factors for the use of Non-Destructive Evaluation (NDE) tools can be categorized between geometric and material properties.

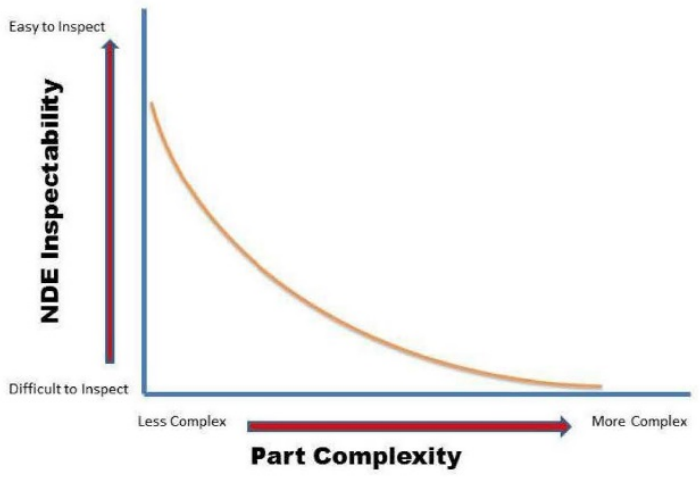

\section{Complex Part Geometry}

Lack of Defined Critical Defect Types and Sizes

Lack of Physical NDE Reference Standards

Lack of Written Inspection Procedures

Lack of Probability of Detection Data

AM processes can add significant design complexity and challenge traditional NDE techniques.

PennState ${ }^{3}$ Todorov et al, "Nondestructive Evaluation (NDE) of Complex Metallic Additive Manufactured (AM) Structures", AFRL-RX-WP-TR-2014-0162, Interim

\section{X-Ray Computed Tomography}
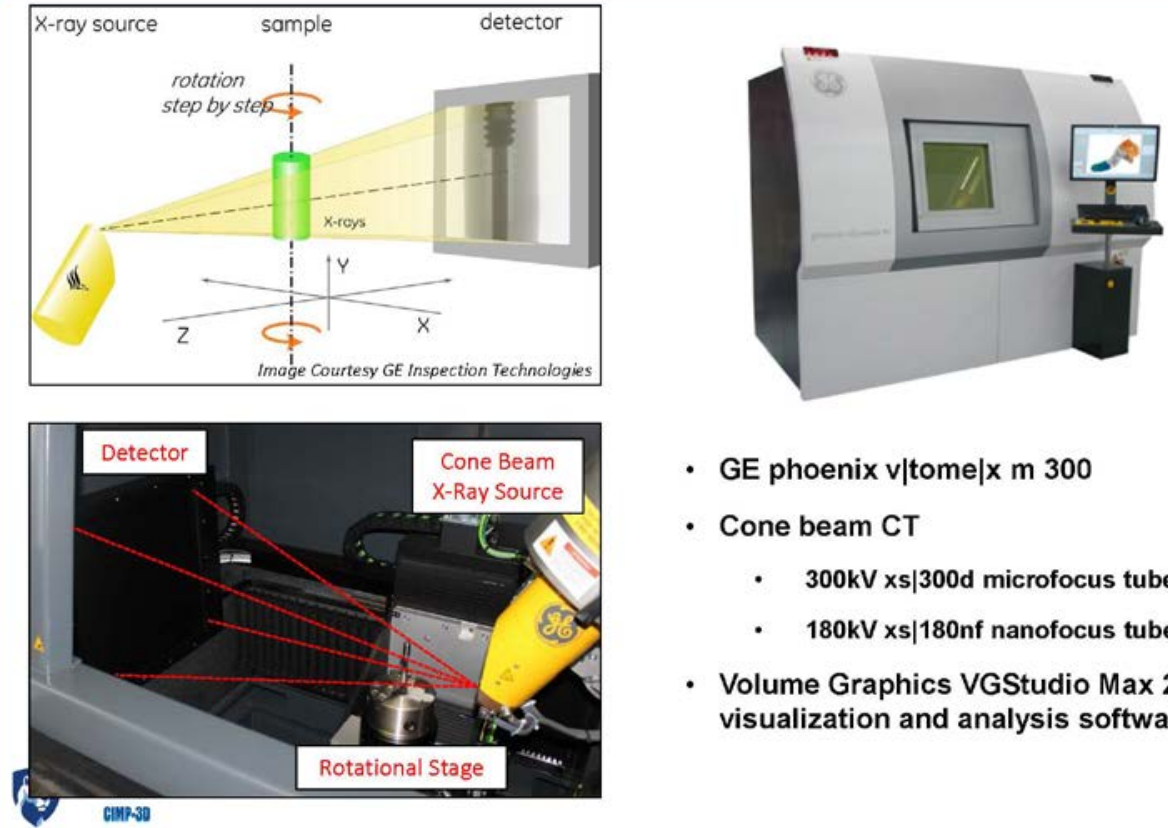

- GE phoenix v|tome|x m 300

- Cone beam CT

- $300 \mathrm{kV} \times \mathrm{s} \mid 300 \mathrm{~d}$ microfocus tube

- $180 \mathrm{kV} \times \mathrm{s} \mid 180 \mathrm{nf}$ nanofocus tube

- Volume Graphics VGStudio Max 2.2 visualization and analysis software 


\section{X-Ray CT is a Powerful Tool for Inspecting Complex Internal Geometries}
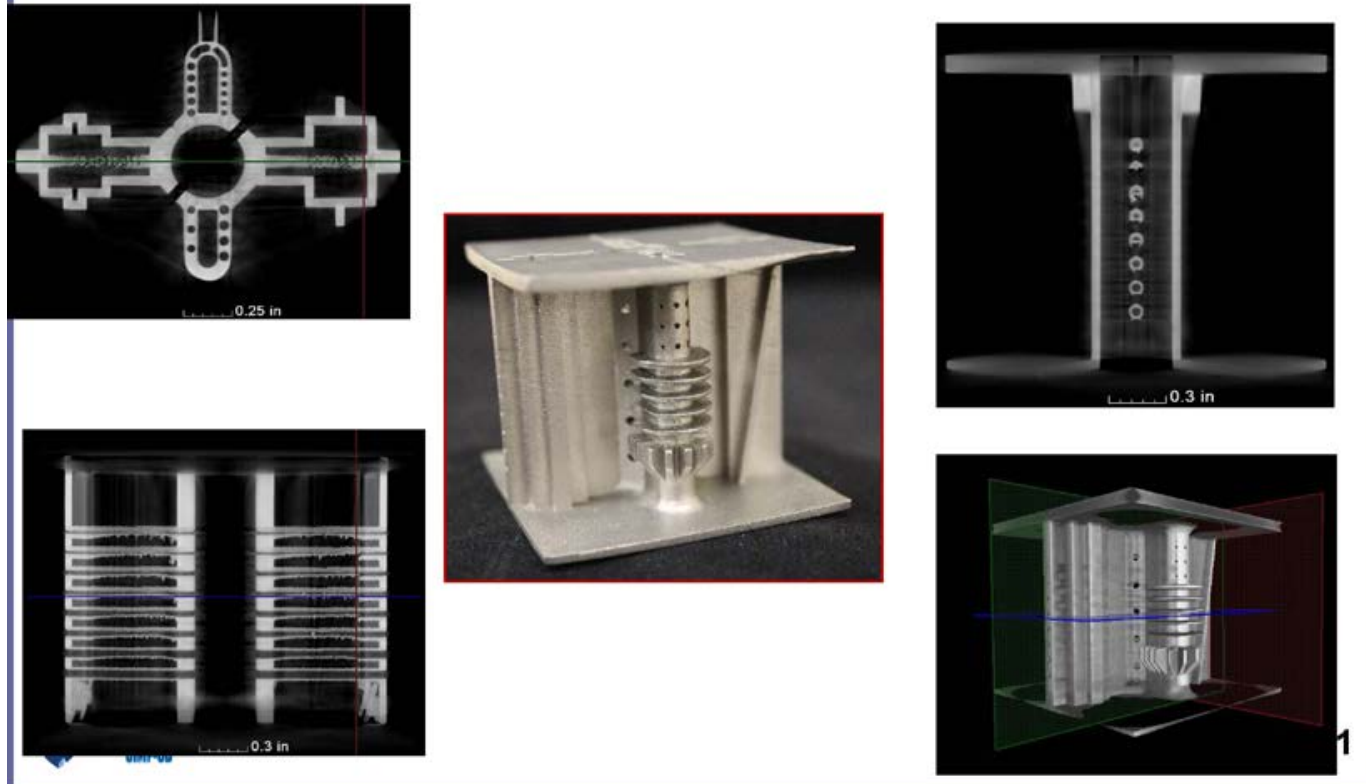

PennState

Applied Research

Laboratory

\section{Obtaining Suitable CT Scans and Artifacts in Reconstruction}

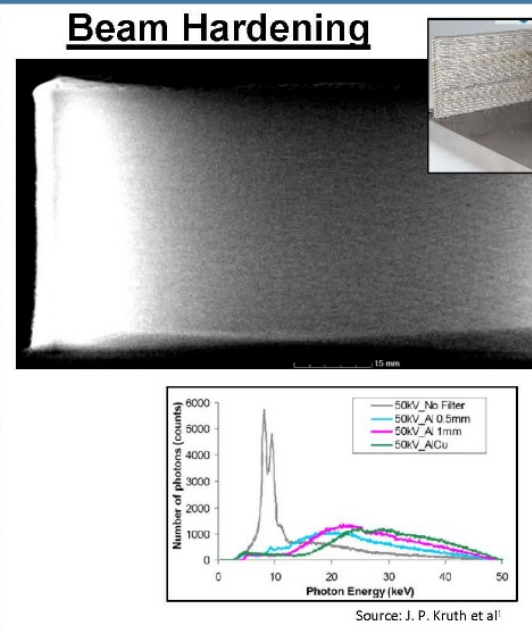

- Polychromatic x-ray source

- Lower energy photons preferentially absorbed

- Effect reduced by pre-filters PennState GIMP.830

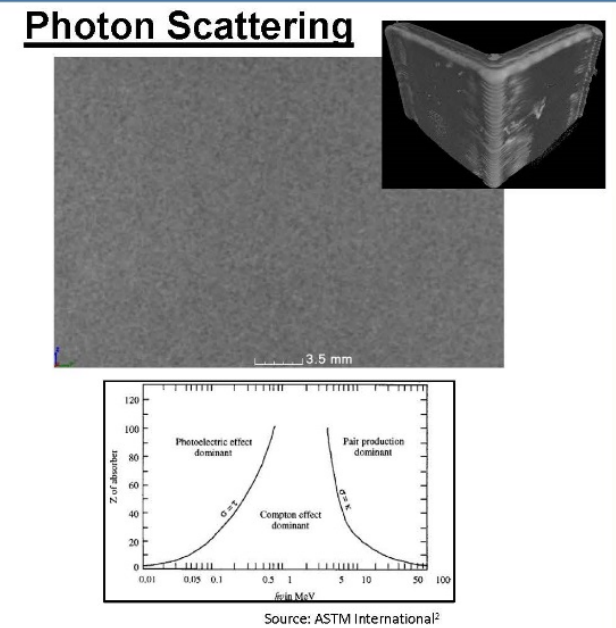

- X-Rays do not follow the expected linear path to the detector

- Results in a greater variation in gray values for a given density condition 


\section{Challenges in Use of Automatic Detection Algorithms}

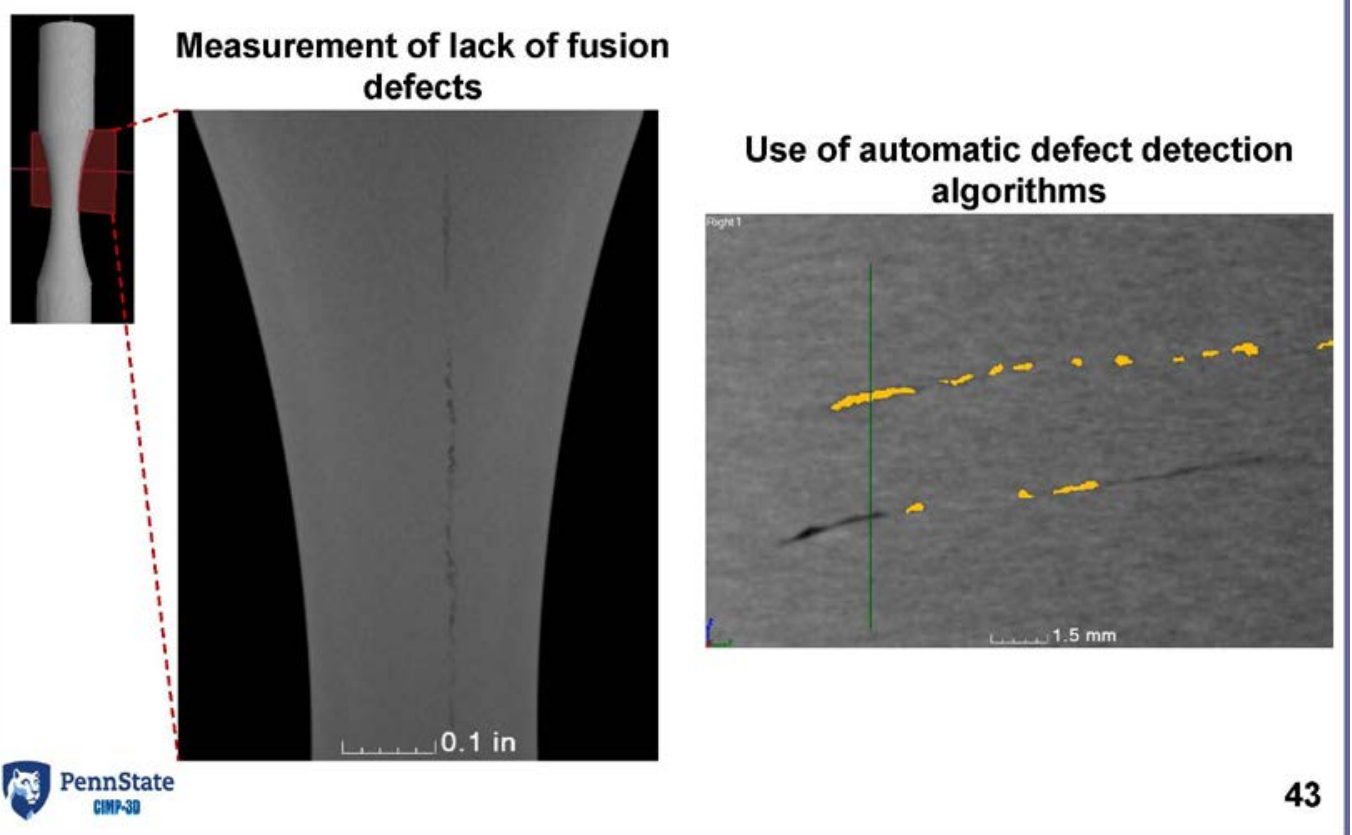

\section{Pennstate How Accurate are the Measurements Using Analysis Software?}

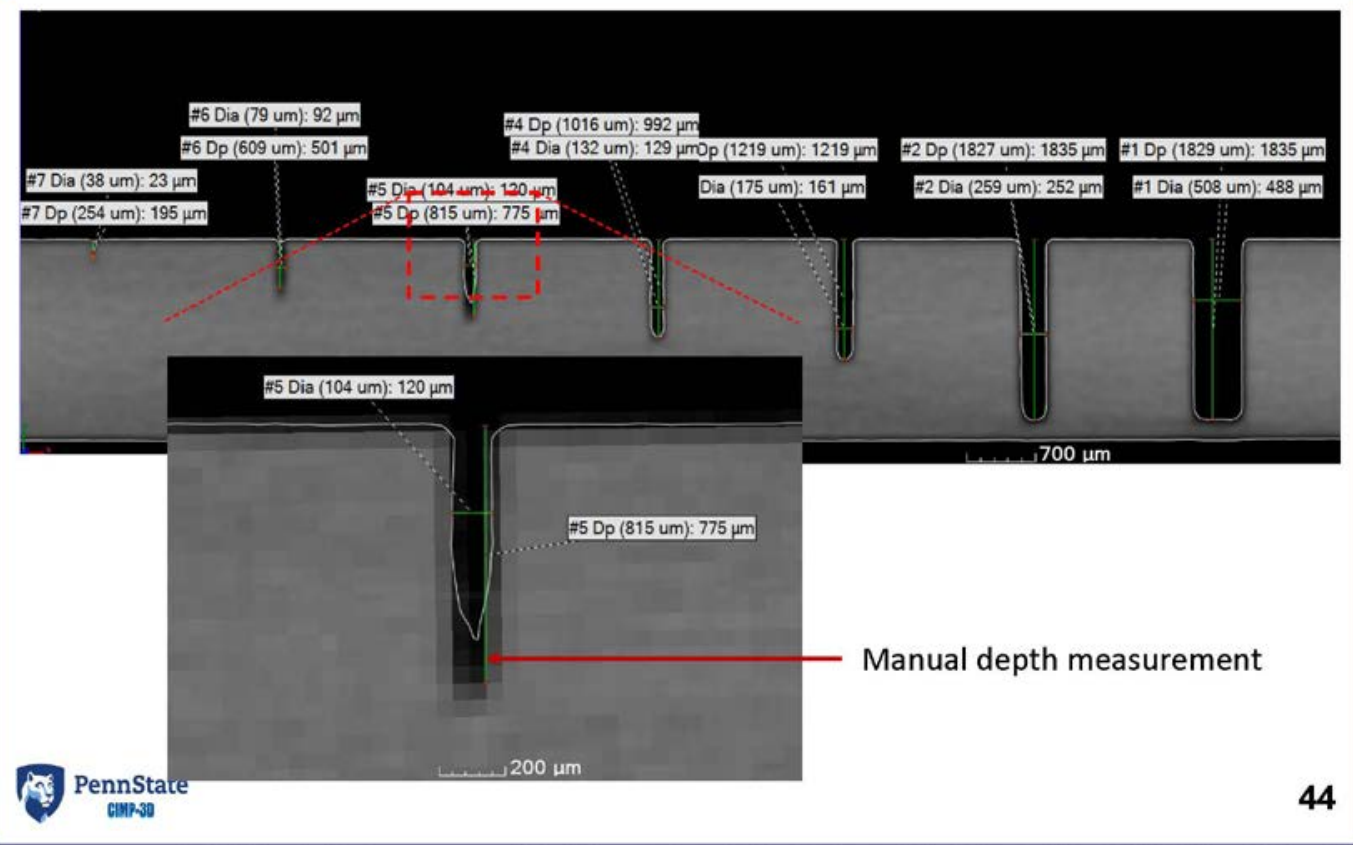




\section{Error in CT Measurements}

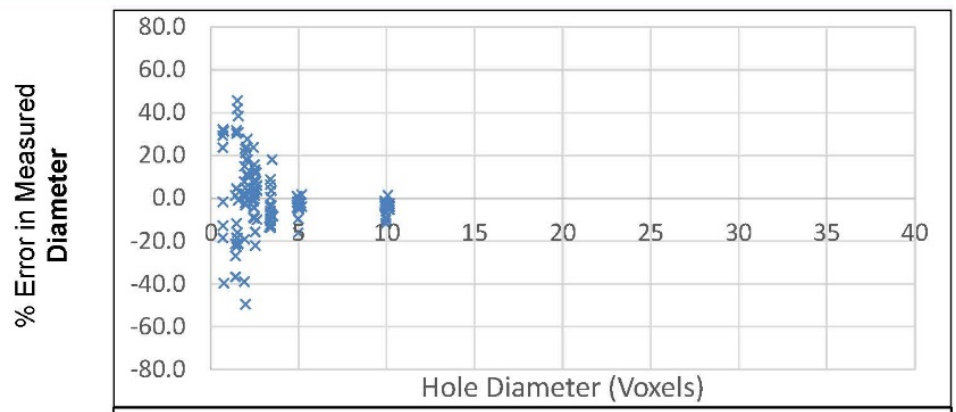

"Hit" Rate = 137/152

Smaller dimension

(diameter or depth)

dominated \% error

Pennstate

Applied Research

Applied Resear
Laboratory

\section{Path Forward}




\section{What are the Challenges for Certifying AM Parts?}

- Lack of material property database or pedigreed data

- Incomplete knowledge of the role of processing on properties

- Anisotropy in the microstructure and mechanical properties

- Unknown relationships between properties and geometries

Since $A M$ is producing finished parts $\rightarrow$ Impossible to provide certification/data for all possible geometries

$>$ Need to develop relationship knowledge base

Pennsteidelationships between Design-ProcessingApplied Research
Laboratory Structure-Properties-Performance

The interrelationships between design, processing, structure, and performance are complicating the certification of AM Ti-6Al-4V components.

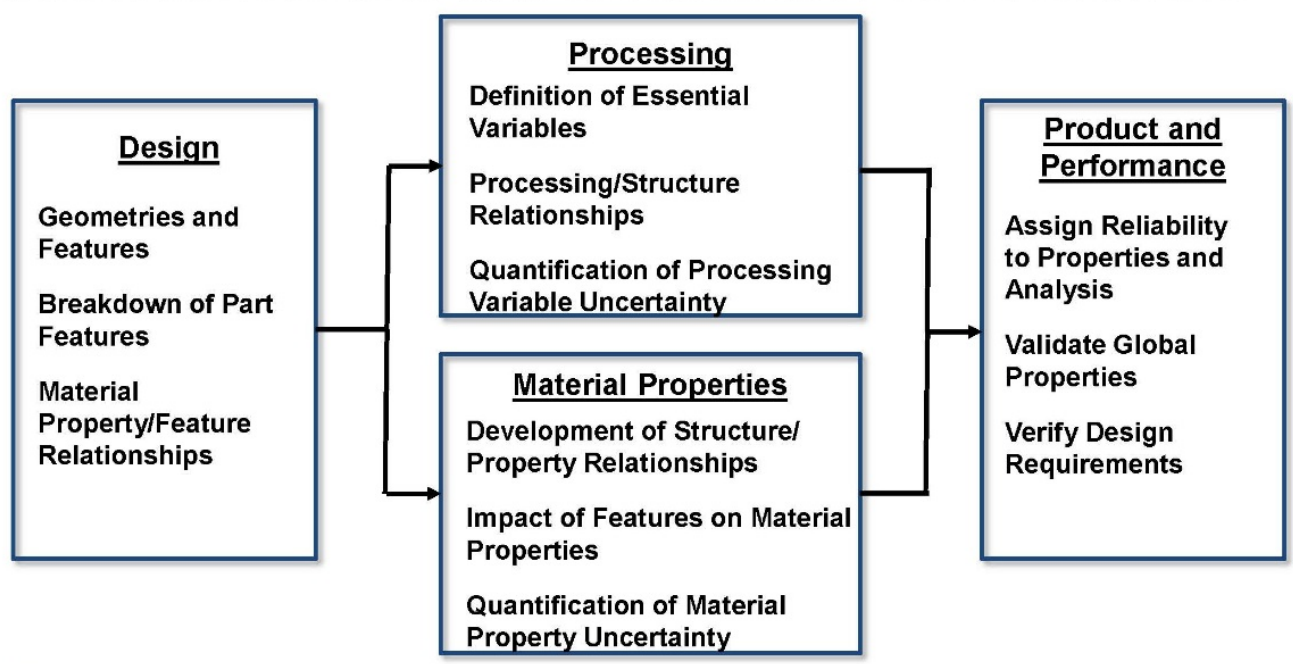


PennState

\section{Pennstate}

Applied Researc
Laboratory

\section{Certification of Additive Manufactured}

\section{Components}

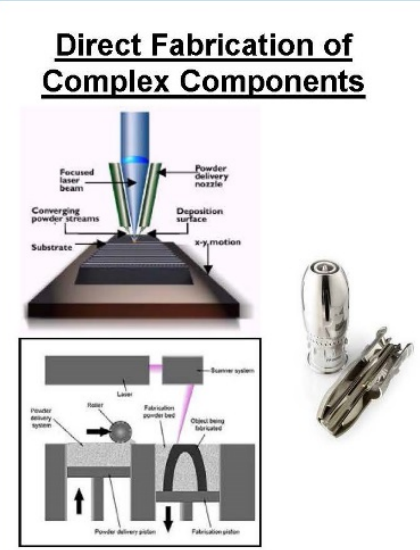

Small lot sizes (Lot of 1)

Complex processing conditions

Undeveloped process and quality controls

PennState CIIMP.30

\section{Challenges to Certification} and Qualification
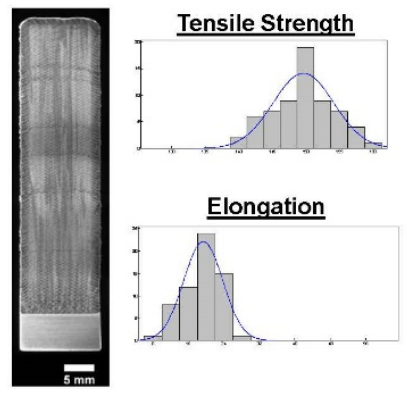

Lack of processing/structure/ property relationships

Lack of material property database or design allowables

Unknown impact of complex geometries on material properties
New Approaches for Additive Manufacturing
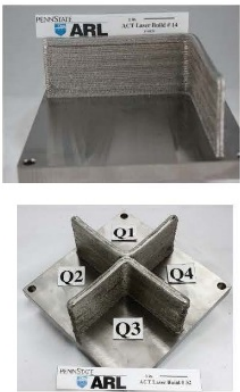

Link geometric features and important processing variables

Knowledge-based expert system

Use canonical features to develop property data base 


\section{Overview of Single Geometry Electron Beam Builds}

\section{L-Shapes}

Single Pass
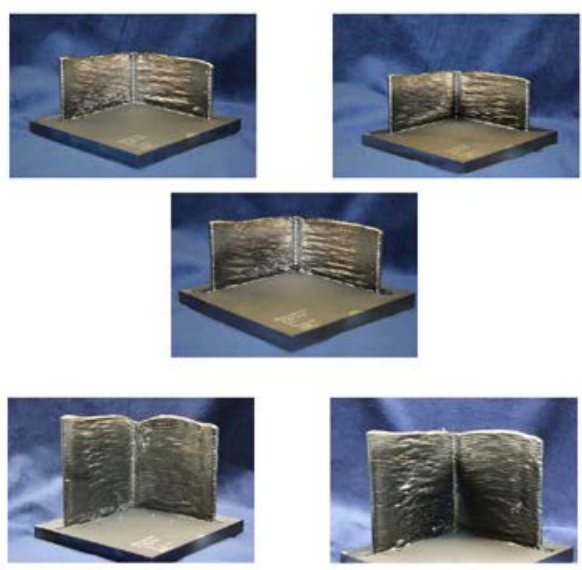

PennState AIMP.30
Three Pass
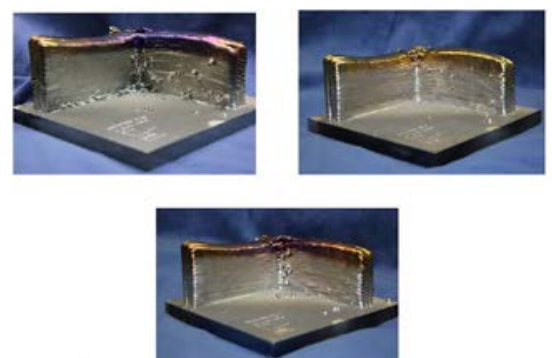

Electron Beam Processing:

- Current, mA : 95 (peak)

- Voltage, kV : 40

- Min Vacuum: 1 uT

- Working Distance: 9.75"

- Wire Feed Speed: $225 \mathrm{ipm}$

- Travel Speed:30 ipm (max)

\section{Comparison Between Laser and Electron} Beam Deposition 


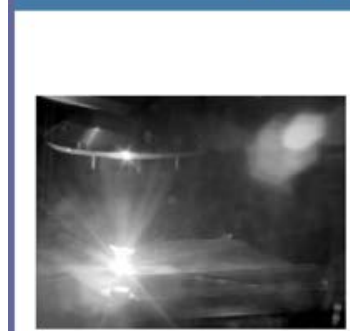

Laser

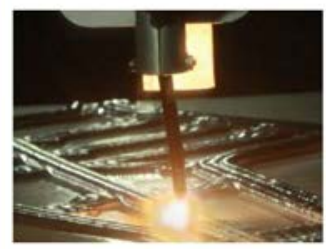

Electron Beam

PennState

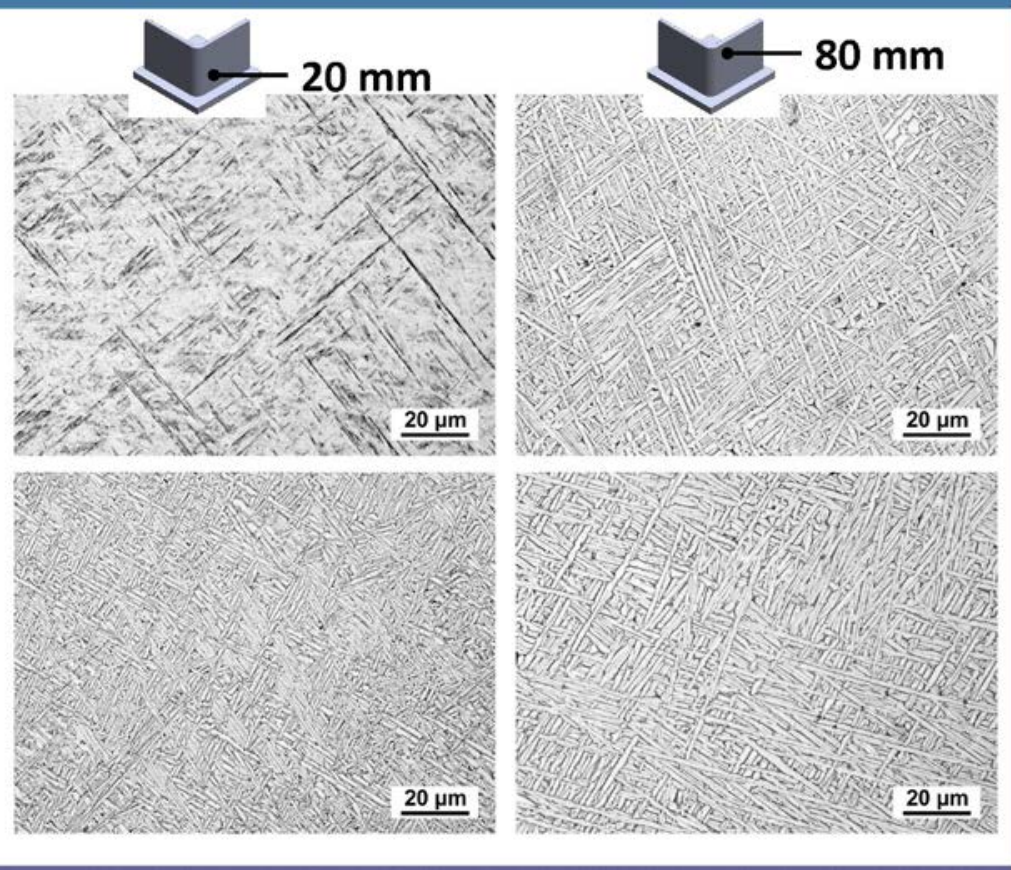

\section{a-Lath Widths Vary Between Different} Conditions

PennState
Applied Research Applied Researc
Laboratory

Electron Beam

As Deposited

Laser

HIP

Electron Beam

HIP
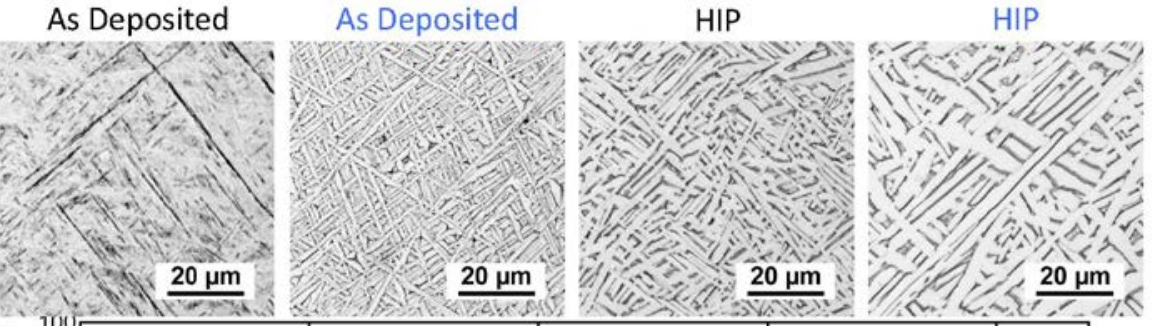

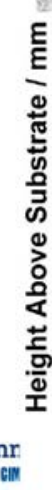

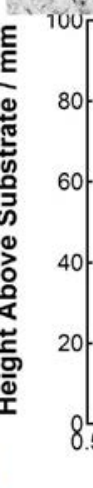
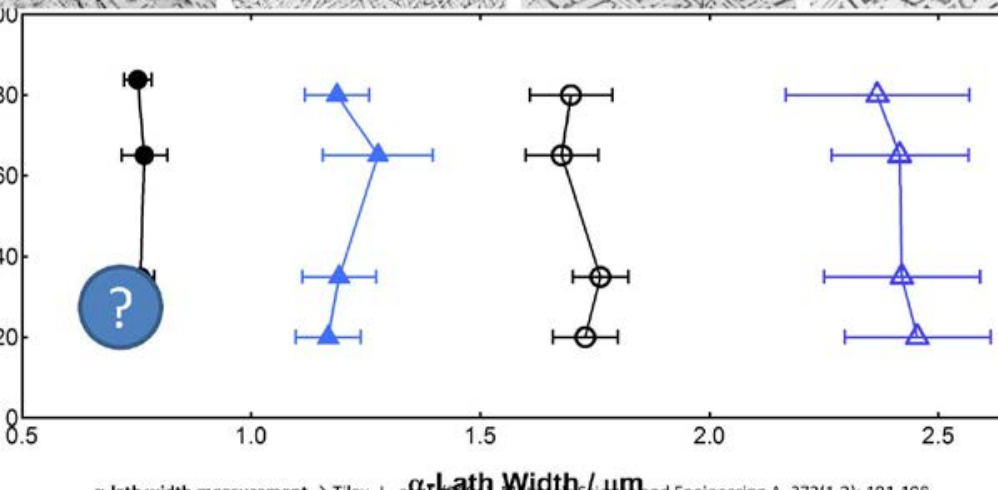


\section{Strengths than Electron Beam Wire Builds}

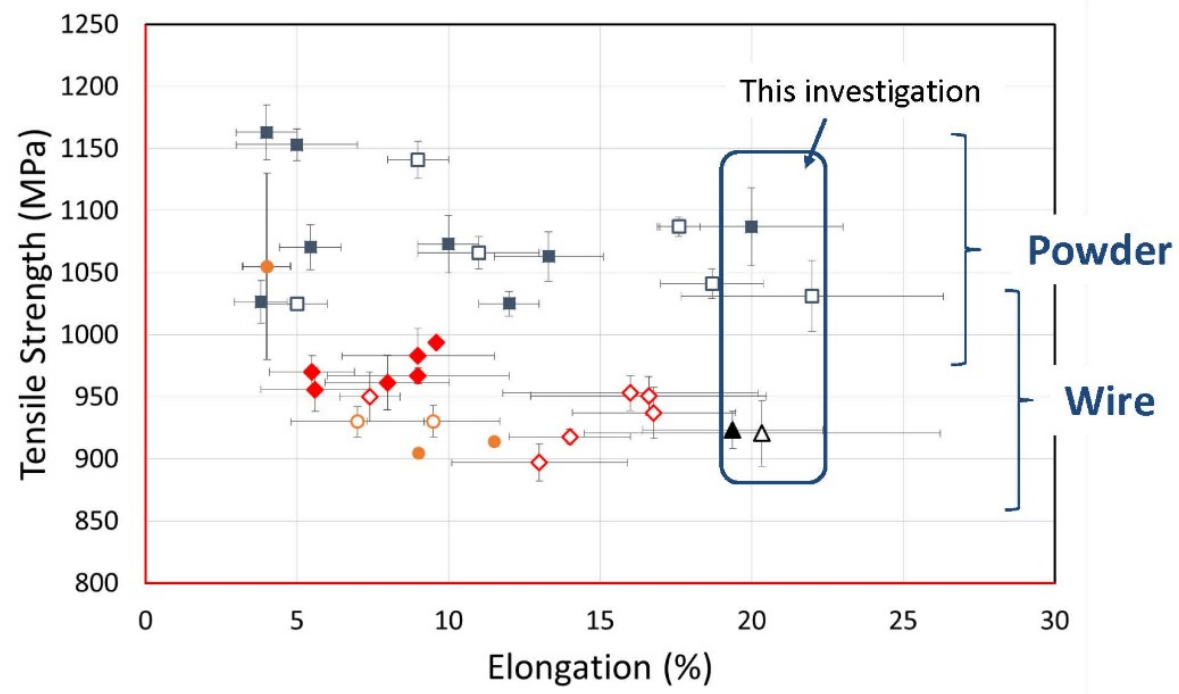

- Laser/Powder - X/Y - Laser/Wire - X/Y a Laser/Powder - Z cImproso
- Arc/Wire - X/Y $\diamond$ Arc/Wire - Z
$\Delta$ E-Beam/Wire - X/Y $\Delta$ E-beam/Wire - Z
PennState

Applied Research Applied Researc
Laboratory

\section{Tensile Strengths Decrease after HIP in}

\section{Laser Builds}
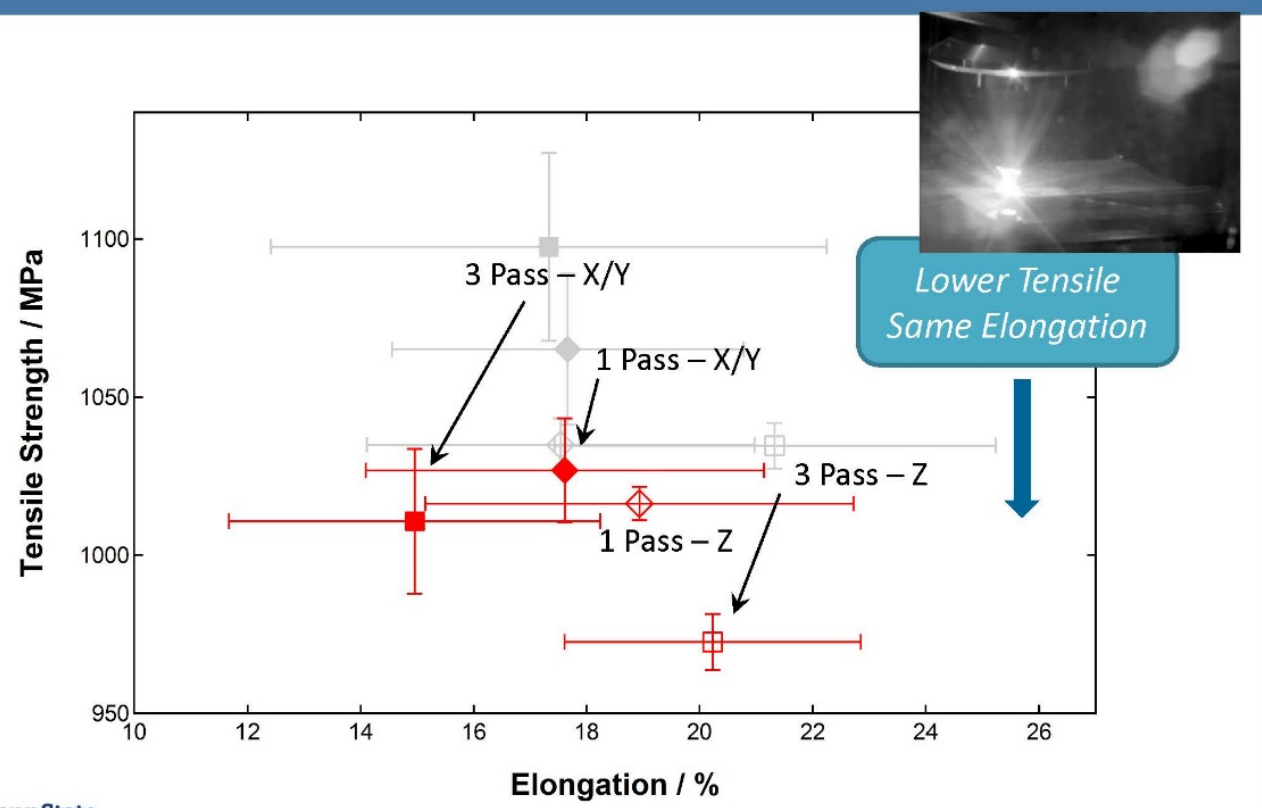


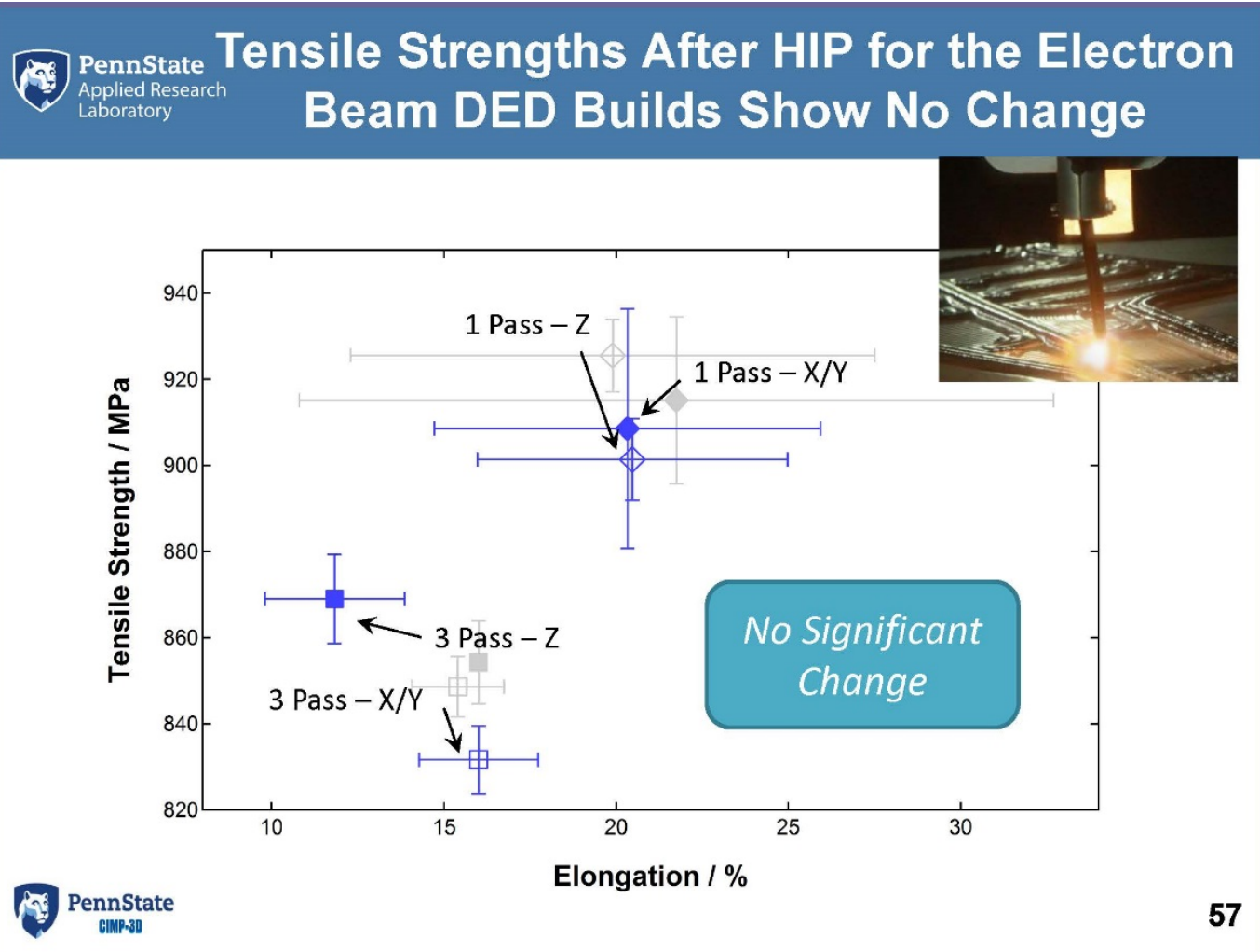

\section{Pennstate Categorization of Geometric Complexity in Applied Research Laboratory \\ AM Components}

Additive manufacturing capable of producing parts with a wide range of geometric complexity.

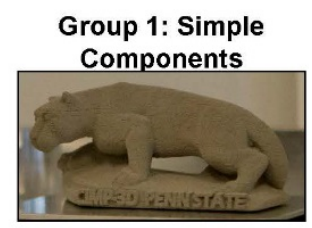

Group 3:

Components with Embedded Features

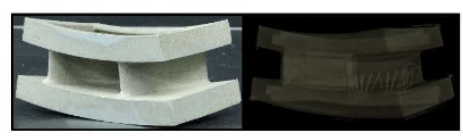

Group 2: Optimized Components

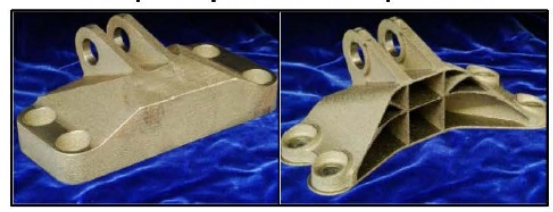

Group 5: Lattice Structures

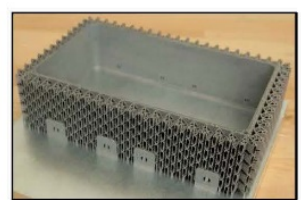

$\begin{array}{ll}\text { Todorov et al "Nondestructive E} & \text { PennState } \\ \text { 2014-0162, Interim Report, } 2014\end{array}$ 


\section{Impact of AM Microstructure on NDE Response}

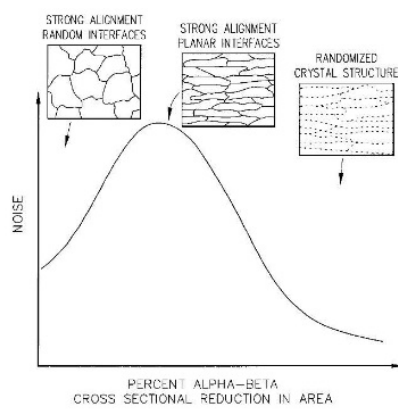

Relative noise during ultrasonic inspection of Titanium alloys as a function of final hot working ${ }^{1}$

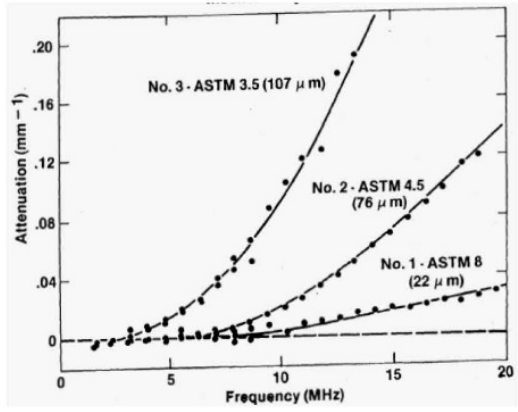

Ultrasonic attenuation in Inconel alloy 718 as a function of frequency for various grain sizes ${ }^{2}$

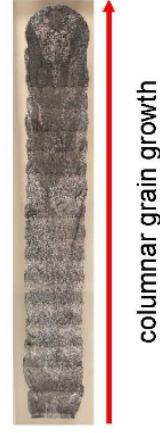

Example Ti-6Al-4V macrostructure from a laser DED build

Large grains and anisotropic grains are known to cause preferential attenuation of ultrasonic waves

Layer-by-layer nature of additive manufacturing promotes epitaxial grain growth

PennState ${ }_{2}^{1}$ Gorman, M.D., Woodfield, A. P., "Processing of titanium-alloy billet for improved ultrasonic inspectability", EP 1136582 A1, 2001 CIMP.30 2Telschow, KL., "Noncontacting NDE for Materials Characterization", Idaho National Engineering Laboratory, 1995.

\section{Range of Surface Finishes are Possible in AM Processing}

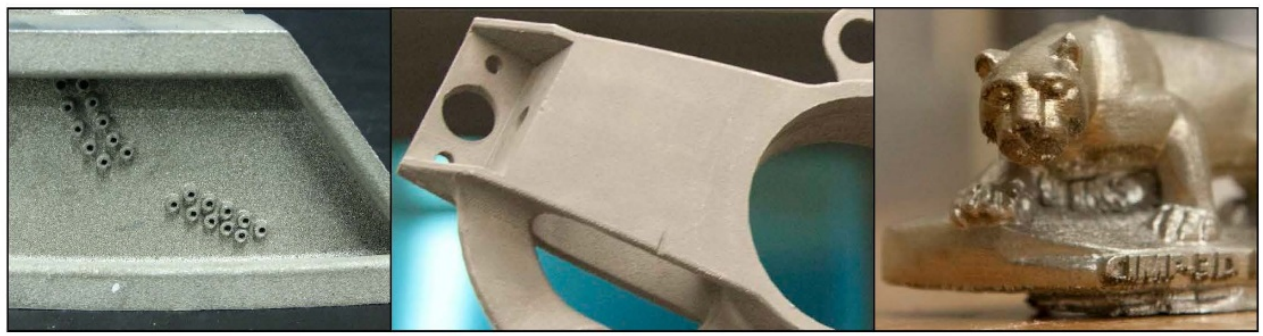

A wide range of surface finish is produced in the as-built condition with various additive techniques

NDE methods that are most sensitive to surface finish include visual testing, liquid dye penetrant testing, magnetic particle testing, eddy current testing and ultrasonic testing

Some surface finishes will prevent the use of these methods

As a near-net shape process, AM will usually require some post-process machining that would enable a wider range of methods to be employed 
INTENTIONALLY LEFT BLANK.

Approved for public release; distribution is unlimited. 


\title{
4. Additive Manufacturing Characterization Utilizing X-ray Computed Tomography
}

\begin{abstract}
Jennifer Sietins
(Army Research Laboratory, Weapons and Materials Research Directorate)

$\mathrm{X}$-ray computed tomography (CT) is a valuable technique for quality control measures, part inspection, dimensional analysis, microstructural characterization, and void identification and quantification. This nondestructive characterization technique allows for 3D imaging that readily captures defects and voids on the conditions that the attenuation, which is approximately related to the material density, is distinctly different from the surrounding material, and the resolution is sufficient for the feature or defect sizes of interest. This work summarizes the CT capabilities at the Army Research Laboratory, with a specific emphasis on the characterization of 3D-printed structures. Analysis examples will include quantification of tolerance differences between the designed and manufactured parts, void sizes and distributions, in-situ compression tests for brittle and elastic truss structures, and mechanical behavior simulations for meshes generated from the CT scan data. These tools can enable faster process optimization time frames and ensure that the final part does not have voids above a critical size prior to fielding.
\end{abstract}



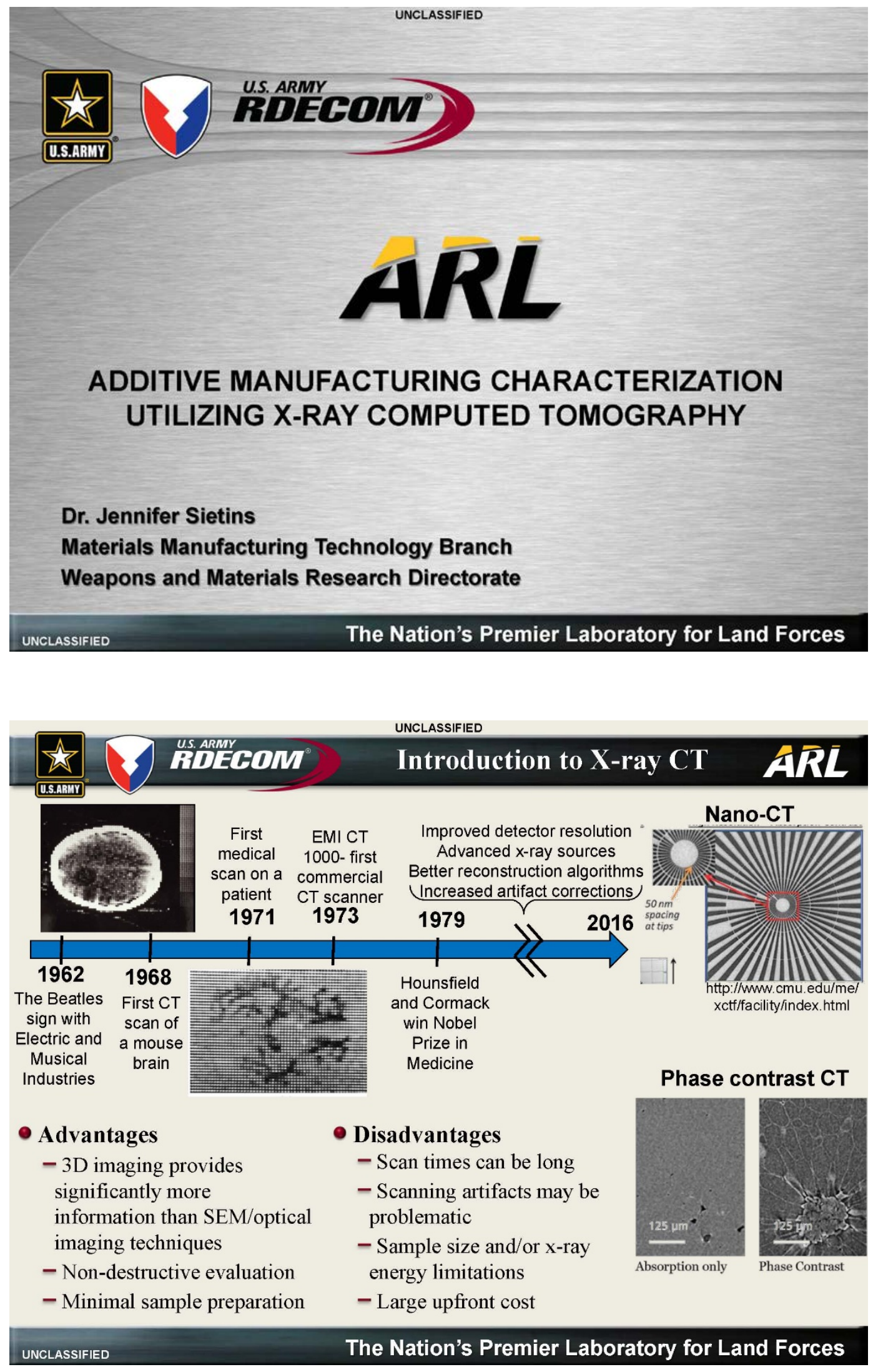

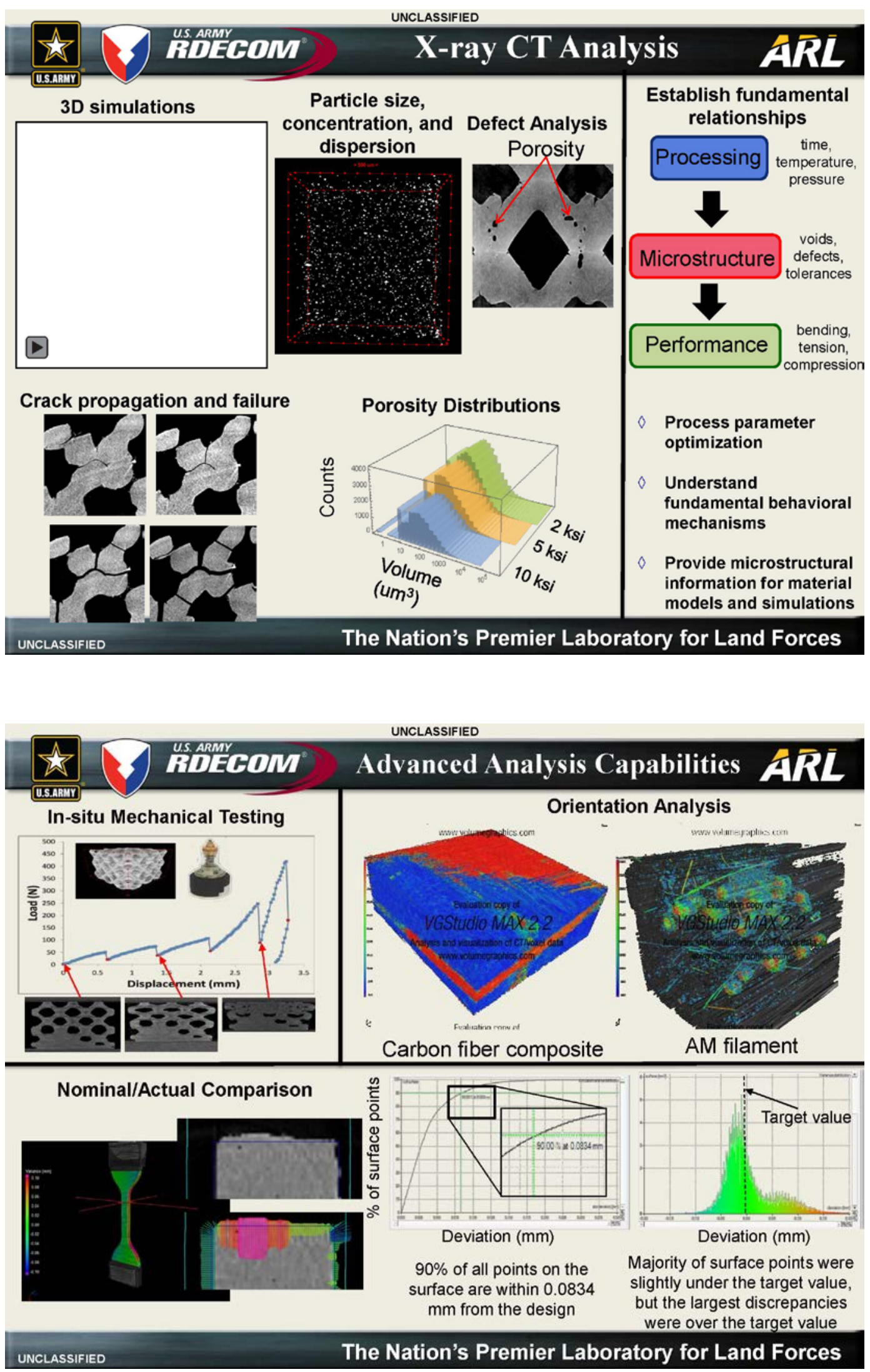


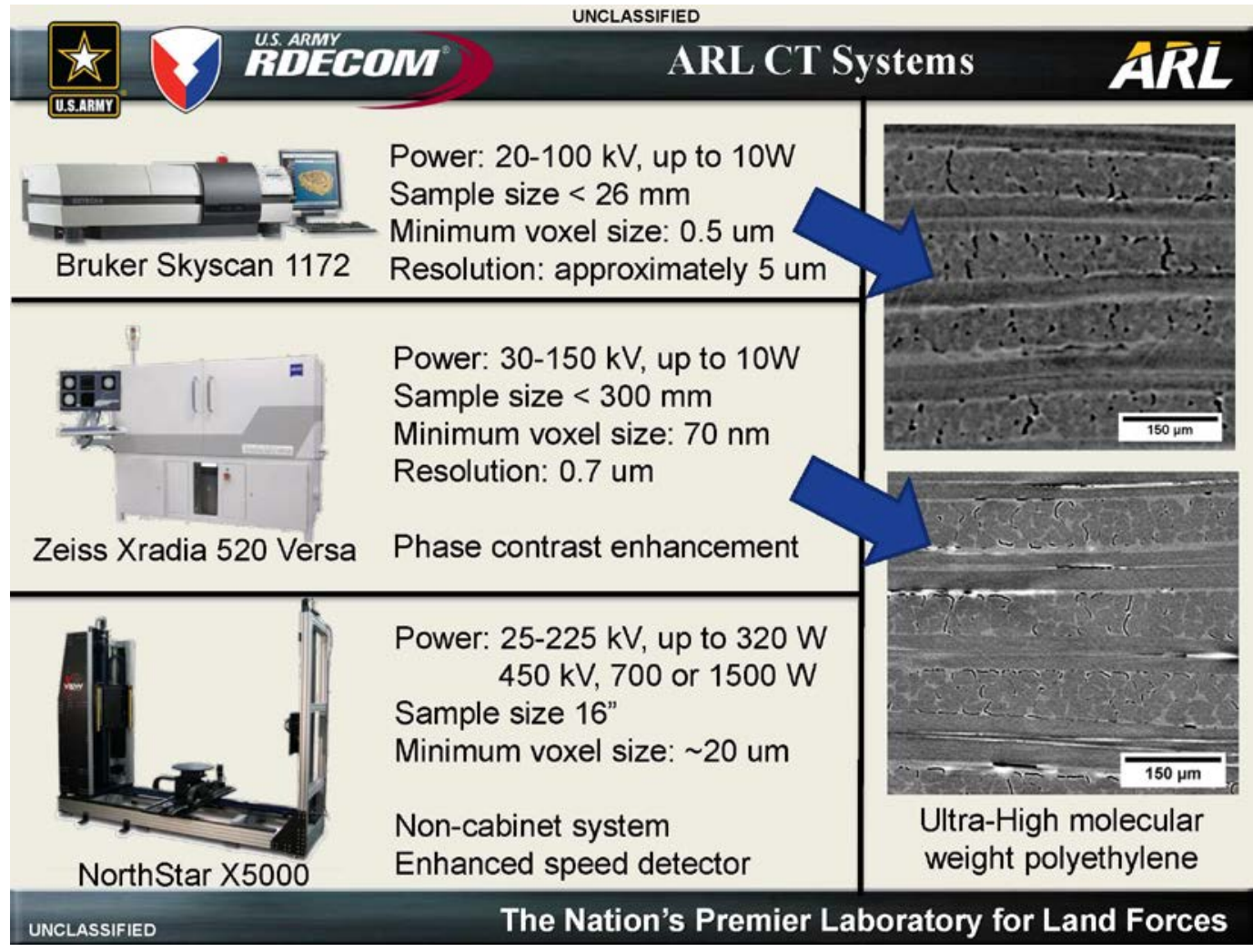

UNCLASSIFIED

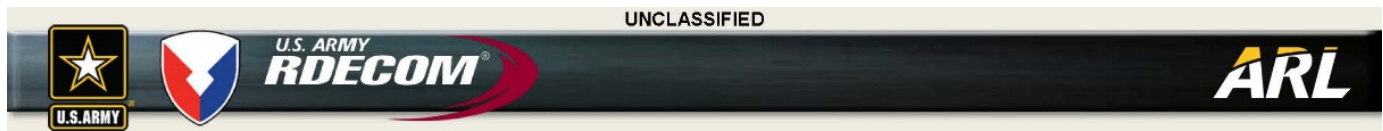

Analysis Example 1:

Nominal/Actual Comparison

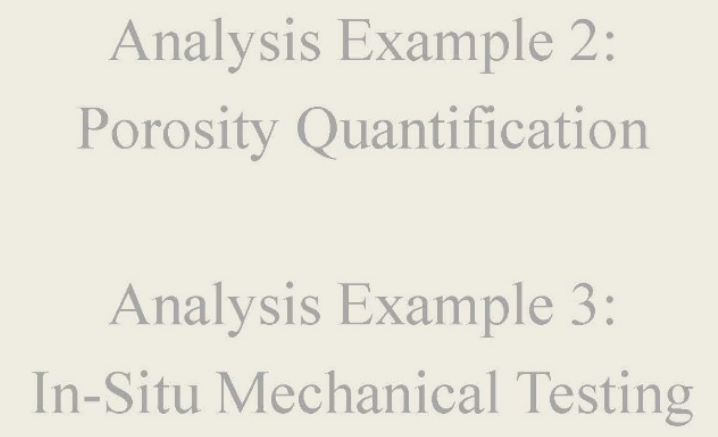



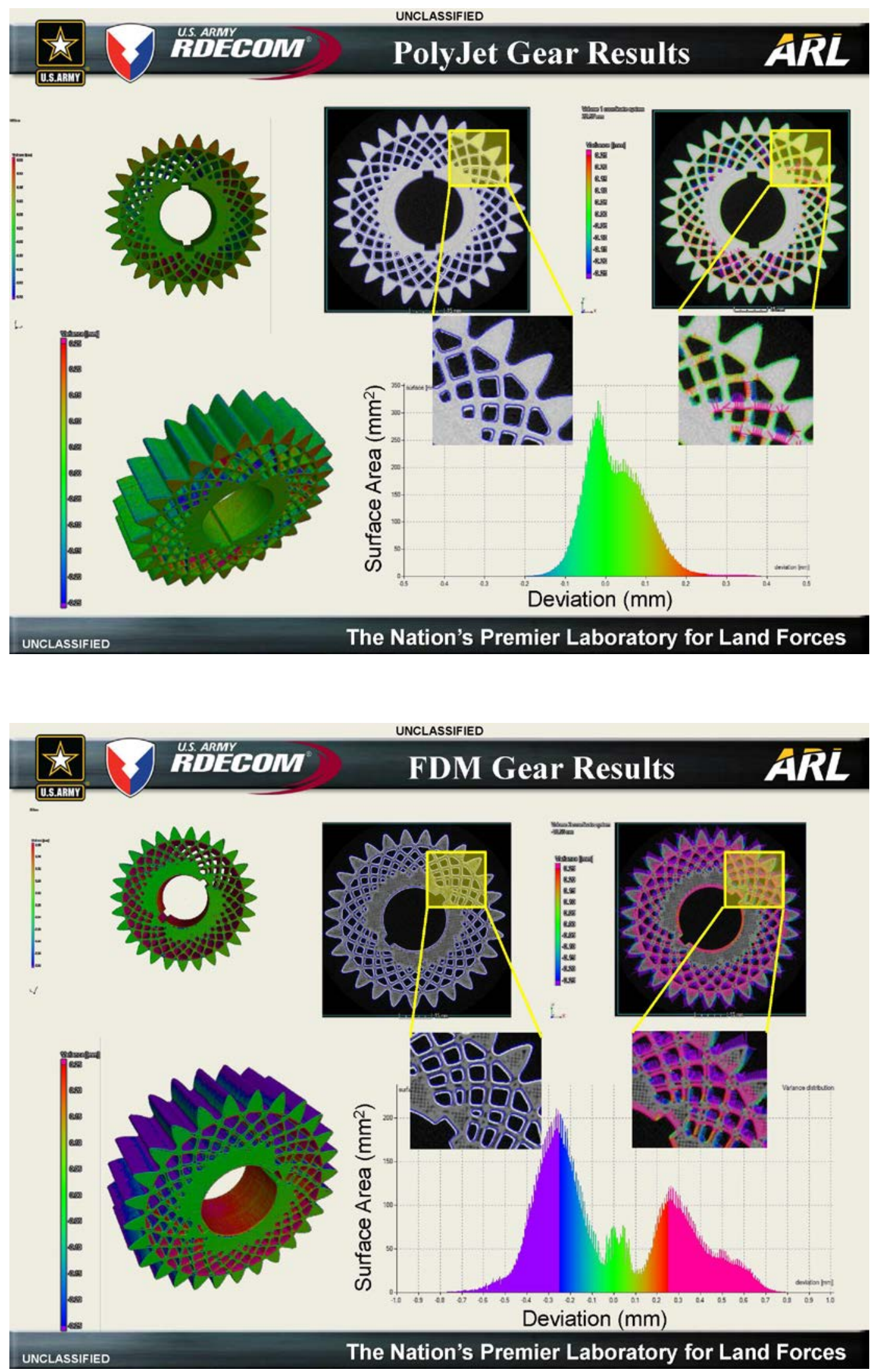

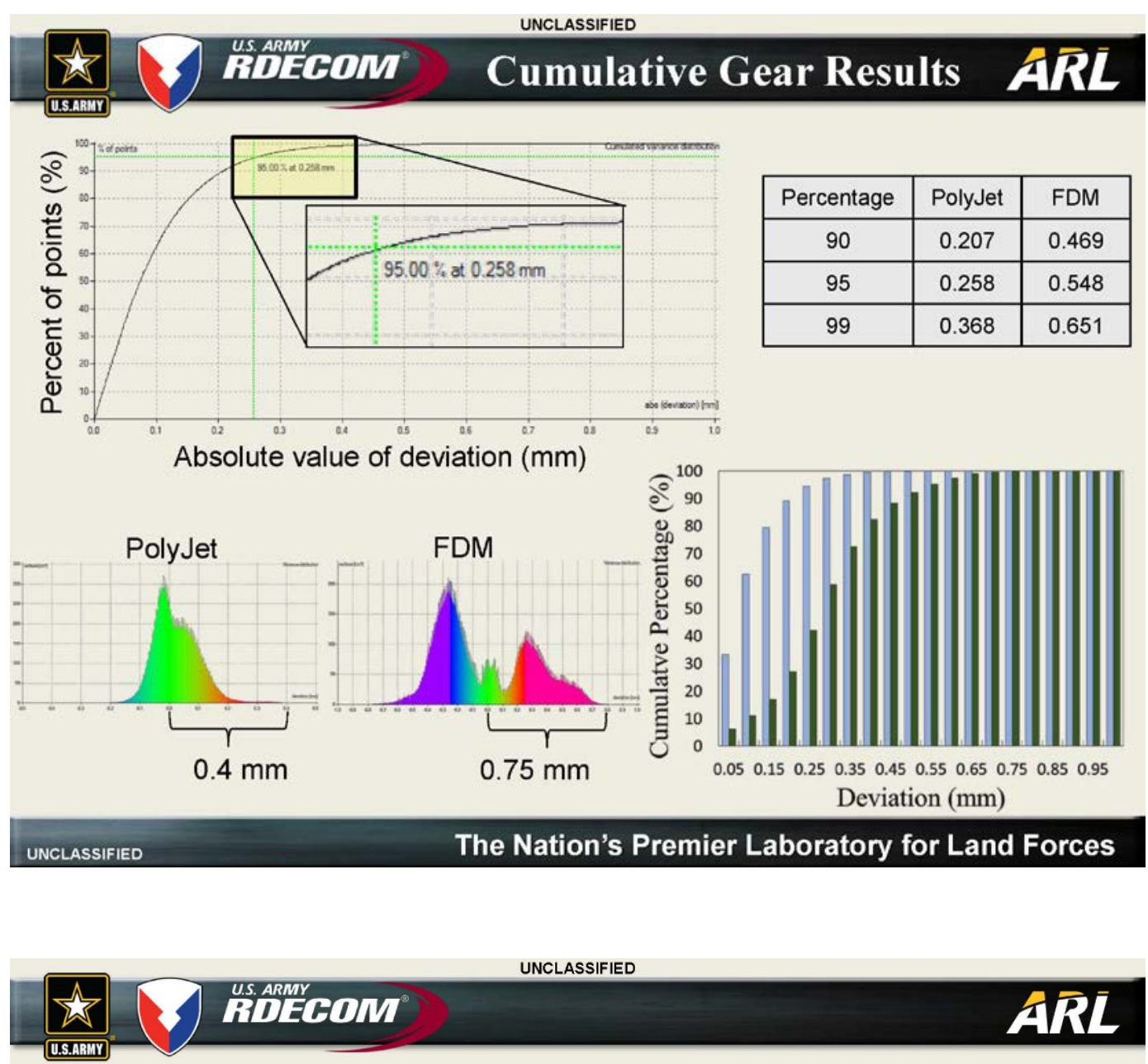

Analysis Example 1:

Nominal/Actual Comparison

Analysis Example 2:

Porosity Quantification

\author{
Analysis Example 3: \\ In-Situ Mechanical Testing
}




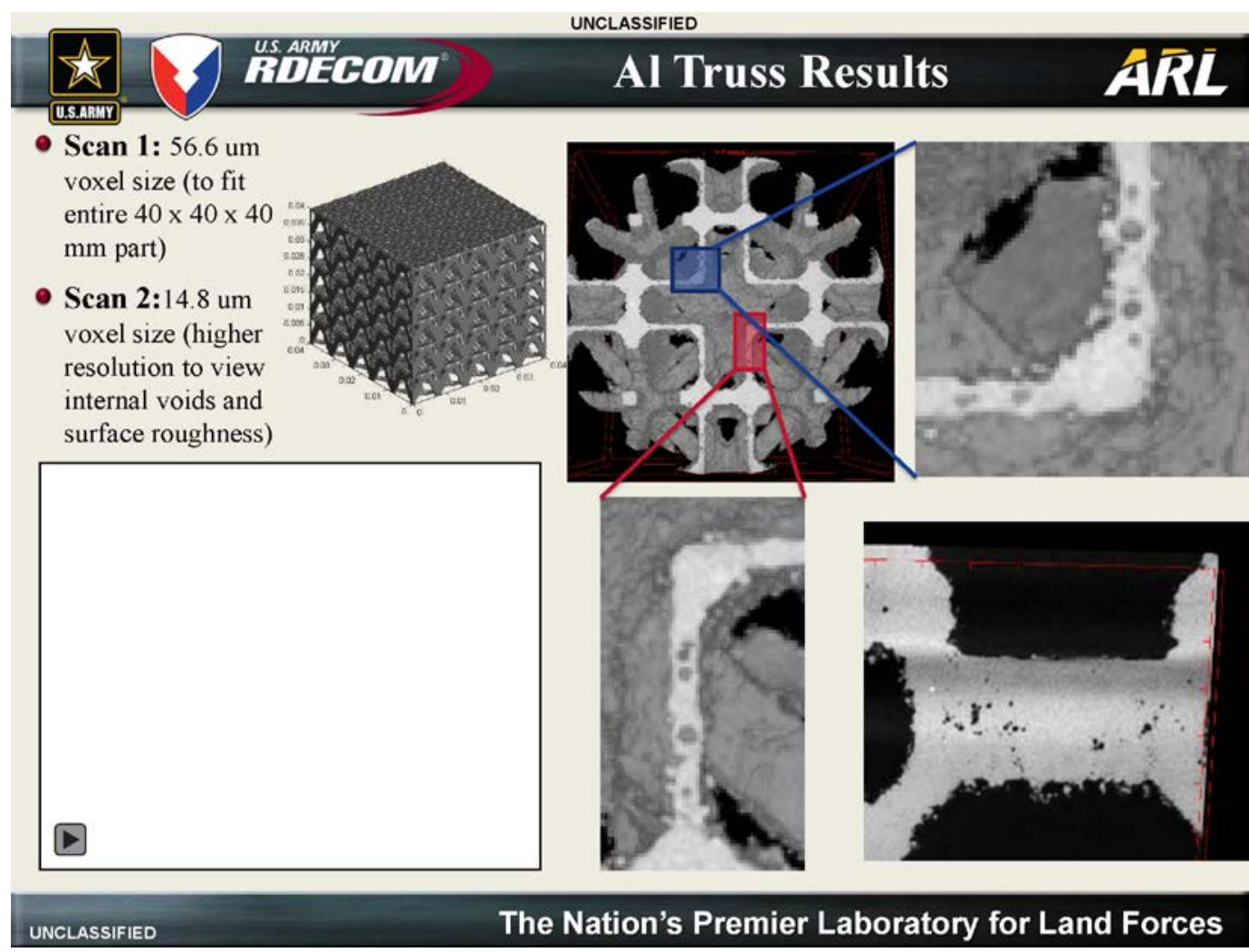

UNCLASSIFIED
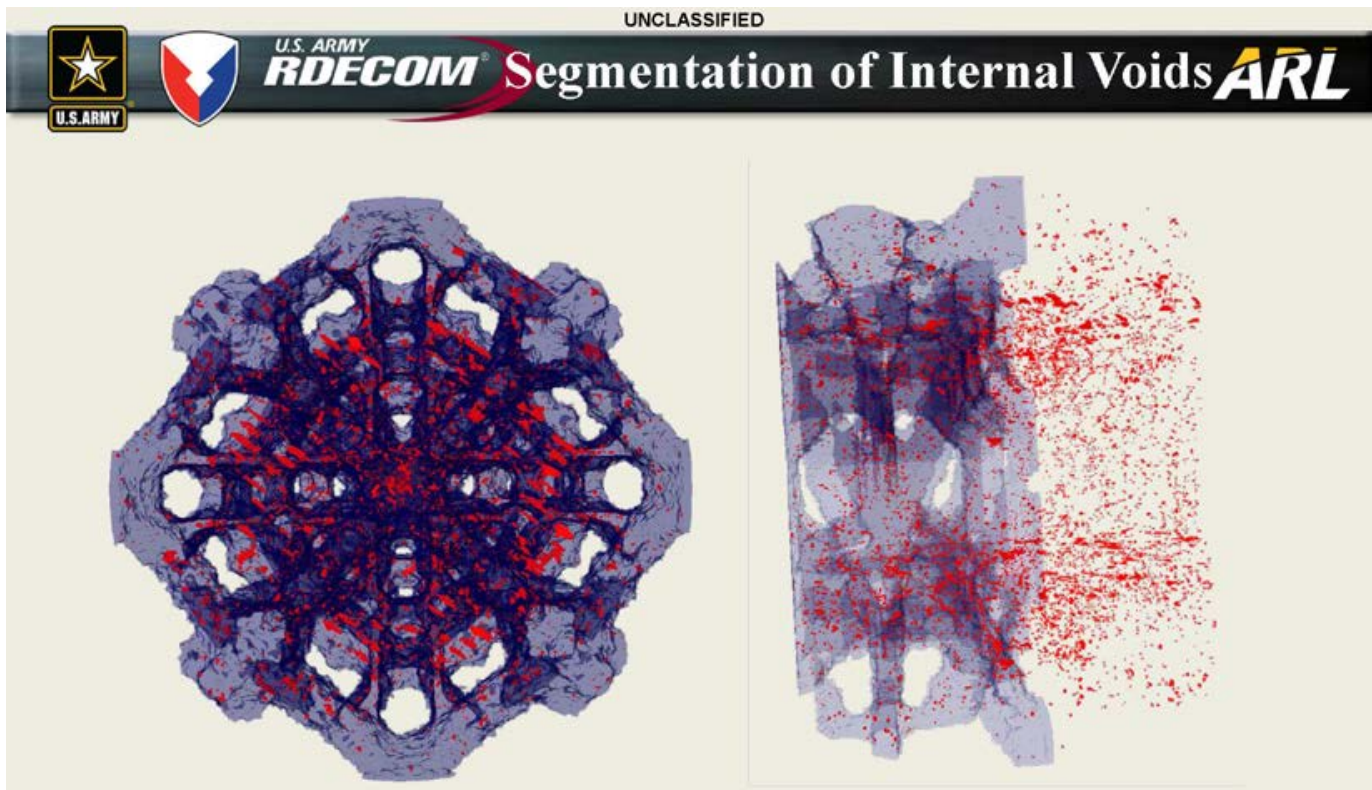

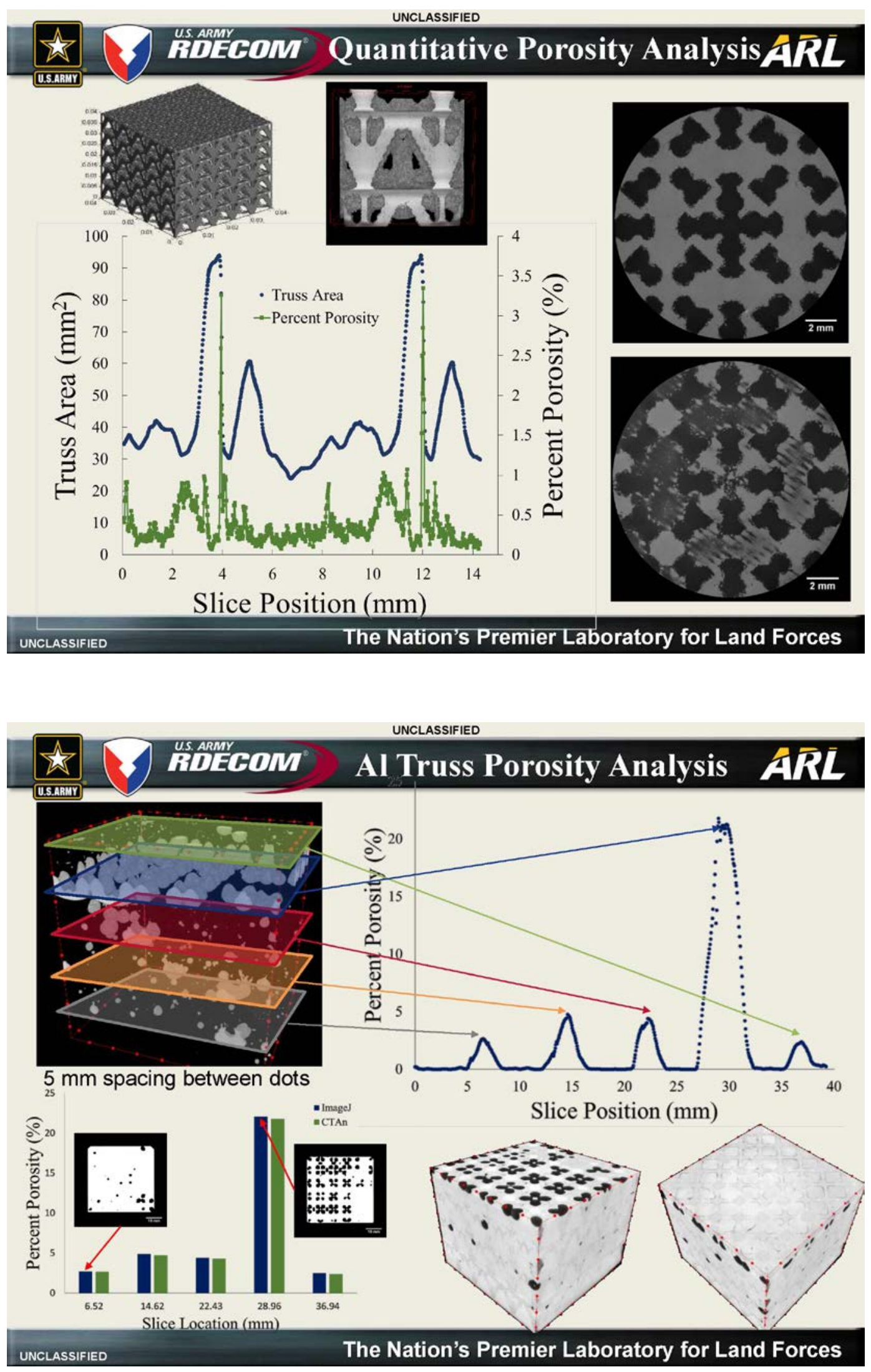


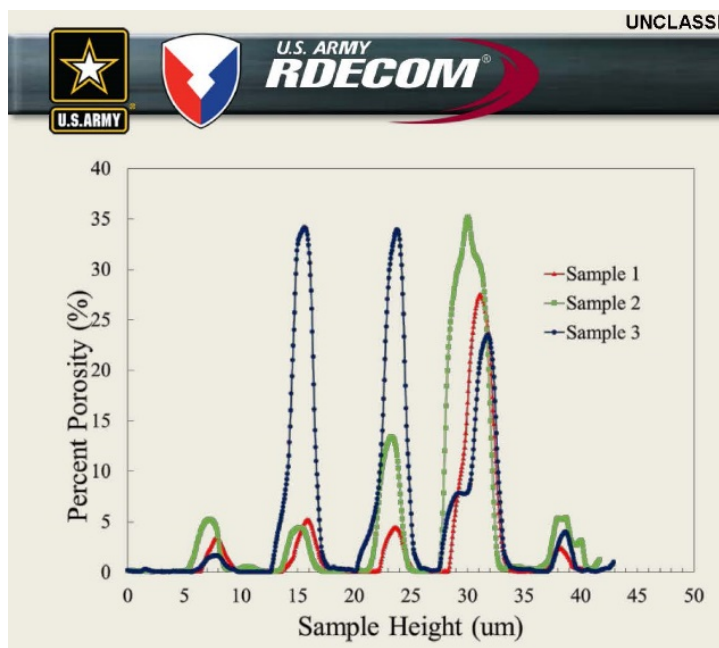

- There are clear regions where there are problems infiltrating the truss structure

- Truss repeats unit cells every $8 \mathrm{~mm}$ which corresponds to the spacing between local maximums

\section{$A \bar{R} \bar{L}$}

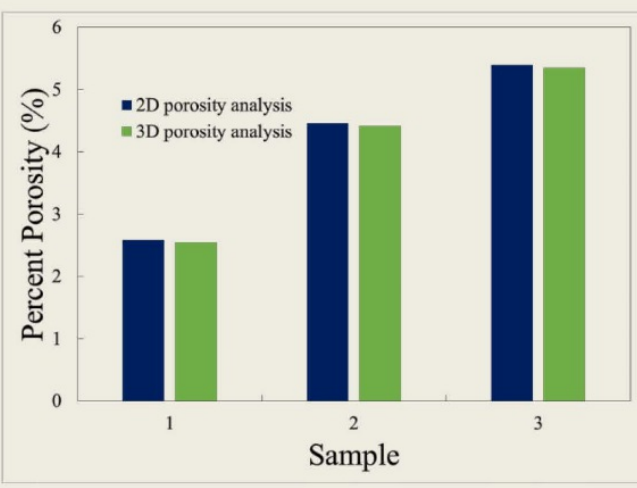

- Overall percent porosity ranges from $2.6 \%$ to $5.4 \%$

- 2D and 3D quantification methods are in close agreement

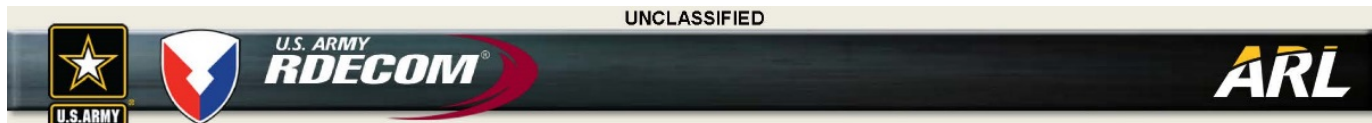

Analysis Example 1:

Nominal/Actual Comparison

Analysis Example 2:

Porosity Quantification

Analysis Example 3:

In-Situ Mechanical Testing 
- Truss 1 (brittle fracture)

- EnvisionTEC resin
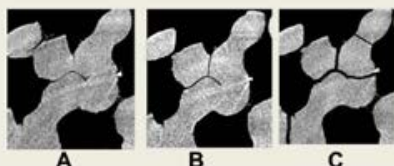

B

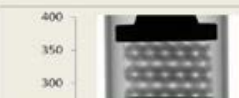

$\bar{z}_{\mathbf{z}^{200}}^{250}$

$\overbrace{150}$

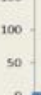

so

$\begin{array}{llllll}A^{0} \quad 0.2 & 0.6 & 0.8 & 1 & 1.2 \\ & & \text { Displacement }(\mathbf{m m})\end{array}$
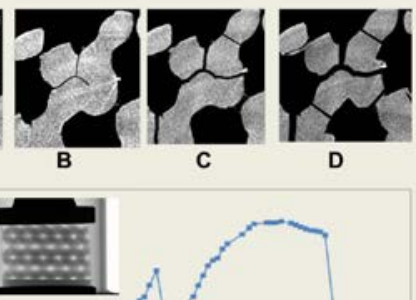

- Truss 2 (elastic deformation)

- FormLabs Clear resin

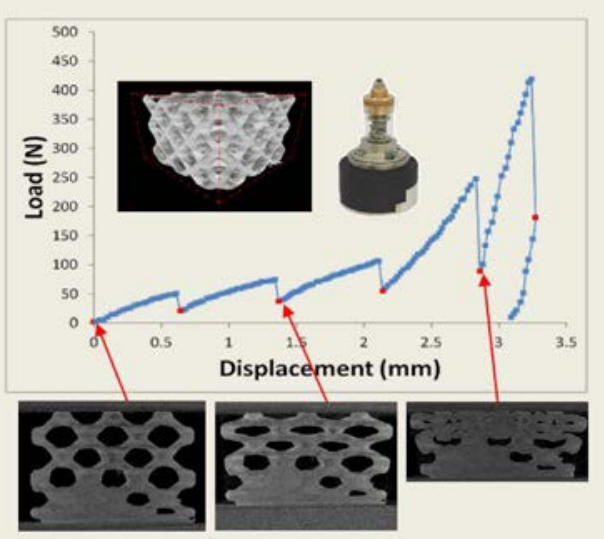

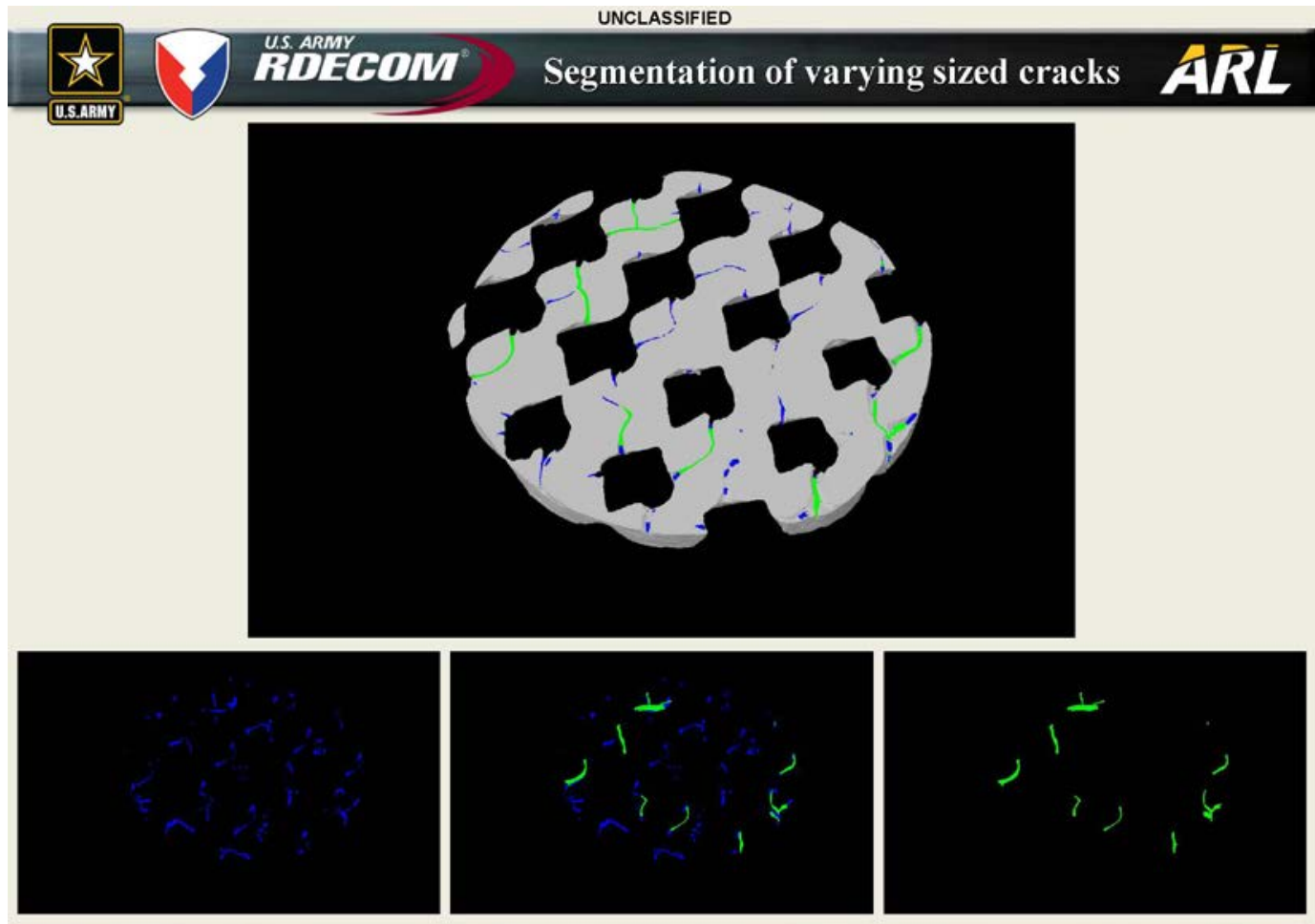


- X-ray Computed Tomography is a valuable technique for 3D, non-destructive evaluation of additively manufactured parts

- Tolerance differences between the designed and manufactured parts were determined for two different processing methods

- The percent porosity and location dependence of voids can be readily quantified

- In-situ mechanical tests can be conducted on stiff or elastic structures to provide insight regarding the fracture and/or deformation response

- Internal porosity or cracks or various sizes can be segmented using bitwise operations

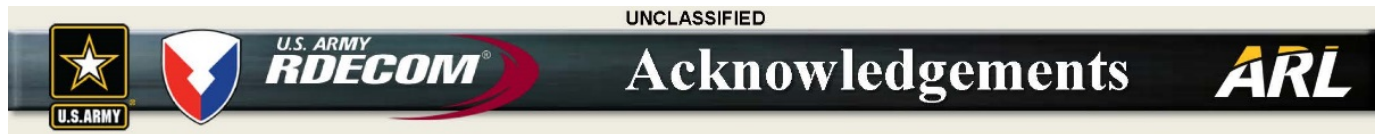

\section{-ARL}

- Marc Pepi

- Ray Wildman

- Bill Green

- Andy Gaynor

- Penn State ARL: Manufacturing of metal truss

- Rutgers University: Prof. Riman 
INTENTIONALLY LEFT BLANK.

Approved for public release; distribution is unlimited. 


\title{
5. Quality Assurance Methods for Additive Manufacturing Processes: Motivation, Challenges, and Opportunities
}

\begin{abstract}
Jonathan Miller
(Air Force Research Laboratory/Metals Branch)

There has been significant work to date in the metal powder bed fusion community focused on understanding the influence of global processing parameters on microstructure and defect content (e.g., beam speed, power, spot size). However, a range of other implicit details are important, though they are not necessarily simply described. The present work focuses on the development of a novel technique to assess the impact of the energy input process details on material quality. This requires transformation of both in-situ process monitoring data and build-intent information into a voxelized representation, subsequent fusion with postbuild $\mathrm{X}$-ray computed tomography measurements, and analysis to identify correlations between processing details and structure. An example case generated in laser powder bed fusion of Ti-6Al-4V demonstrates this process by identifying correlations between location-specific processing details and porosity.
\end{abstract}




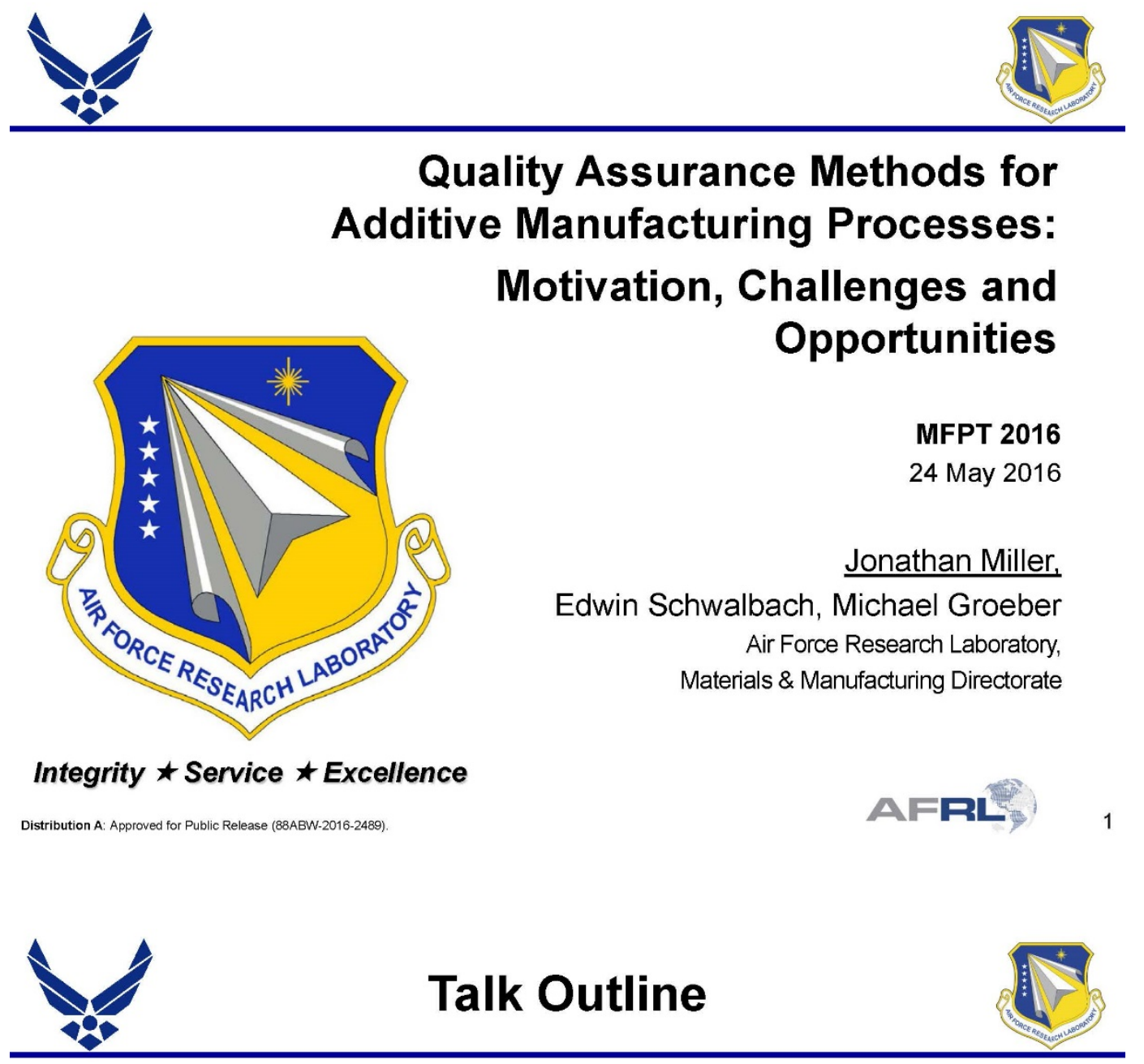

- Metal Powder Bed AM Process Explanation

- Quality Assurance Methods

- Post-Build Methods

- In-Situ Methods

- Data Fusion \& Analytical Tools 


\section{Motivation}

- Additive Manufacturing is "a process of joining materials to make objects from 3D model data, usually layer upon layer" - ASTM F2792

- Potential benefits include:

- Rapid turn-around \& short lead times

- Extended geometric complexity

- Ability to control local processing state

- However

- Immature understanding of Process - Structure - Property links

- As a result: AM design practices \& process specs. lacking or non-existent

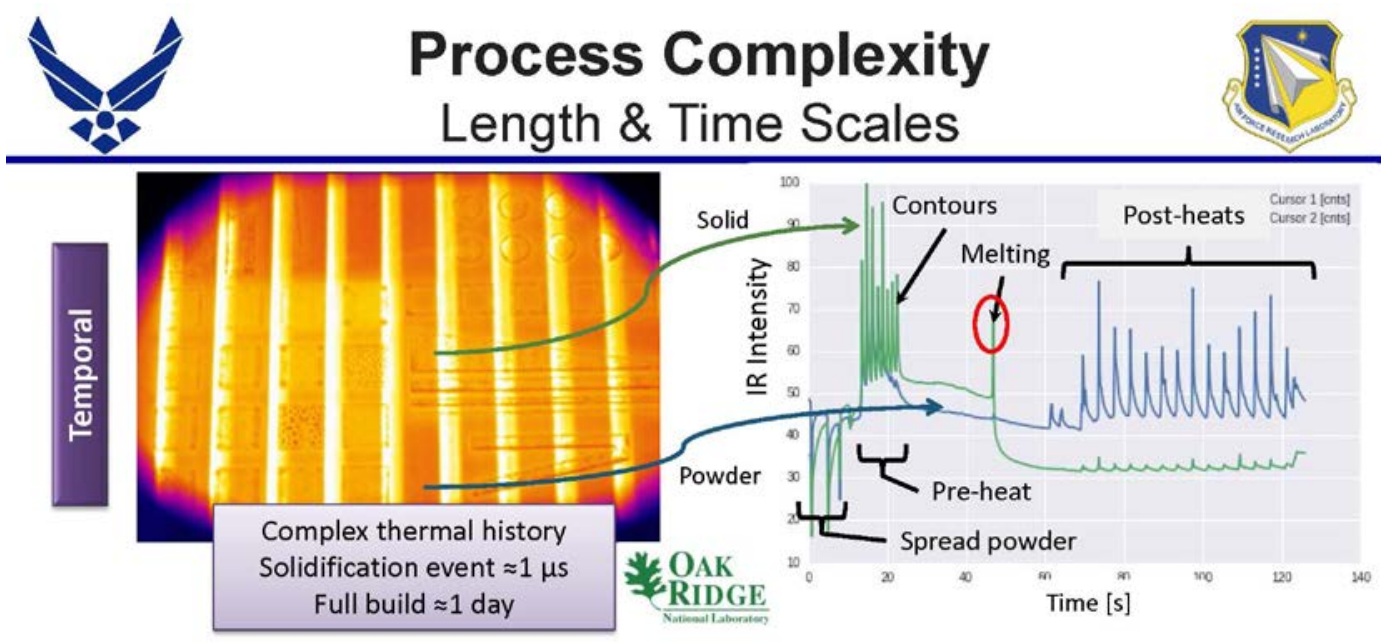

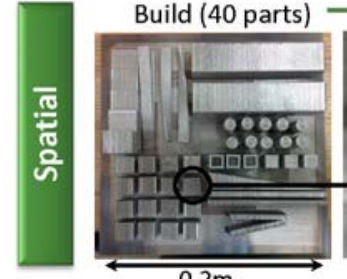

$0.2 \mathrm{~m}$

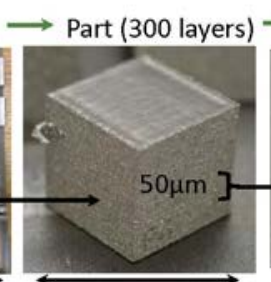

$15 \mathrm{~mm}$

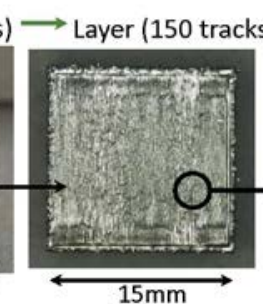

$15 \mathrm{~mm}$

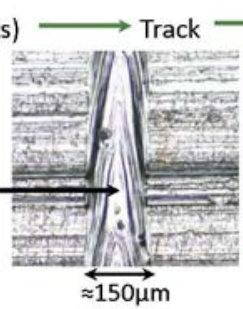

A. $=\mathrm{IL}^{2}$
Wide range of spatial scales, complex build can easily have $10 \mathrm{~km}$ of track 


\section{Process Complexity
Tool Path \& Interpass Temperature}

Path plan for a single layer colored by elapsed time

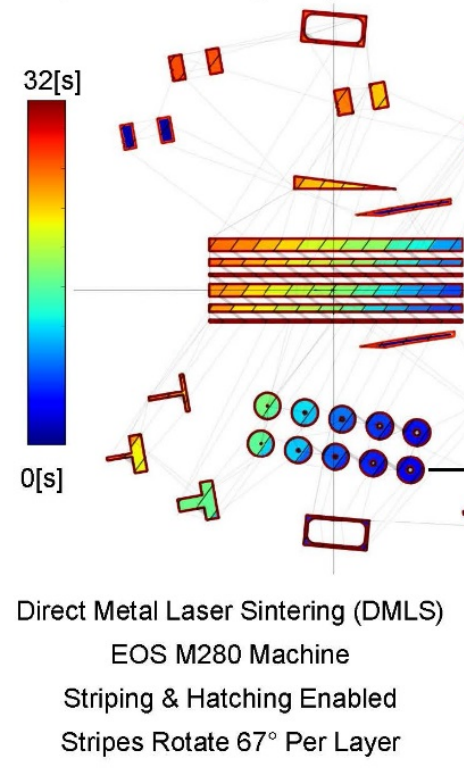




\section{Talk Outline}

- Metal Powder Bed AM Process Explanation

- Quality Assurance Methods

- Post-Build Methods

- In-Situ Methods

- Data Fusion \& Analytical Tools

Volumetric Inspection (Ultrasonic)

\section{Quality Assurance Methods Conventional Approaches}

Surface Inspection

- As-deposited porous surface finish reduces inspection effectiveness

- Fluorescent Penetrant: High background fluorescence and false positives

- Ultrasonics: Poor coupling of sound from coarse and non-planar surfaces

- EBAM of Ti-6Al-4V with Beta Anneal heat treat

- Results in coarse and columnar microstructure

- Limits effective inspection depth to $<1$ inch to detect 3/64" D FBH

- Result: UT inadequate for some AM material-process-component configurations

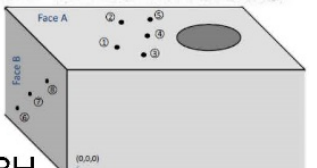




\section{Quality Assurance Methods Computed Tomography}

Volumetric Inspection (CT)

FDM Structure

- Post-manufacturing inspection is an integral component of quality assurance

- Conventional inspection methods are inadequate: surface and volumetric requirements

- Computed Tomography likely viable approach but lacks standardization and validation

- Assisted Defect Recognition tools inadequate: unstandardized and highly variable

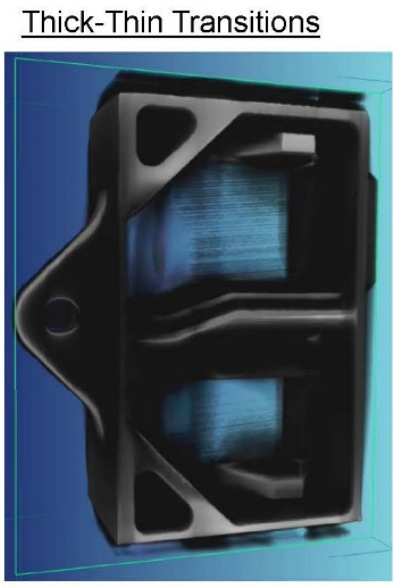

Fine, Distributed Porosity

Fine Features: $\mathrm{x}$-ray Scattering
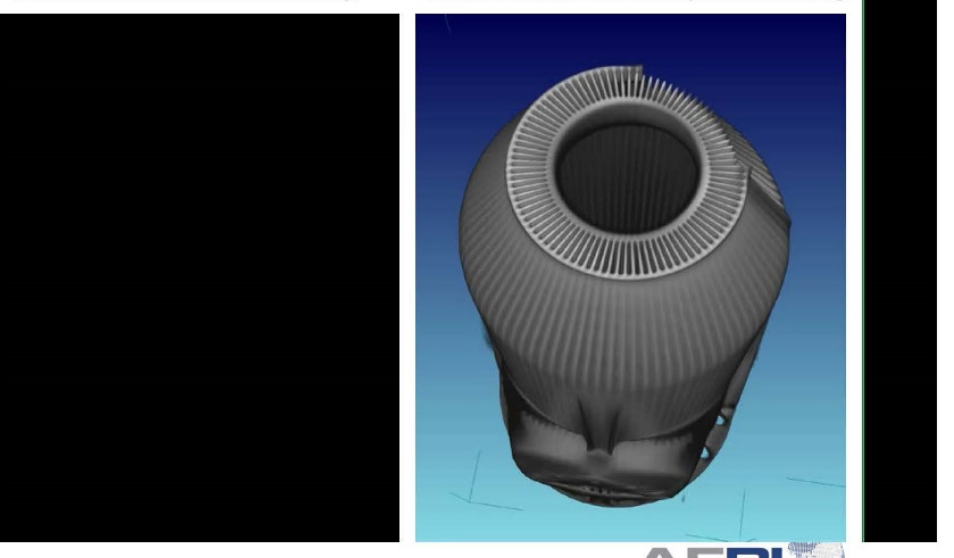

$A F R=9$

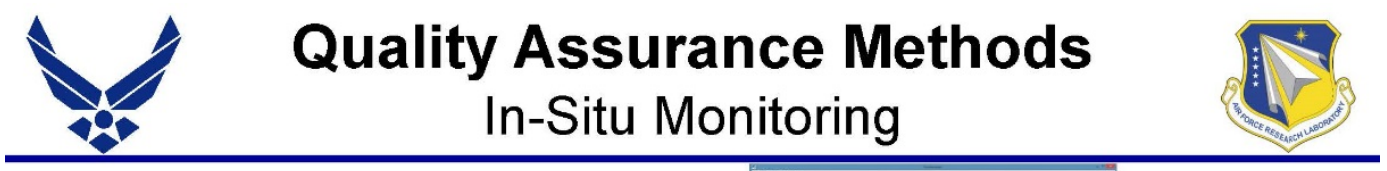

In-Process Inspection / In-Situ Monitoring

- Validated tools don't exist

- Data-intensive tools

- Single location probes, @50kHz: 1+TB/in

- Time resolved IR videos, @100Hz: 500GB/in

- HD images per layer

- Execution log files \& environment

- Process interferences

- Need analytical tools

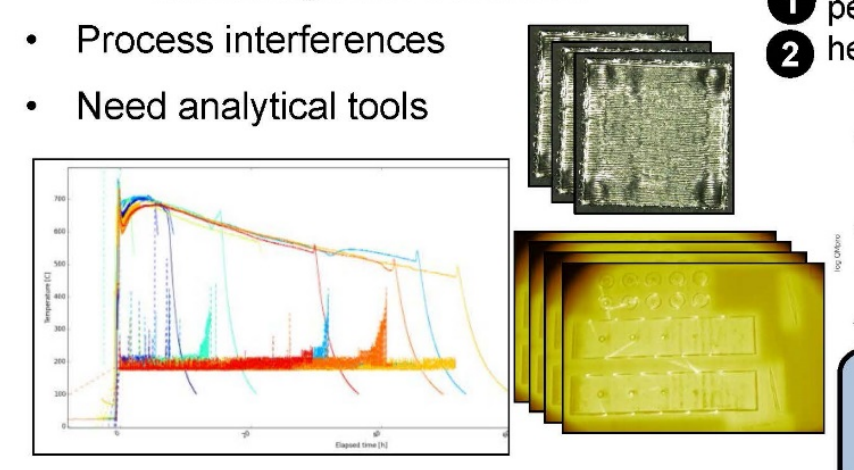

DISTRIBUTION STATEMENT A: Approved for public release. (8SABW-2016-1012)

(1) peak temperature

2 heating rate, 3 cooling rates

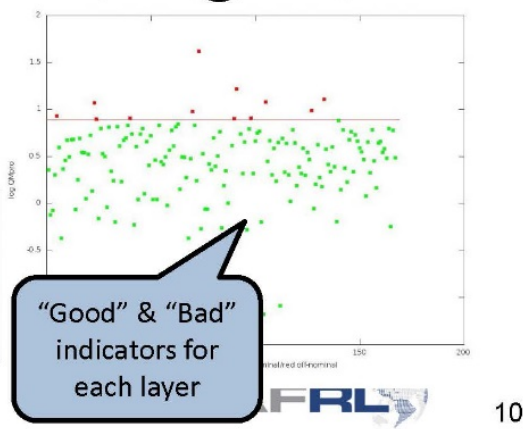




\section{Talk Outline}

- Metal Powder Bed AM Process Explanation

- Quality Assurance Methods

- Post-Build Methods

- In-Situ Methods

- Data Fusion \& Analytical Tools

\section{Data Fusion \& Analytical Tools}

Systematic collection and analysis of planning,

execution, and post build characterization data sets

Planning: process intent

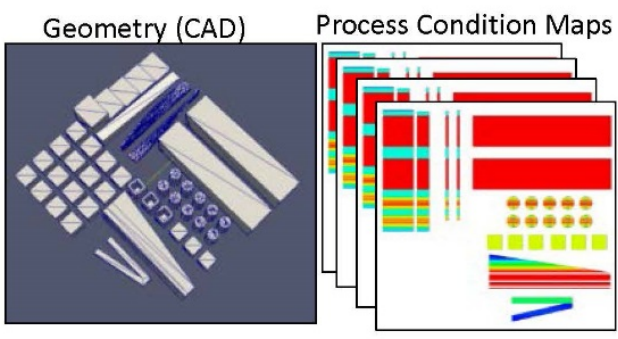

Execution: process reality

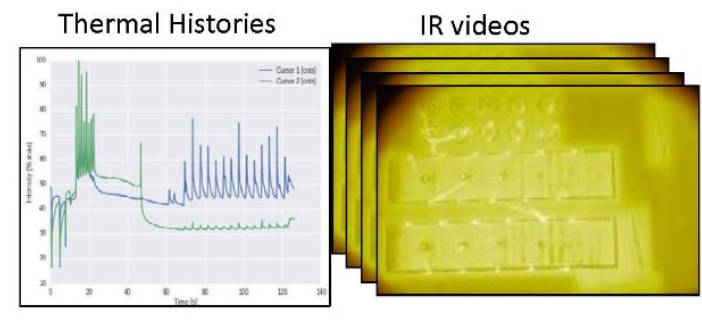

Outcome: microstructure, defects \& properties

Ultrasound
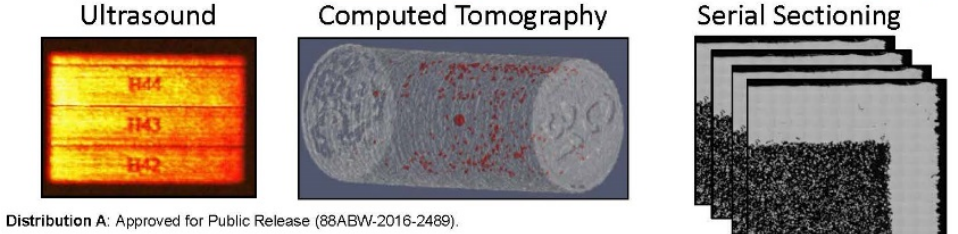

Mechanical Testing

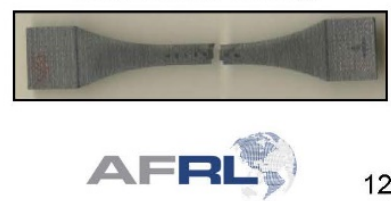



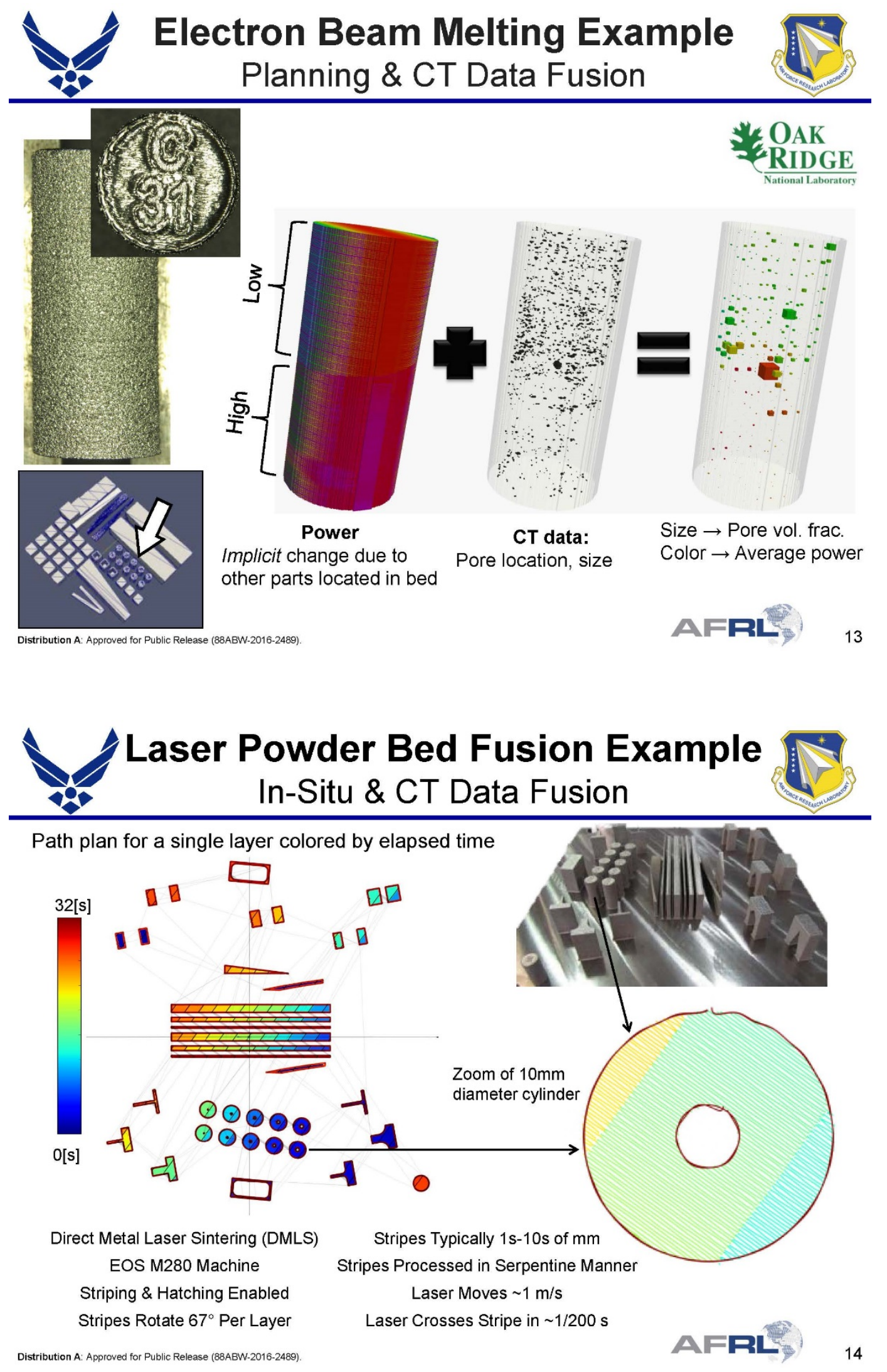


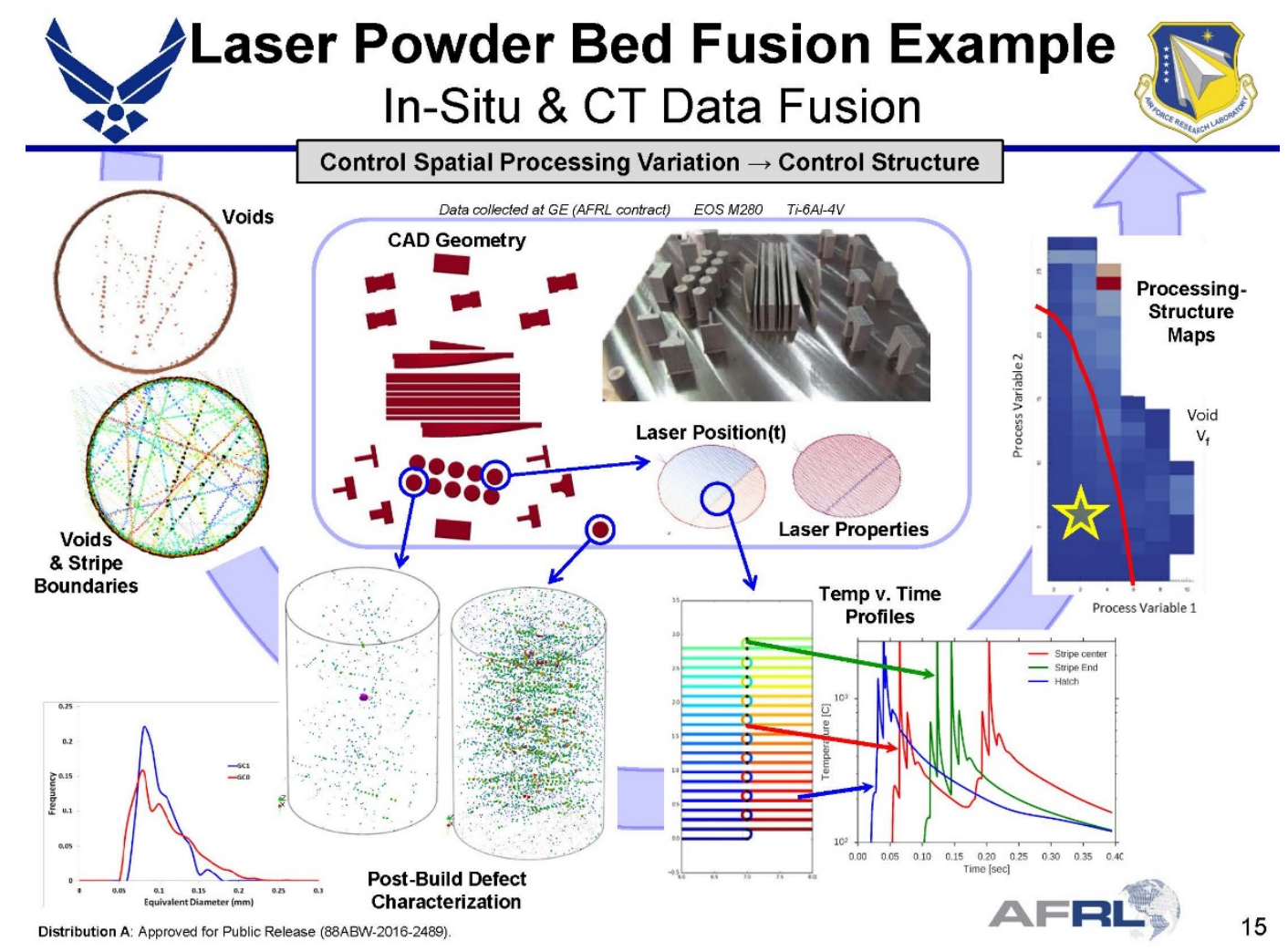

\section{Acknowledgements}

Materials \&Processing Team

Dr. Lee Semiatin

Dr. Michael Uchic

Dr. Adam Pilchak

Lt. Andrew Nauss

\section{UT Inspection}

Dr. Eric Lindgren

Norman Schehl

\section{Students}

Jordan Danko Austin Harris

Brandon Pfledderer Tyler Weihing

Capt. Evan Hanks (AFIT)
Mechanical Properties

Dr. Reji John Dr. William Musinski

Dr. Dennis Buchanan William Porter Norman Schehl

$\begin{array}{ll} & \frac{\text { X-ray CT }}{\text { John Brausch }} \\ \text { David Roberts } & \text { Brian Shivers }\end{array}$

ORNL Manufacturing Demo. Facility

Dr. Ryan Dehoff Dr. Vincent Paquit

Dr. Brett Compton Larry Lowe

Michael Goin Ralph Dinwiddie 

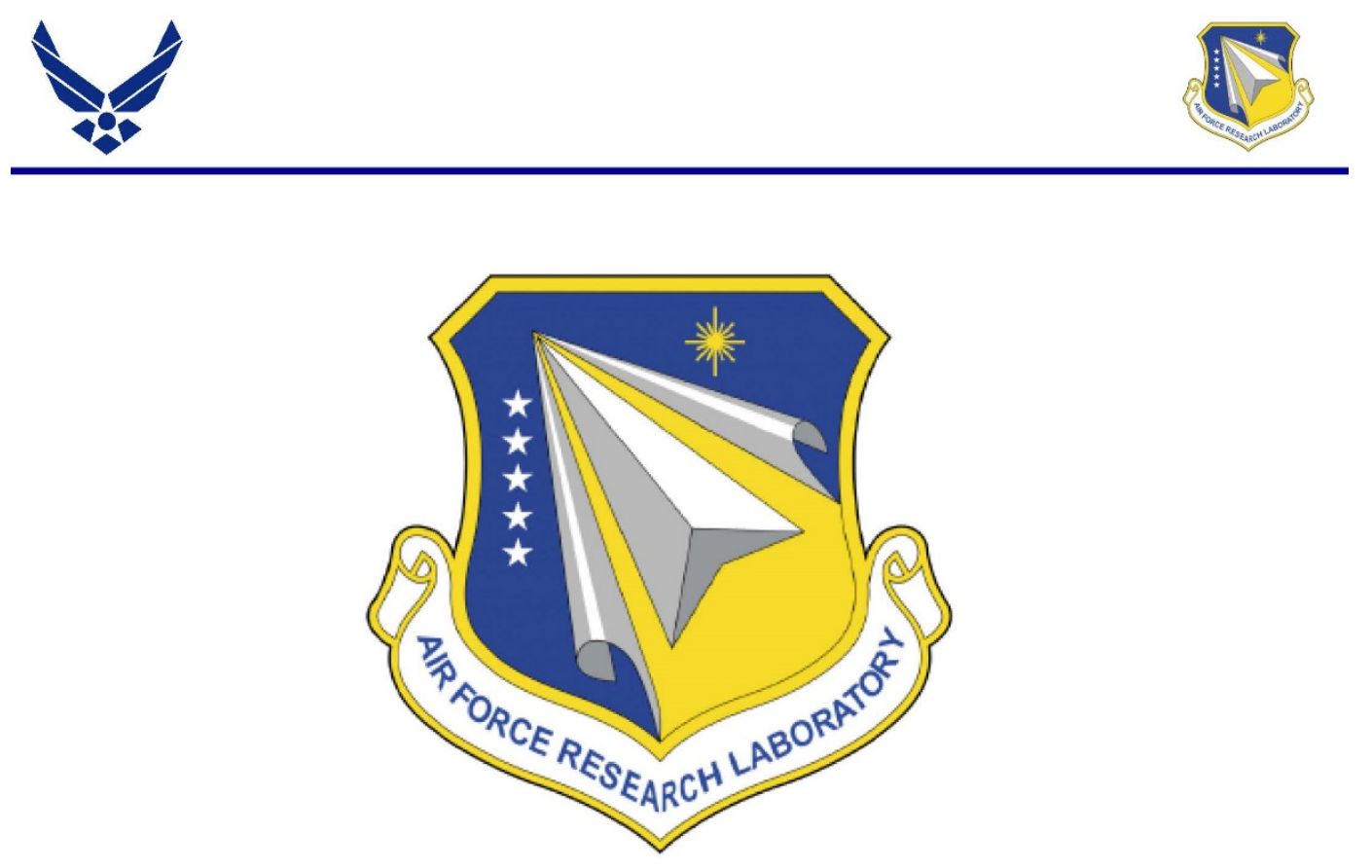

AFRI 17 


\title{
6. Air Force Vision and Challenges for Additive Manufacturing of Functional and Soft Matter Materials
}

\begin{abstract}
Dan Berrigan
(Air Force Research Laboratory/Metals Branch)

Flexible hybrid electronics (blending printed and places devices) is the focus of our research team at the Air Force Research Laboratory's Materials and Manufacturing Directorate. In this talk we highlight a few projects in additively manufactured electronics (e.g., batteries, capacitors, antennas) that span bench-level research to engineered solutions. In addition, we will discuss our path forward as we begin to explore the fundamental materials and processing challenges associated with pattern stimuli responsive materials and design of soft mechanical structures/ actuators.
\end{abstract}




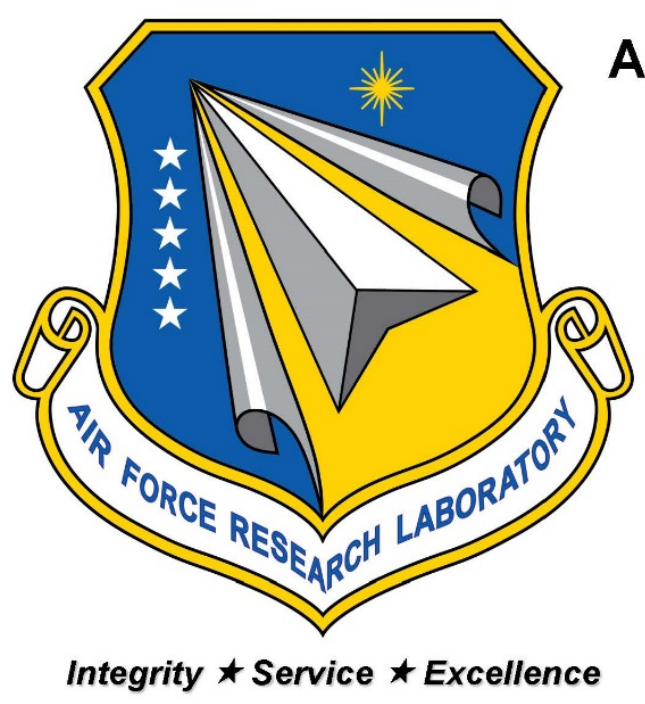

Distribution Statement A. Approved for Public Release. Distribution is unlimited.
Dan Berrigan, Ph.D.

AFRL/RXAS

Materials \& Manufacturing Directorate Air Force Research Laboratory Wright-Patterson AFB, OH 45433

\section{Acknowledgements}

- Mike Durstock, Research Lead for Flexible Materials \& Devices

- Mary Kinsella, AFRL AM IPT Lead

- Jon Miller, Structural Materials Lead

- Ben Leever, CTO NextFlex

- Chris Tabor, Research Engineer

- Jim Deneault, Researcher

- Giorgio Bazzan, Researcher

- James Hardin, Researcher 


\section{Air Force Research Laboratory Technical Competencies}

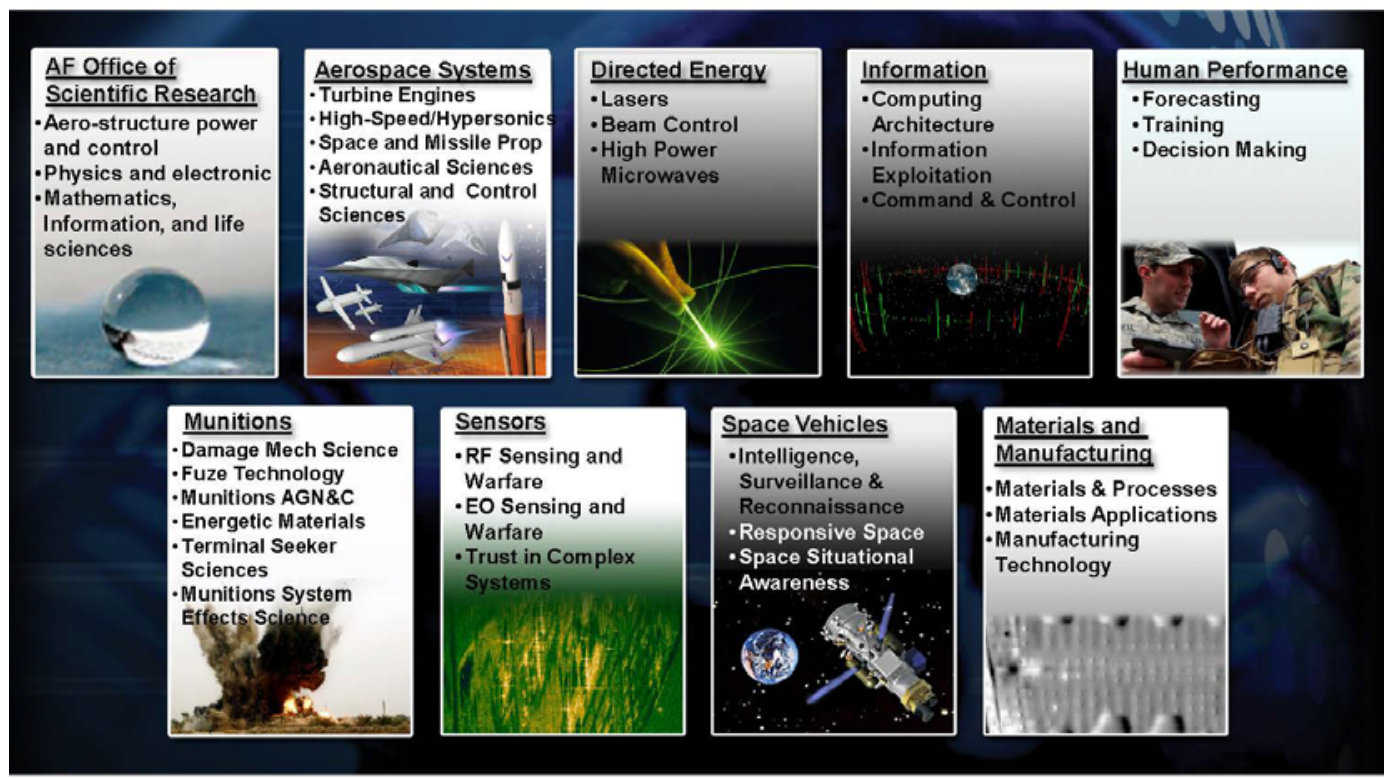

\section{Some Aspects of the Hype}

- Additive manufacturing (AM) promises reduced lead time, reduced cost, mass customization, weight reduction, part consolidation and enhanced geometric complexity.

- Single process lead time, cost and energy consumption advantage potentially overwhelmed by limitations in pre-AM and post-AM processes

- Feedstock Availability \& Energy

- Machining, Heat treatment

- Breadth of AM technology across process speeds, spatial resolution, material classes, material quality and sense of "the replicator" confuses the uninitiated 


\section{Benefits and Challenges}

AF Benefits:

- Reduced lead time and cost for small production runs

$\rightarrow$ Aircraft Availability \& Sustainment Affordability

- Mass customization and enabling geometric complexity

$\rightarrow$ Adaptive Warfighter \& Energy Efficiency

-Weight reduction via part consolidation/material substitution

$\rightarrow$ Reduced Sustainment Burden \& Energy Efficiency

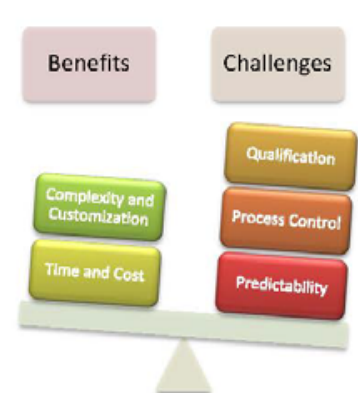

\section{Technical Challenges:}

- Unquantified material quality with undefined inspection protocols to meet structural requirements

- Highly variable material properties and lack of statistical databases for design

- Lack of standardized process controls typically required for structural applications

- Inadequate cost mode/s for representation of post-processing requirements

- Inspection, Machining, and Heat Treatment

\section{AFRL Additive Manufacturing Strategy}

- Quantify Risk Upon Substitution and Implementation of AM

- Inform the Qualification of Additive Materials and Processes

- Process monitoring and sensing

- NDE and material characterization

- AM-tailored material development

- Component demonstration

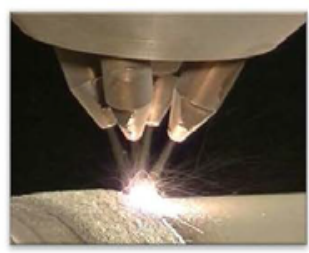

\section{- Advance AM Capabilities via Modeling \& Simulation}

- Process simulation for design \& control

- Verification \& Validation for qualification

- Process-structure-property relationships

- Develop digital thread for AM components

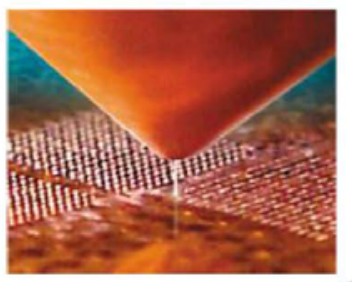




\section{Staged Implementation Potential of AM An AFRL/RX Perspective}

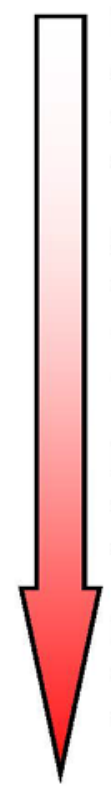

Now...

- early design prototypes

- process implements (fixtures, tooling)

- polymeric applications (ducting, brackets)

How to Shortcut the Timeline

- Design for AM

- Quantify Risk

- Quantify Mfg Variability

- Develop Cost Models

Soon...

- niche AM applications

- reduced-life or 'safe-life' components

- 'attritable' applications (RPVs, munitions)

What are "niche AM apps"?

- Component Redesign

- Complex Geometry

- Non-critical Hardware

- Small Lot Production

Later...

- Short Life Applications

- full-life, non-critical structural applications

- embedded electronics/sensors

Far-Term...

- fracture-critical hardware ...?

- hybrids and graded materials ...?

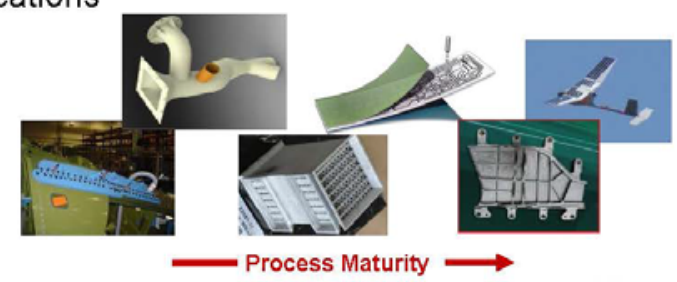

Distnibution Statement A. Approved for Public Release. Distribution is unlimited.

AFRL, 7
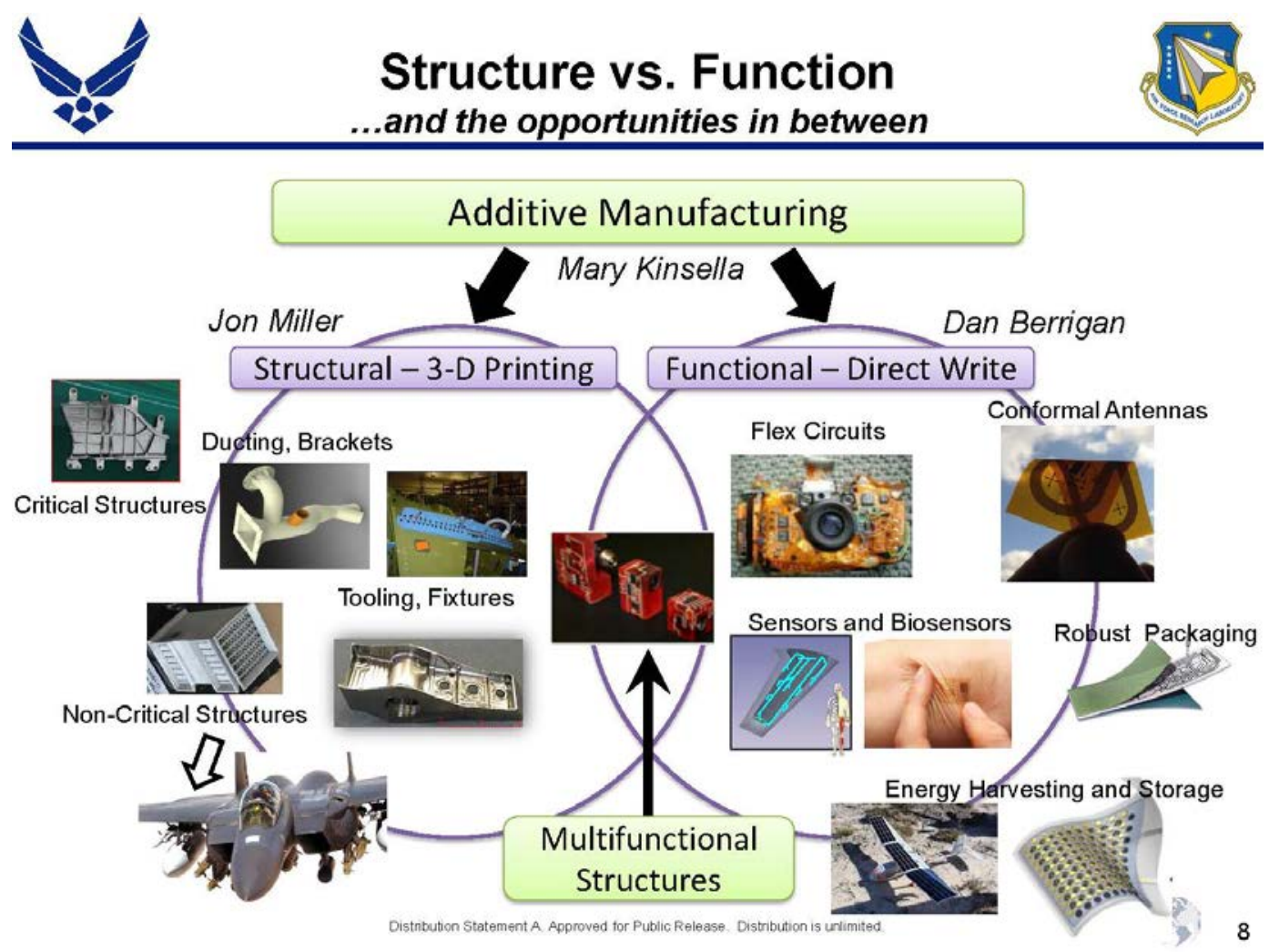

Approved for public release; distribution is unlimited. 


\section{Flex Hybrid Concept}

Print what you can, place what you can't

Printed Electronics

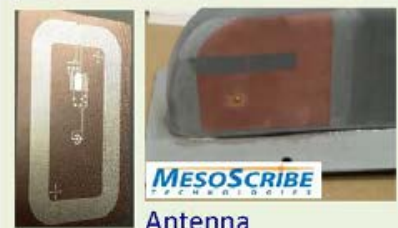

Antenna

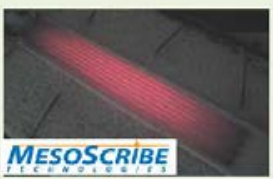

Heaters

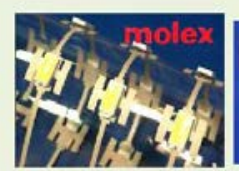

Passive Elements

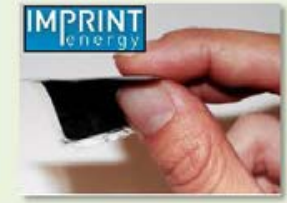

Batteries \& Solar

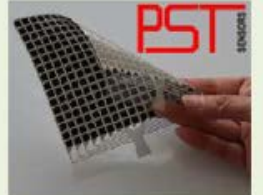

Sensors
Placed Electronics

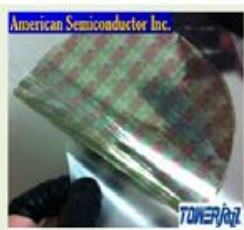

Silicon ICS

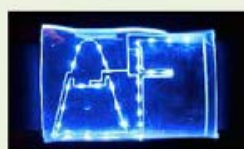

Displays, High Perf. Elements
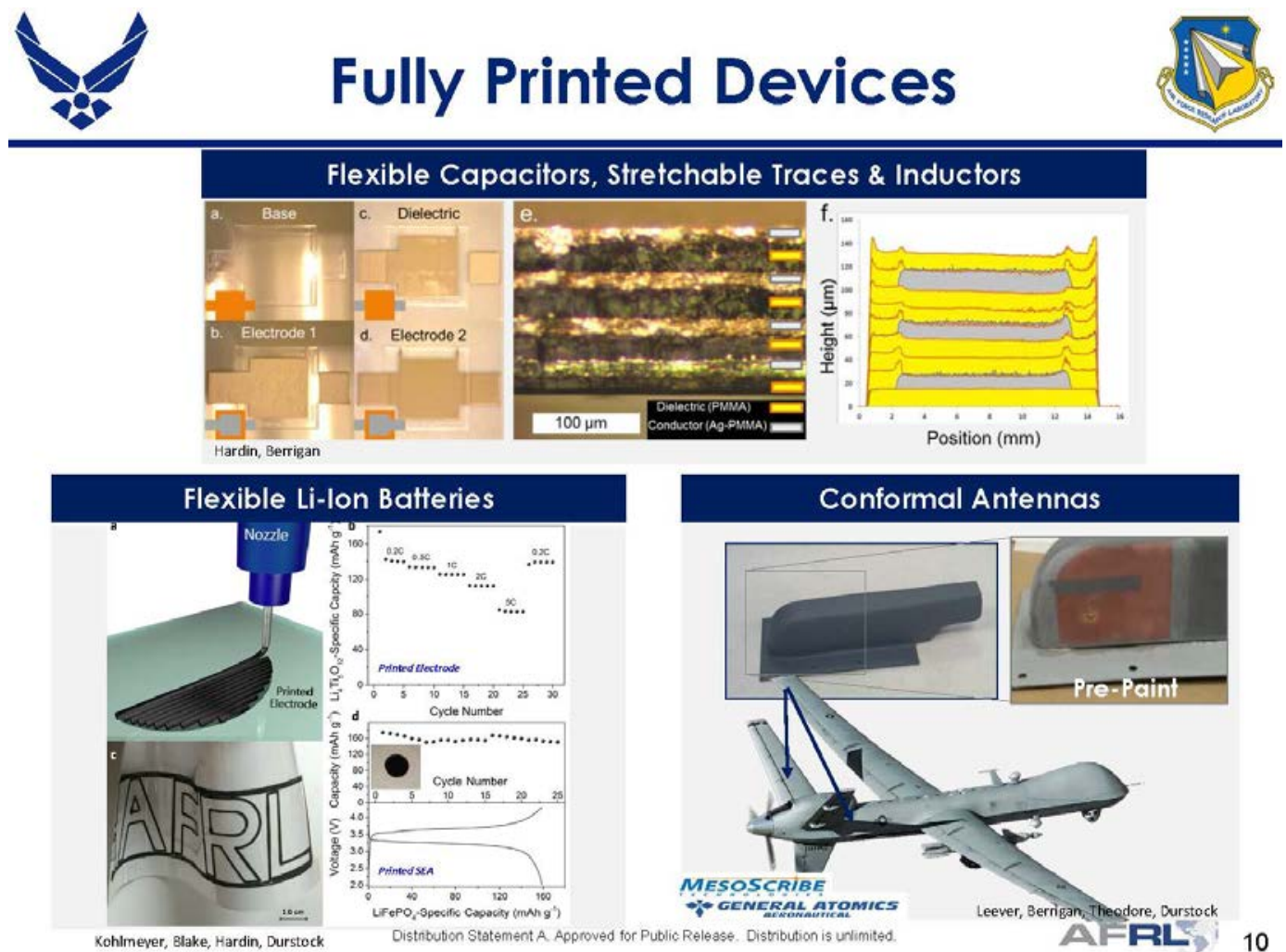

on Batteries

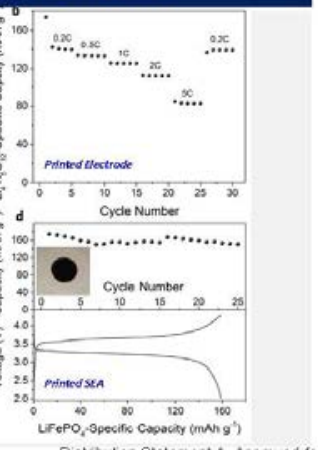

Distribution sociay (ming
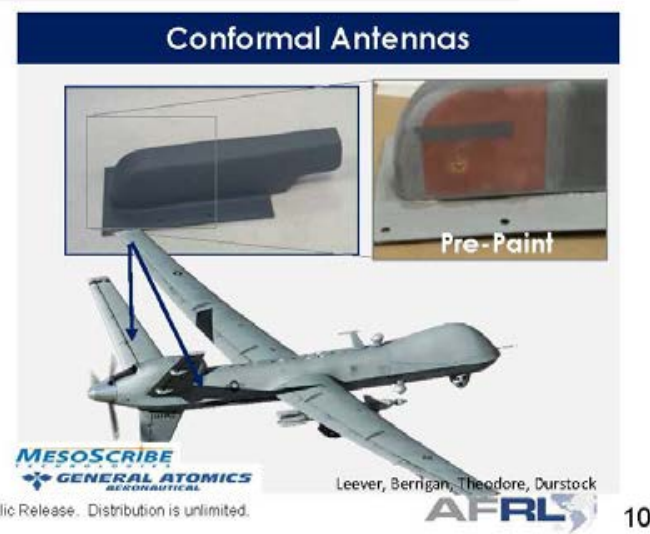


\section{Adaptive Materials \& Design}

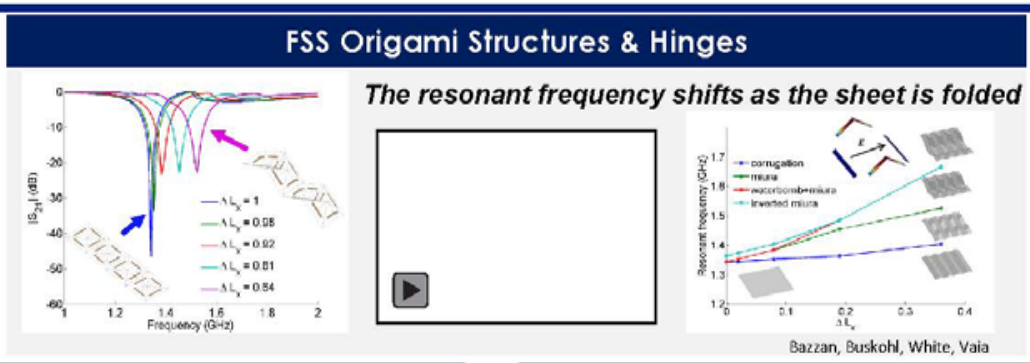

Fold Topology Optimization

Responsive Polymers

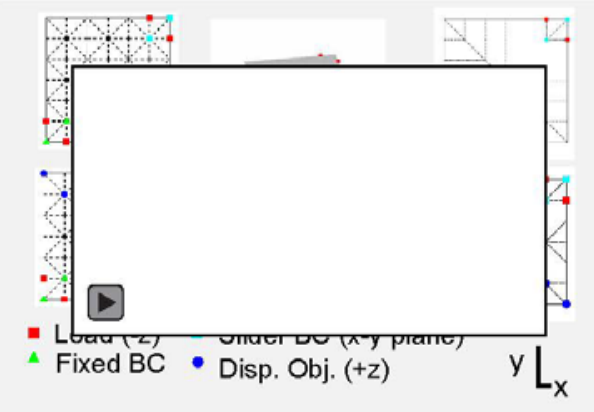

Buskohl, Vaia

Distribution Statement A. Approved for Public Release. Distribution is unlimited.

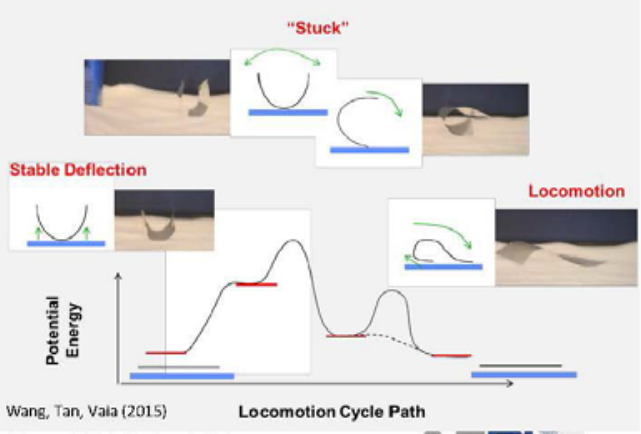

FHE Packaging

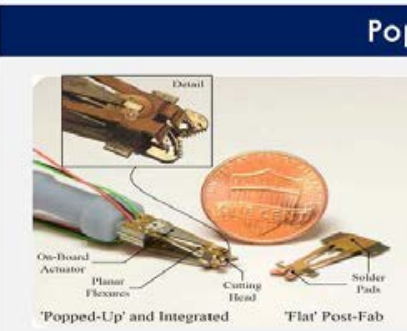

Pop-Up Book MEMs (DARPA A2P)

Inexpensive soft actuators and end-effectors for microsurgery tools.

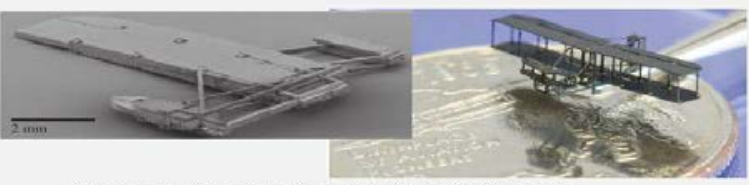

Strategic Lamination in $2 \mathrm{D}$, and unfold to $3 \mathrm{D}$ structure.

Wood, Berrigan

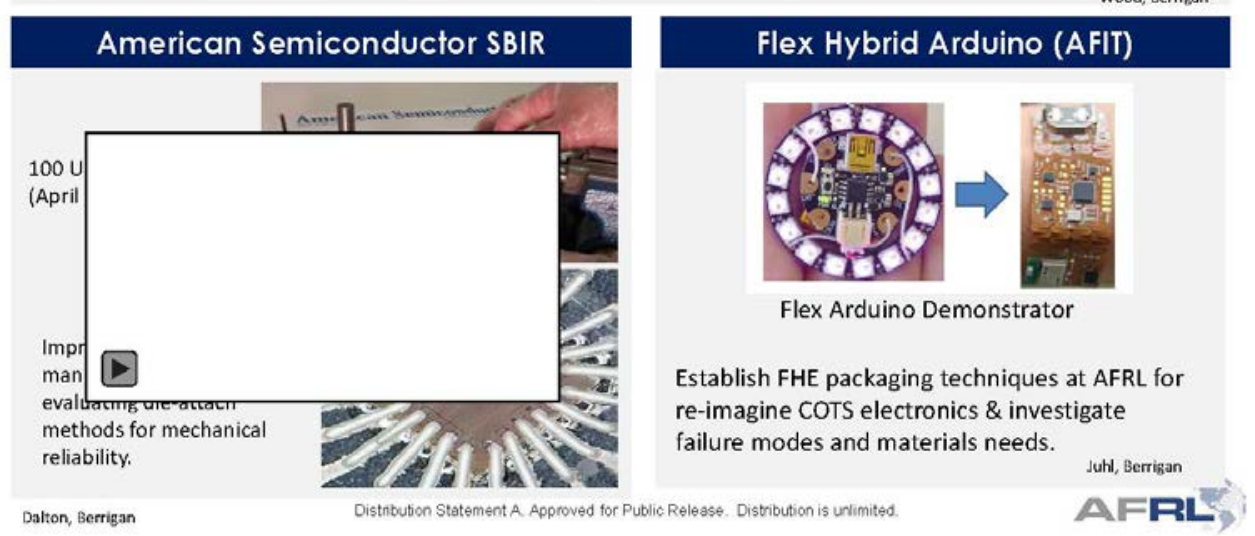



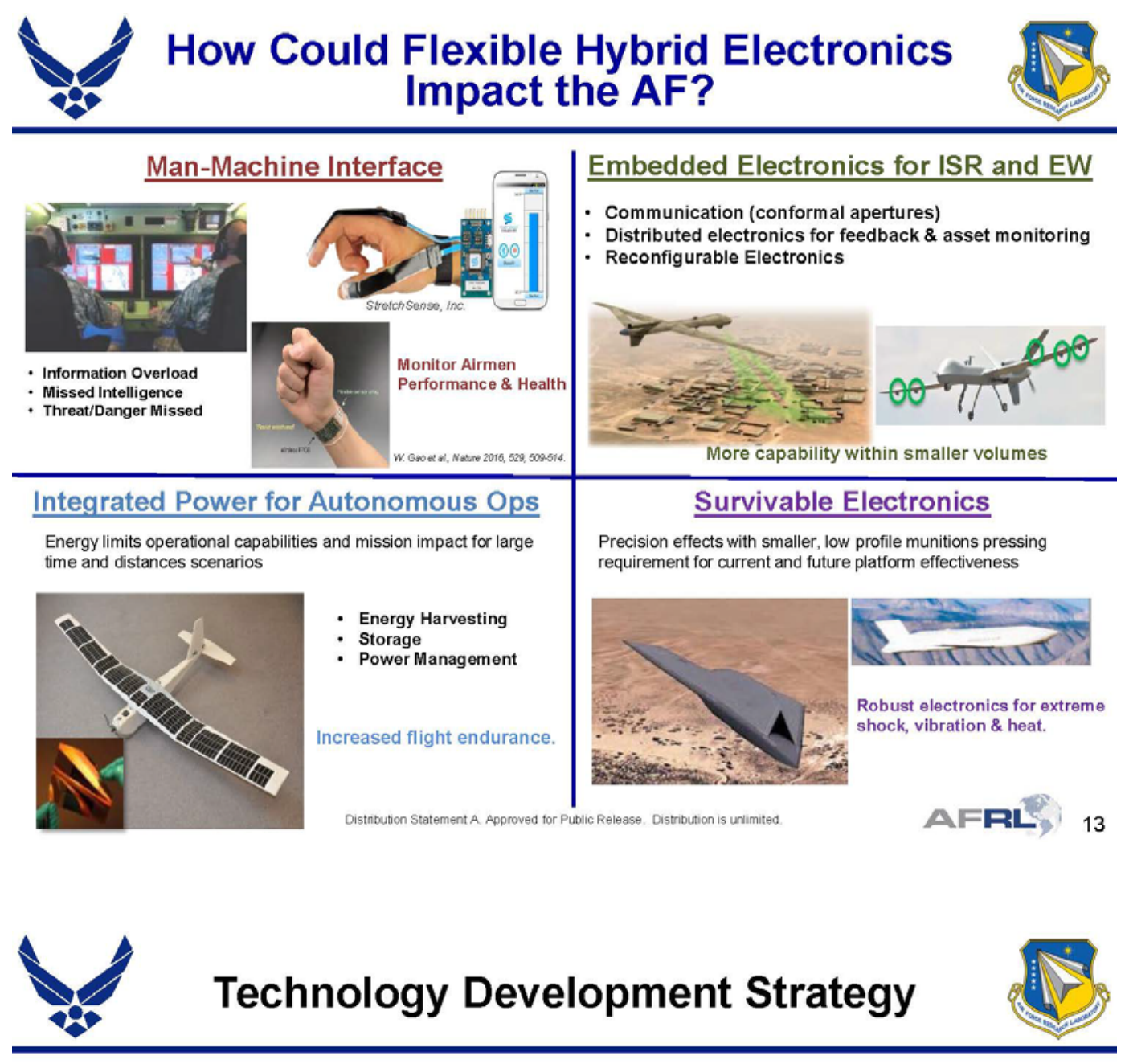

- Accelerate development and transition of AM technologies to AF functional materials community

- Phased plan for functional AM technology insertions

AF Transition Timeframe:

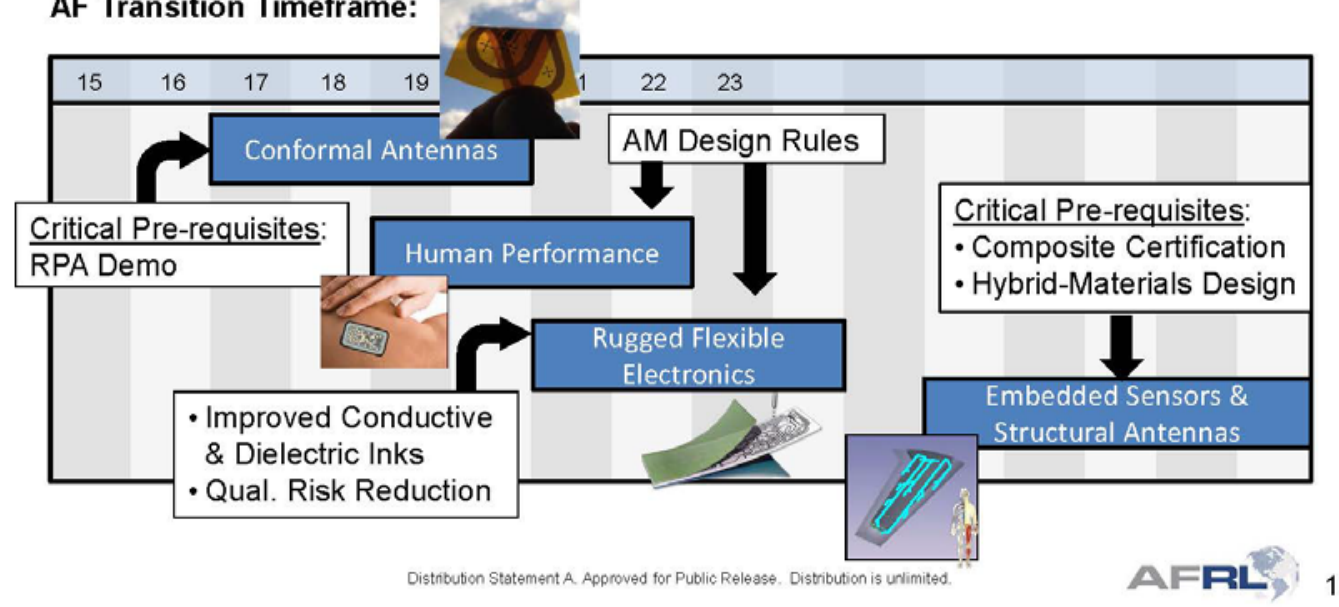

Approved for public release; distribution is unlimited. 


\section{Summary}

- AF pursuing additive manufacturing to enable numerous capabilities including

- Human/airman performance monitoring

- Rugged/durable electronics

- Embedded electronics \& optics

- Flexible Hybrid Electronics (rather than fully printed solutions) are nearterm focus

- In-house R\&D

- External efforts with universities and industry

- Leveraging NBMC, America Makes, and NextFlex

- Key Challenges

- Ink development - both metals \& dielectrics

- Process enhancements - in-situ process monitoring, improved resolution, etc.

- Multi-material print heads or print systems

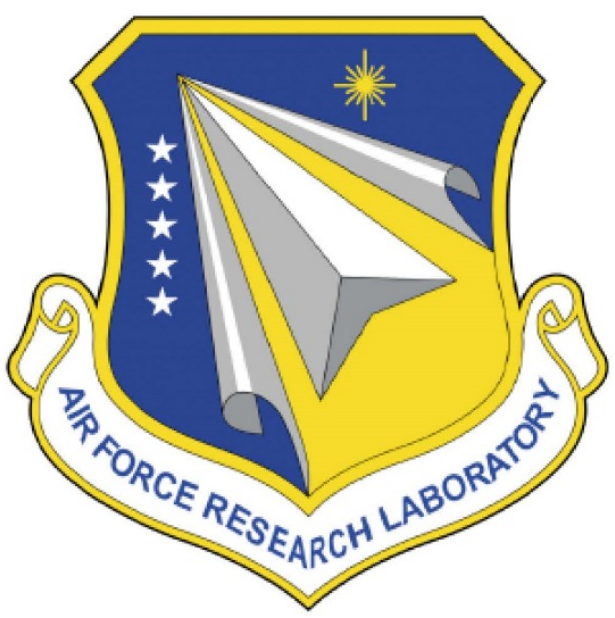


INTENTIONALLY LEFT BLANK.

Approved for public release; distribution is unlimited. 


\title{
7. Army Research Laboratory's Additive Manufacturing for the Future Expeditionary Force
}

\begin{abstract}
Ricardo Rodriguez
(Army Research Laboratory, Weapons and Materials Research Directorate)

One major Army focus is in converting our traditional force into a more expeditionary force. This will result in severe reductions in the logistics tail but will require Army forces to become more adaptive. Units, equipment, and personnel will need to be configurable and reconfigurable based on mission parameters. To accomplish this, the Army will be conducting more in-field, or point-of-need, manufacturing than ever before. Other areas of concentration include man-machine interface, capabilities organic to the Warfighter, unmanned systems, networks, and robotics. Many of the materials and technologies needed to accomplish these goals are still experimental, if they exist at all. This presentation will cover the Army Research Laboratory's Additive Manufacturing activities and discuss several research topics that will allow for the success of this future expeditionary force.
\end{abstract}



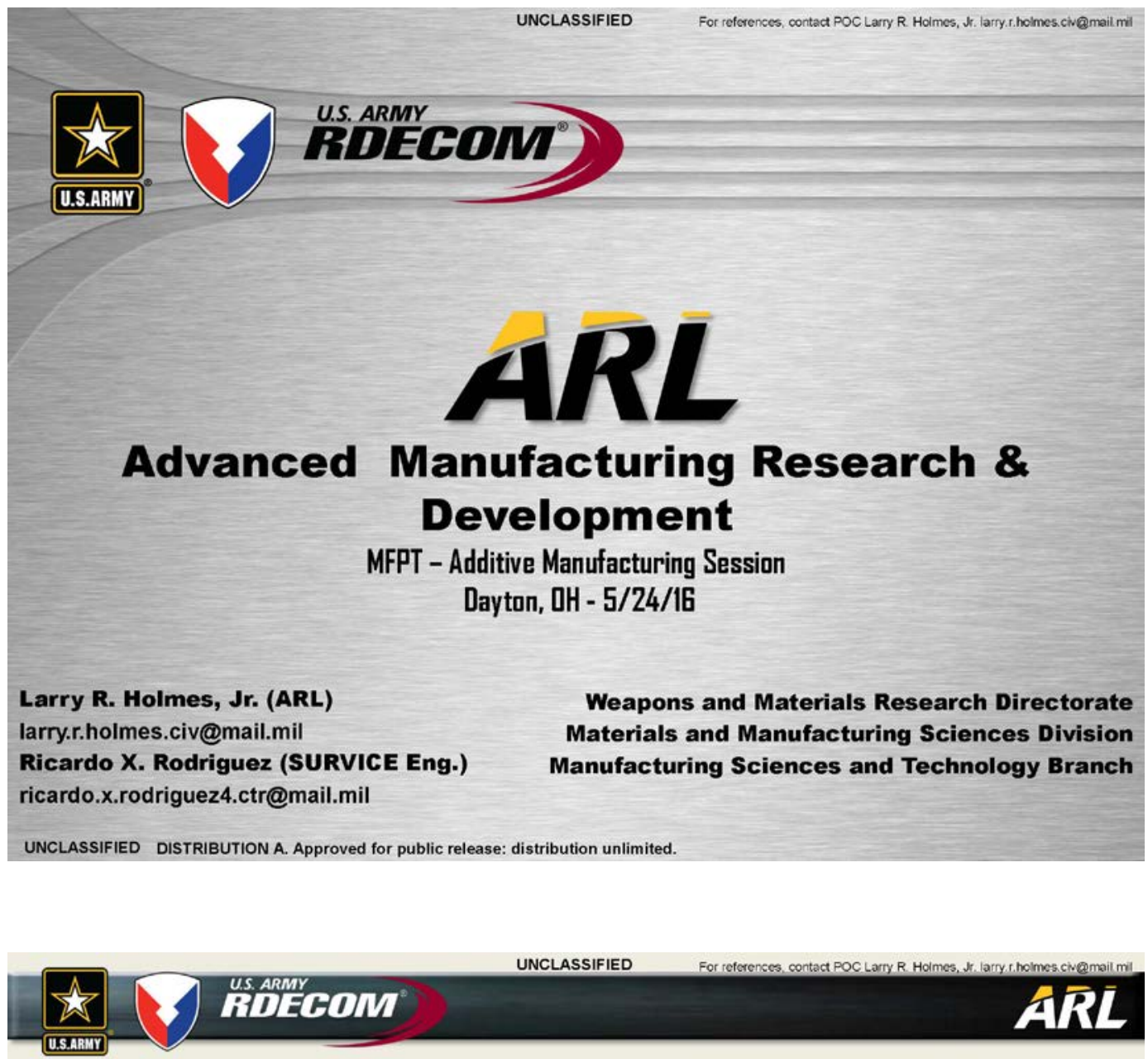

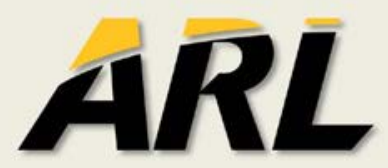

Background

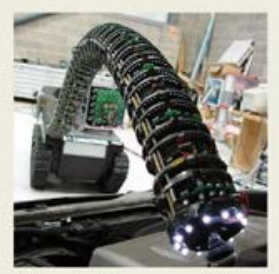

Next Generation

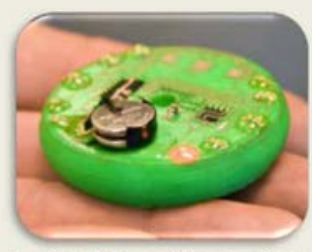

Agile Manufacturing Lab

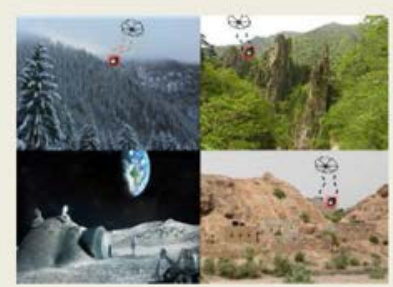

Final Thoughts

UNCLASSIFIED DISTRIBUTION A. Approved for public release: distribution unlimited. 


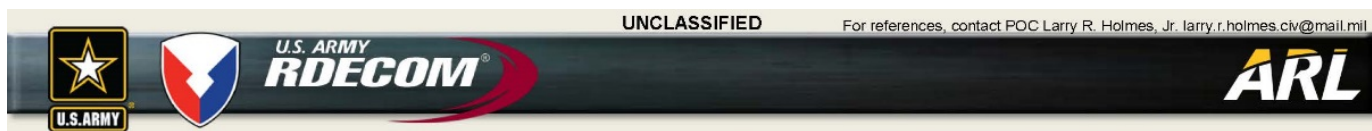

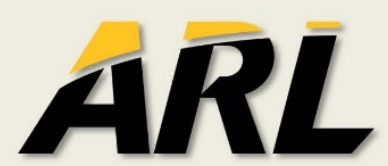

Background

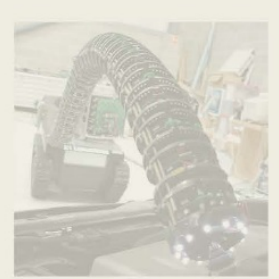

Next Generation

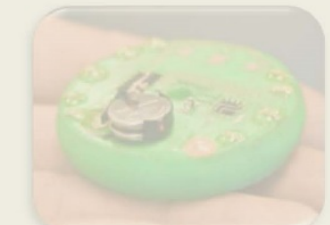

Agile Manufacturing Lab

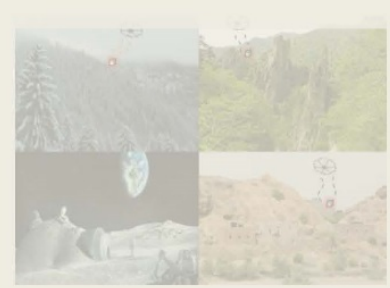

Final Thoughts
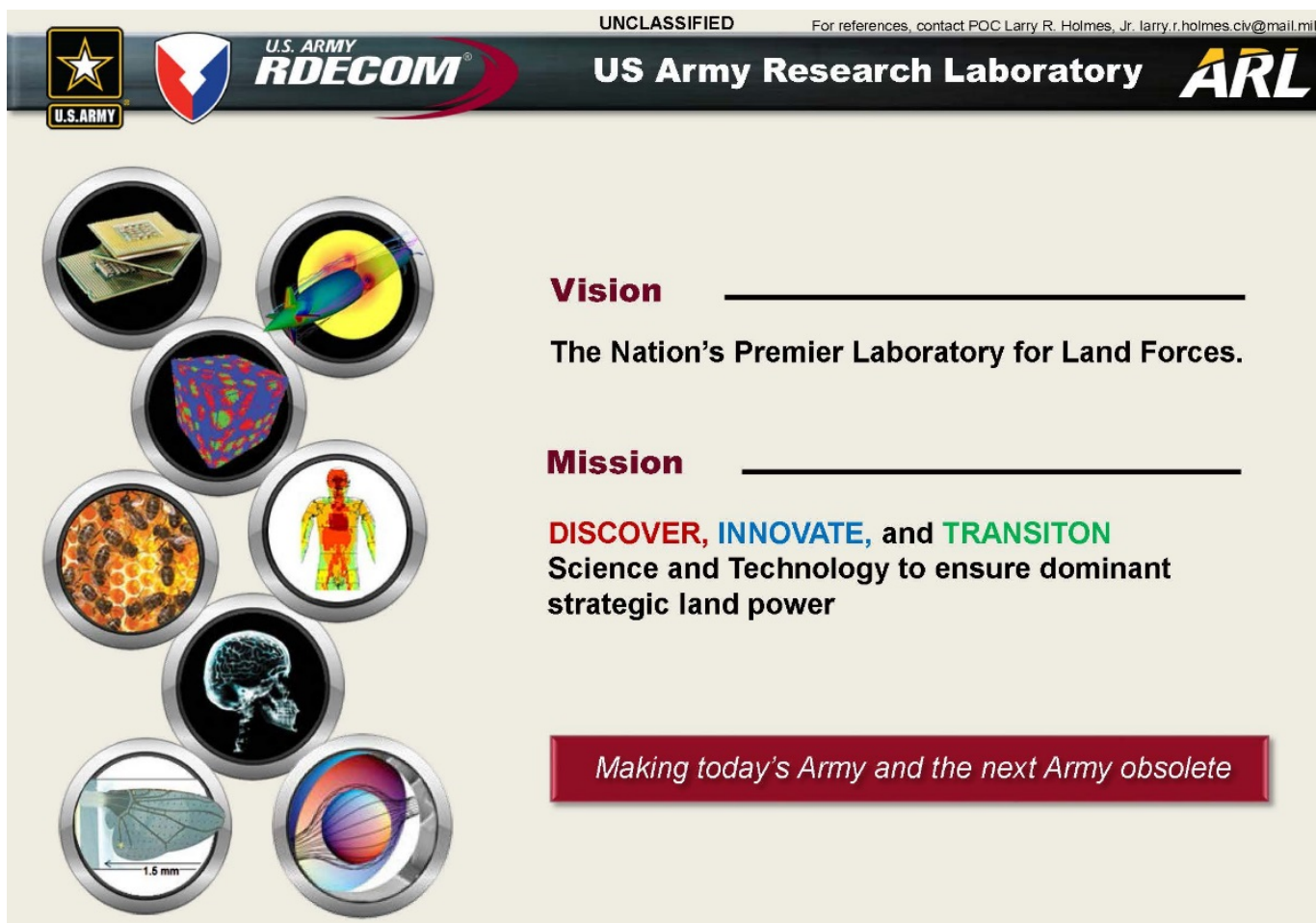

\section{Vision}

The Nation's Premier Laboratory for Land Forces.

\section{Mission}

DISCOVER, INNOVATE, and TRANSITON

Science and Technology to ensure dominant strategic land power 

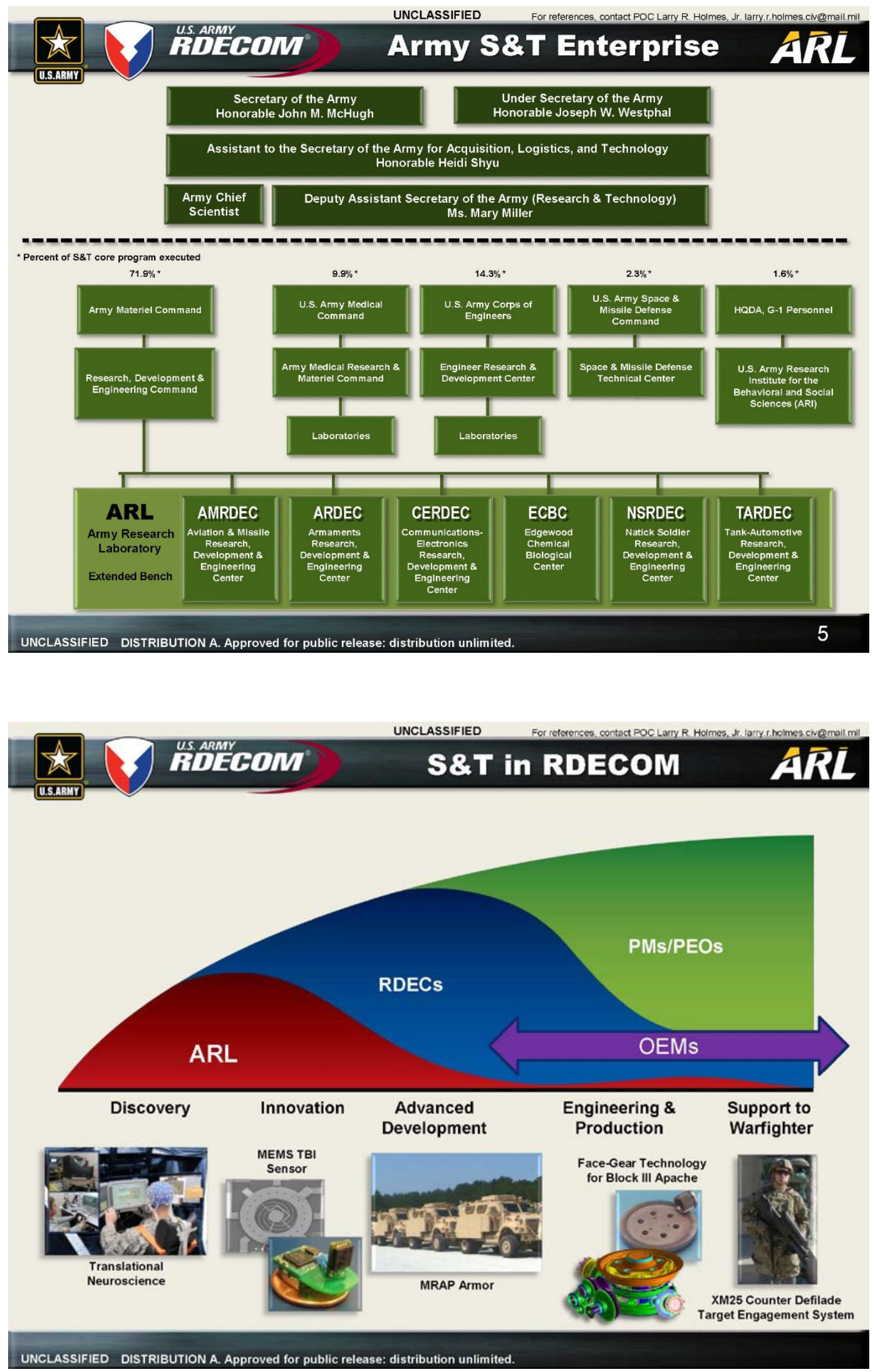

Approved for public release; distribution is unlimited. 

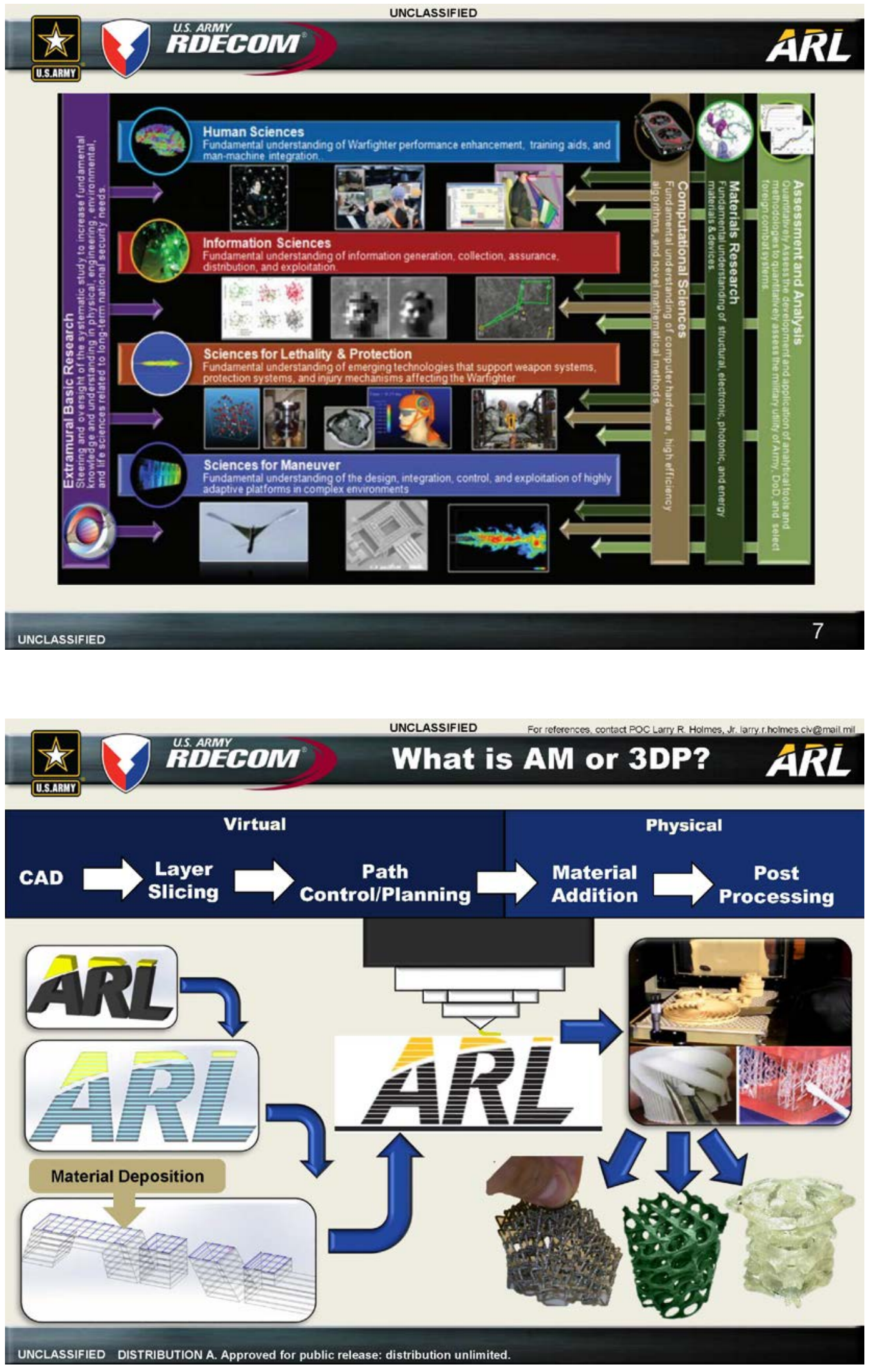

Approved for public release; distribution is unlimited. 


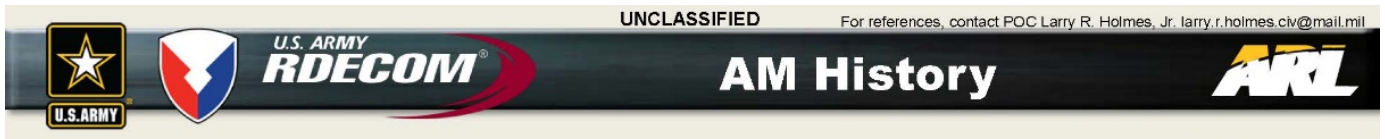

It is not widely known, but three dimensional printing has been around for almost 150 years...
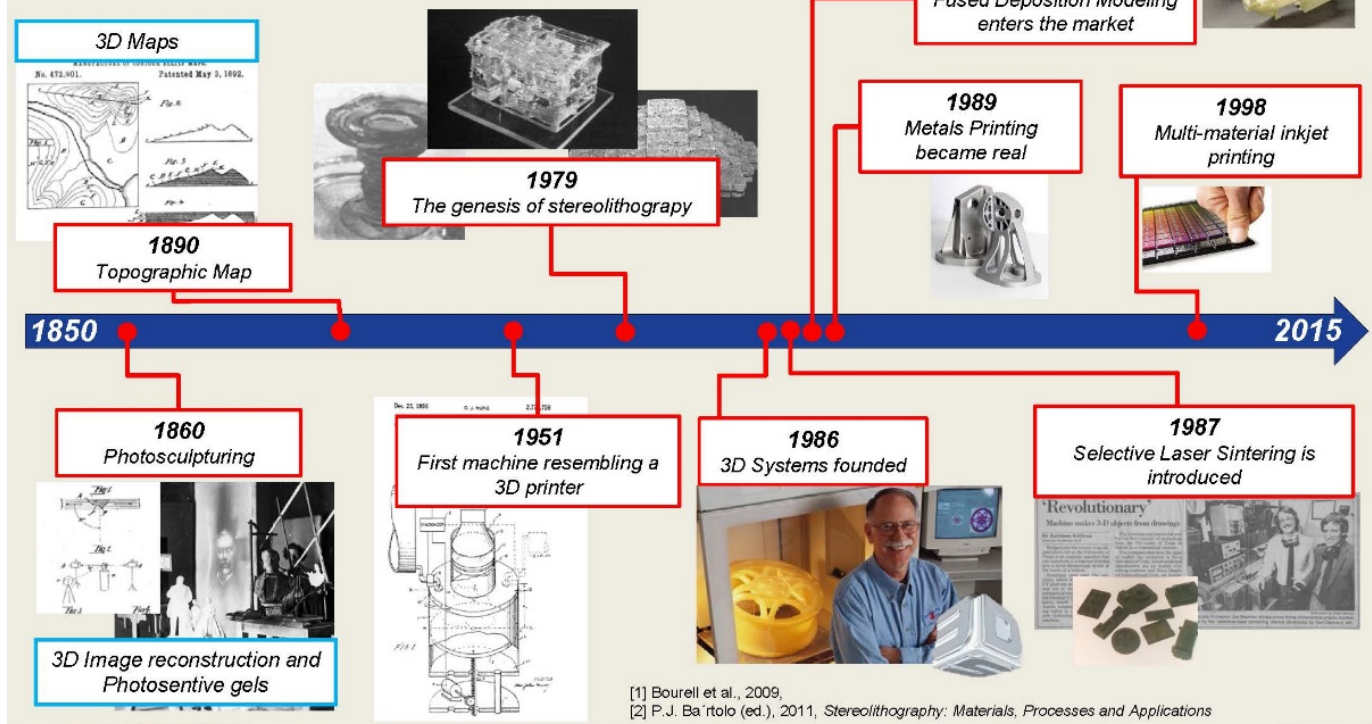

UNCLASSIFIED DISTRIBUTION A. Approved for public release: distribution unlimited.
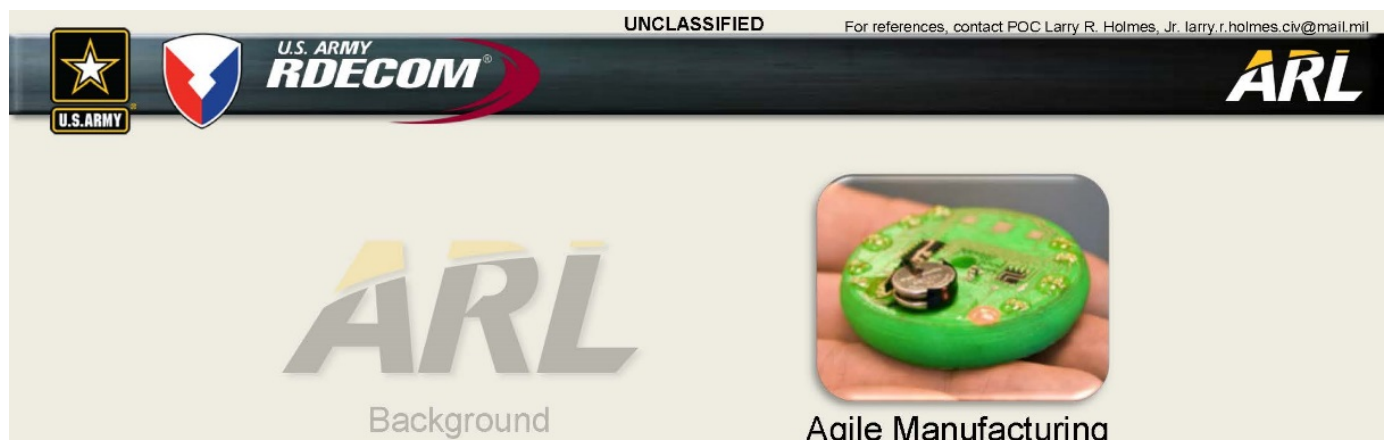

Lab

UNCLASSIFIED DISTRIBUTION A. Approved for public release: distribution unlimited.

Approved for public release; distribution is unlimited. 
- Expeditionary

\section{The BIG Army Vision}

- Reduce the logistical tail

- Adaptive to location. .... jungle, mountain, desert, etc.

- Adaptable, configurable

- Real-time, on-time manufacturing

- Point of use; In-field

- Organic capability

- Realize lightweightening

- Complex manufacturing

- Man-machine interface

- Unmanned vehicles

- Robots

- Networks
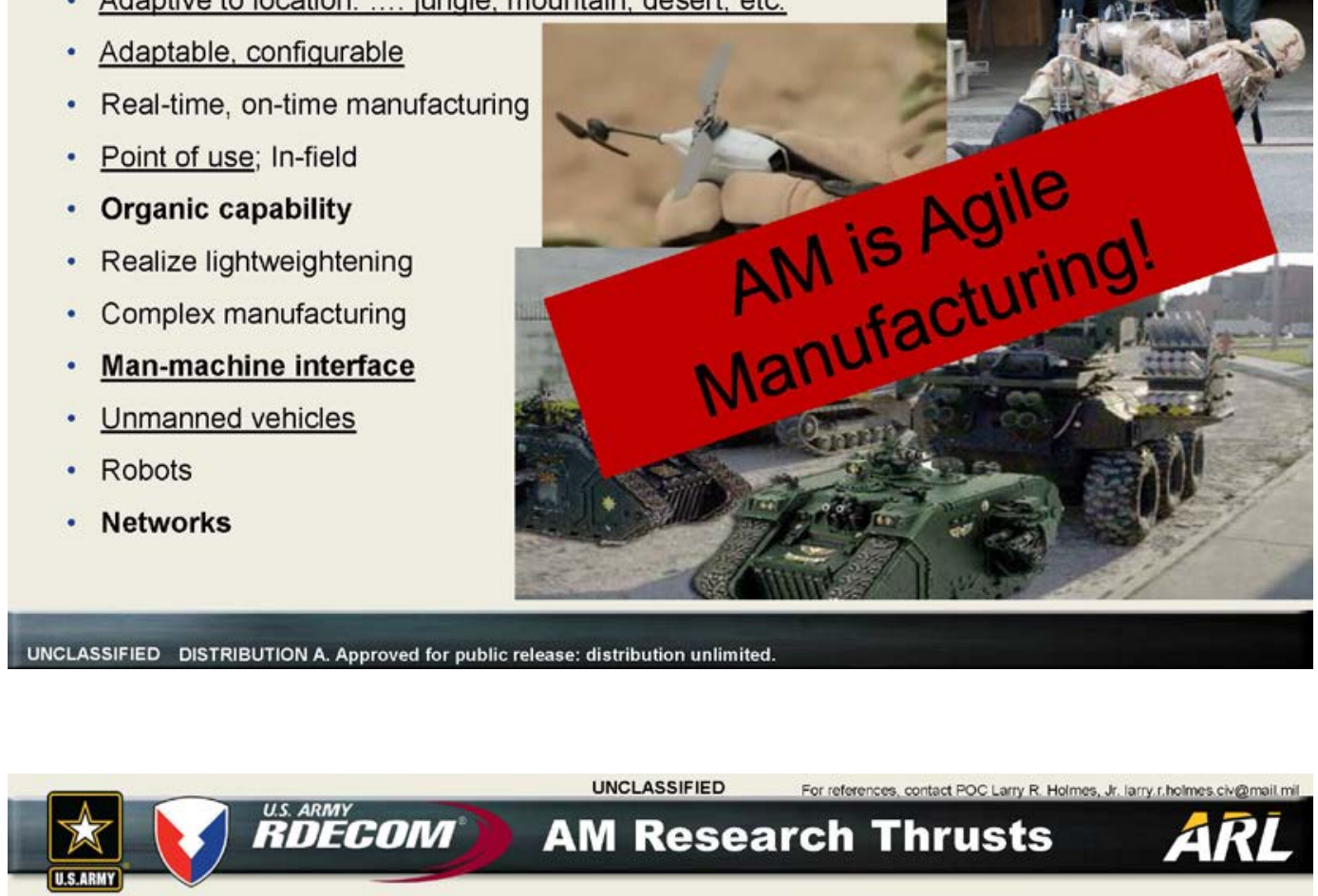

\section{Materials Development for Additive Manufacturing}

- Develop Army robust materials

- Electrically/Thermally compatible and efficient materials

Bridge the Gap Between Direct Write and Additive Manufacturing

- Ultra high fidelity additive manufacturing

- Repeatable performance

Hybridization of Materials and Processing Technologies

- Graded material/structure

- Multi-material processing systems

- Multifunctionality
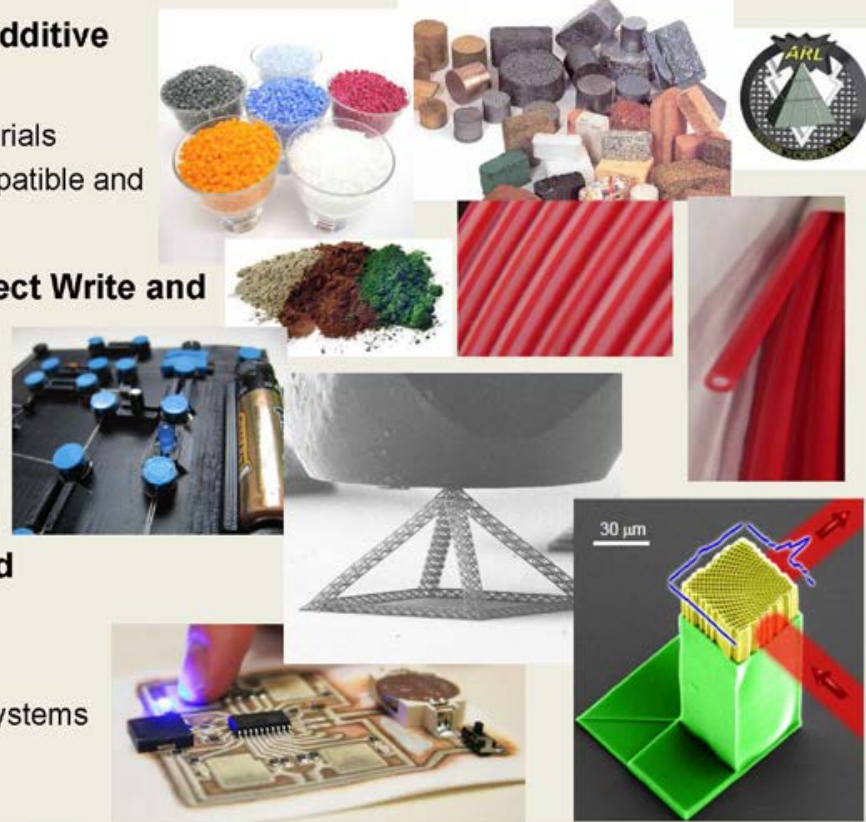

UNCLASSIFIED DISTRIBUTION A. Approved for public release: distribution unlimited. 
The Expeditionary On-Demand Manufacturing Lab is the Army Research Laboratory's Flagship facility for Direct Write and Additive Manufacturing Innovation.

ARL is Developing Next Level Functionality for Additive Manufacturing Technologies Through:
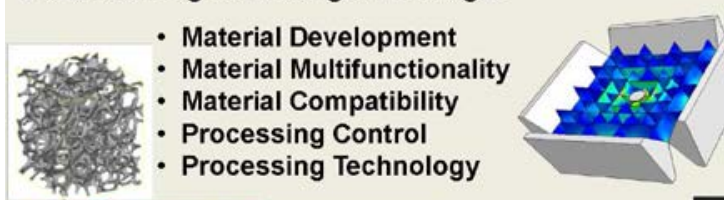

\begin{tabular}{|c|c|}
\hline $\begin{array}{l}\text { Commercial } \\
\text { Processes }\end{array}$ & $\begin{array}{l}\text { - Polymer micro-extrusion } \\
\text { - Micro-dispensing pump } \\
\text { - Vat polymerization } \\
\text { - InkJet } \\
\text { - Aerosol jet } \\
\text { - Cold spray } \\
\text { - Micro-machining } \\
\text { - Direct Metal Laser Sintering }\end{array}$ \\
\hline $\begin{array}{l}\text { ARL } \\
\text { Novel/Experimental } \\
\text { Processes }\end{array}$ & $\begin{array}{l}\text { - Field-aided vat polymerization } \\
\text { - Fiber reinforced micro-extrusion } \\
\text { - Multi-material vat polymerization } \\
\text { - Capillary cold spray } \\
\text { - PRINT, a roll-on deposition } \\
\text { - } 6 \text { axis multi-material processing } \\
\text { - Direct Write/ AM combined }\end{array}$ \\
\hline
\end{tabular}
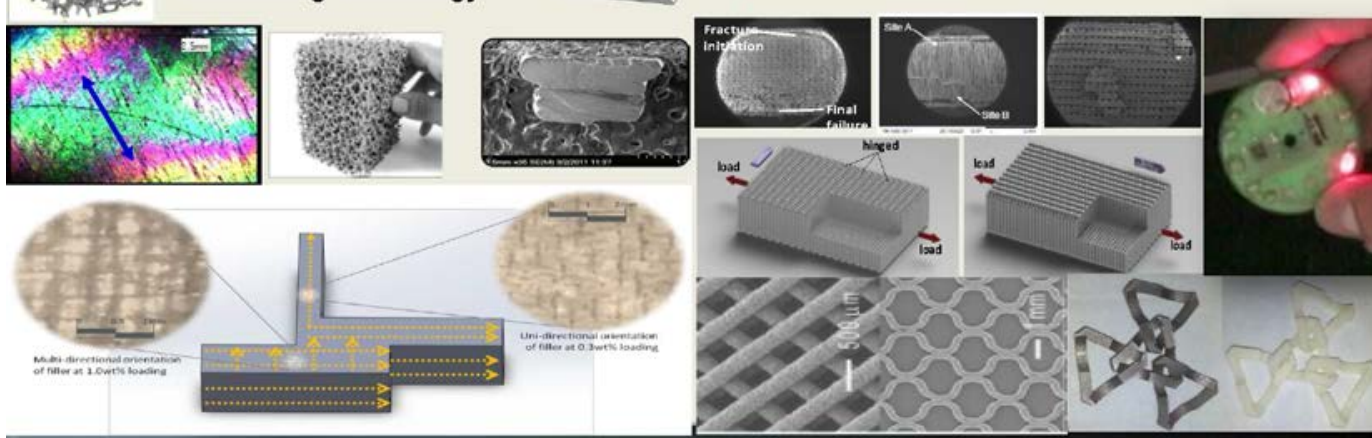

UNCLASSIFIED DISTRIBUTION A. Approved for public release: distribution unlimited.

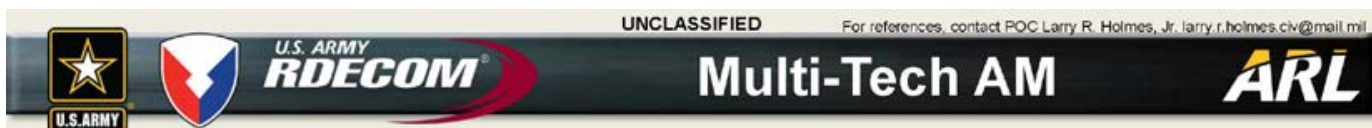

\section{Hybrid Manufacturing}

An active example of a multi-technology printing system. The system is based on universal processing controls and software, which are fully open for manipulation (variation of processing parameters). This system includes:

- Line Scanning

- Thermoplastic Extrusion (up to $400^{\circ}$

-Thermoset Deposition

-Ink Deposition

-6-Axis Motion Control

- Tool Switching

-Pick-n-Place

-Micro-spray

-Micro-milling

- Laser Sintering

-Aerosol Jet Deposition

- Micro Cold Spray Deposition

- Hopper and auger based feeding
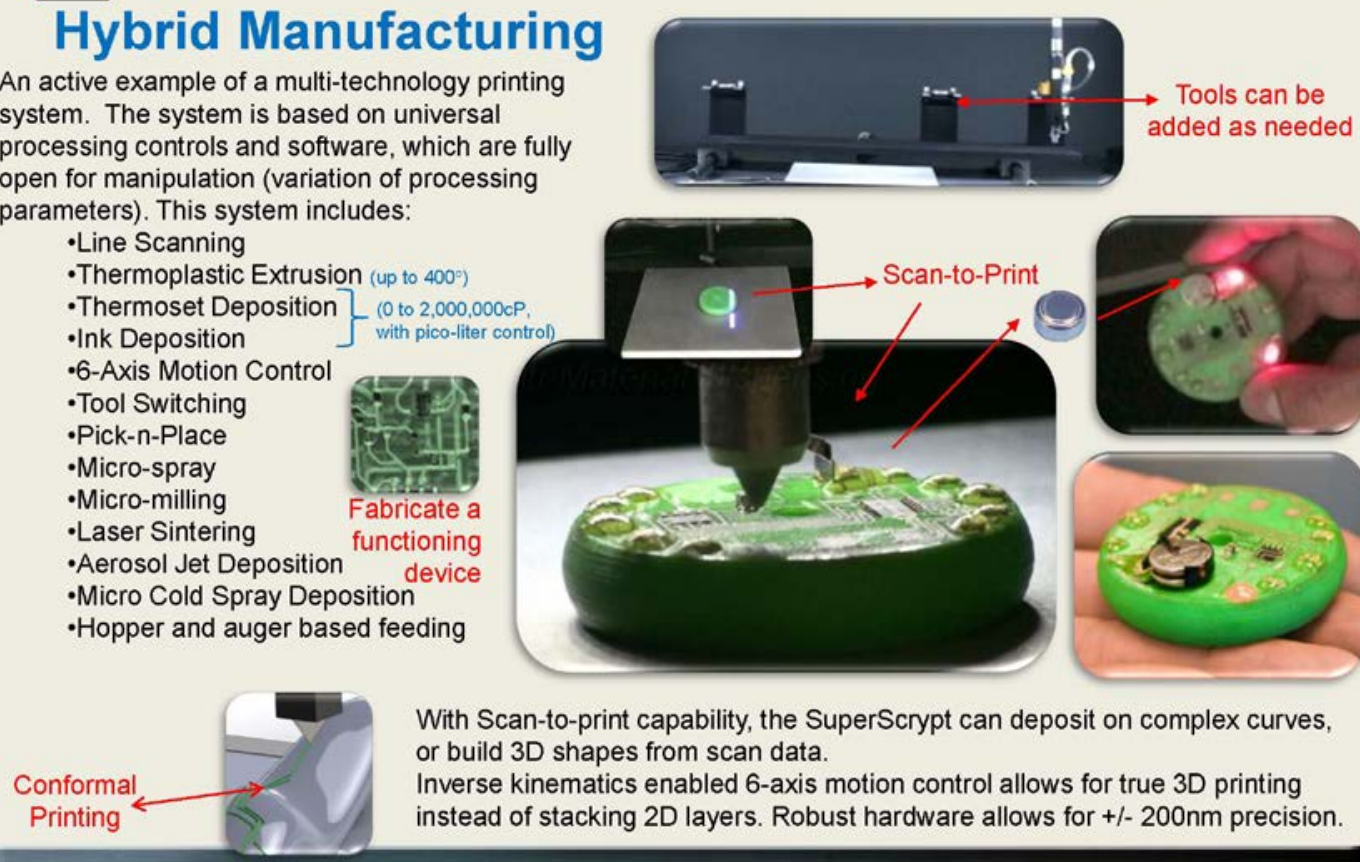

With Scan-to-print capability, the SuperScrypt can deposit on complex curves, or build 3D shapes from scan data.

Inverse kinematics enabled 6 -axis motion control allows for true 3D printing instead of stacking 2D layers. Robust hardware allows for $+/-200 \mathrm{~nm}$ precision.

UNCLASSIFIED DISTRIBUTION A. Approved for public release: distribution unlimited. 

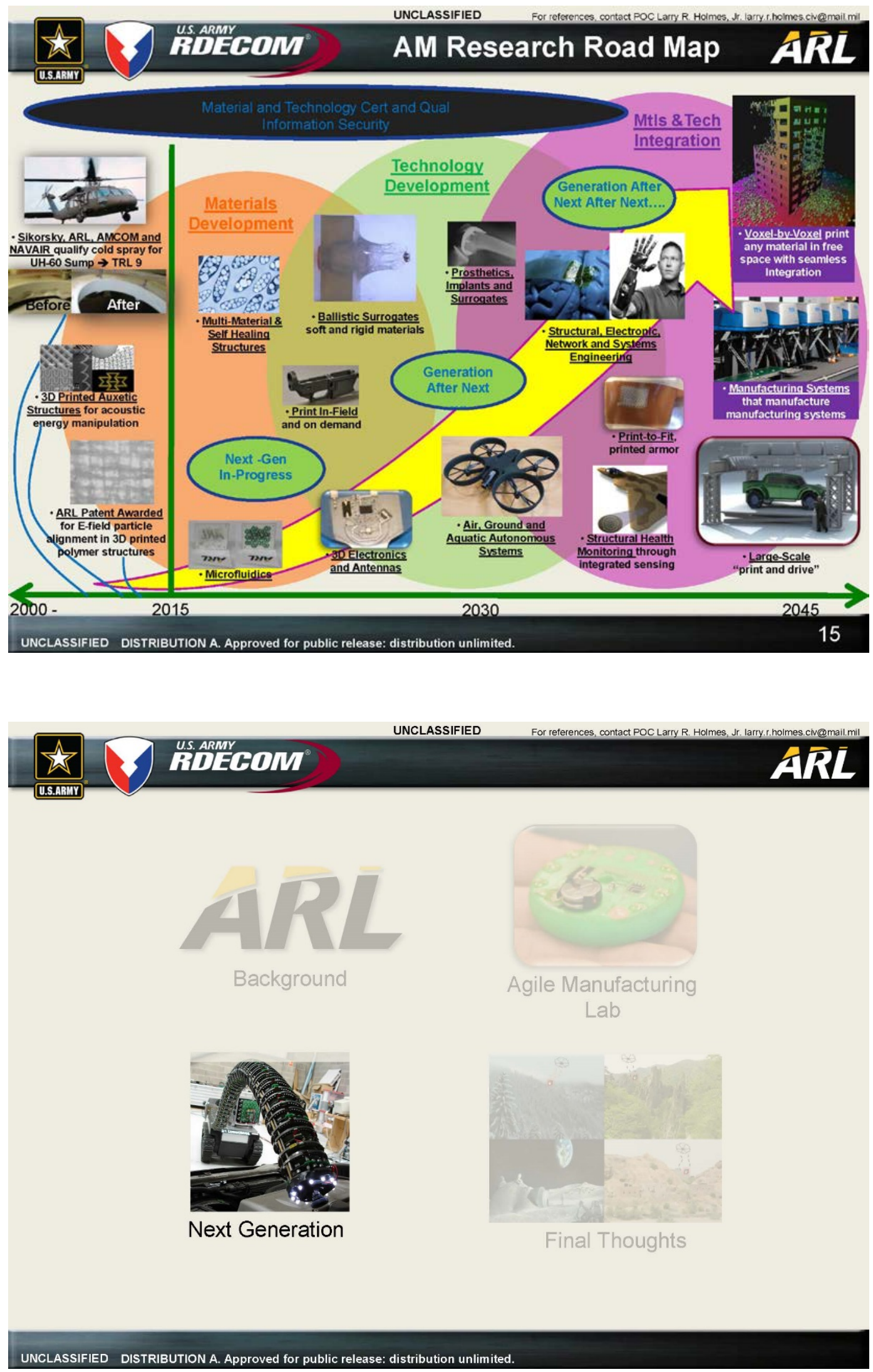

Approved for public release; distribution is unlimited. 

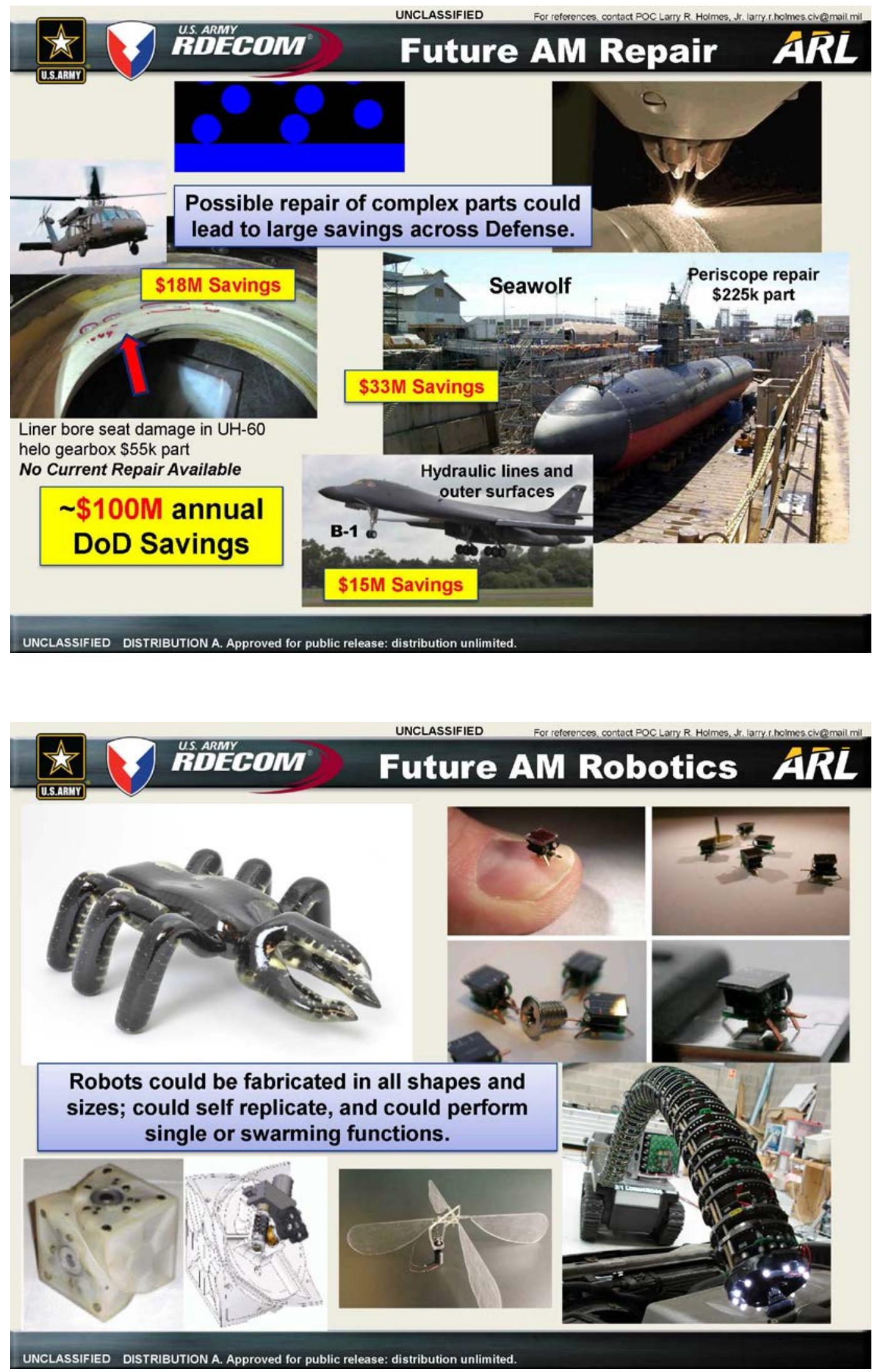

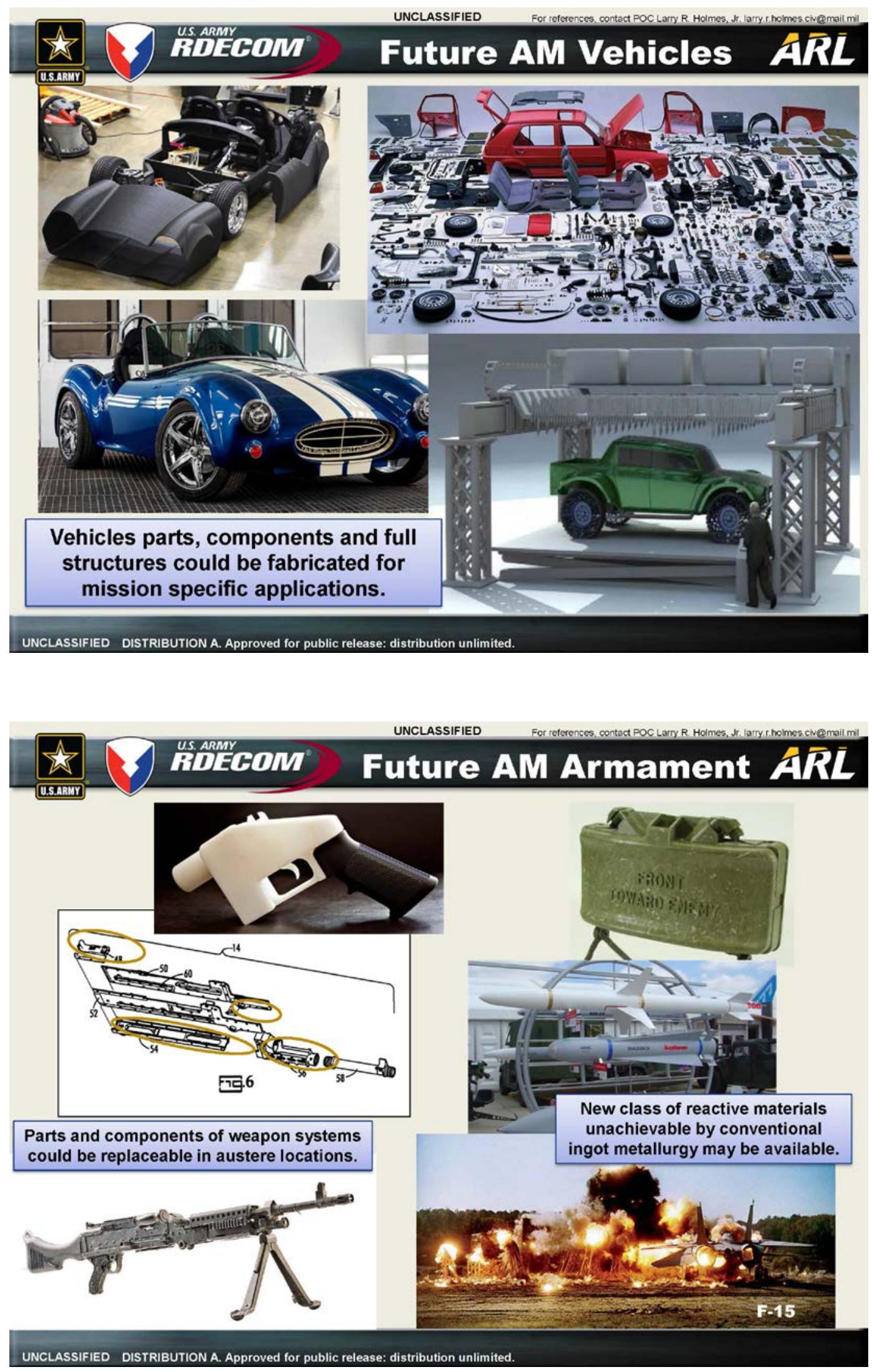

Approved for public release; distribution is unlimited. 

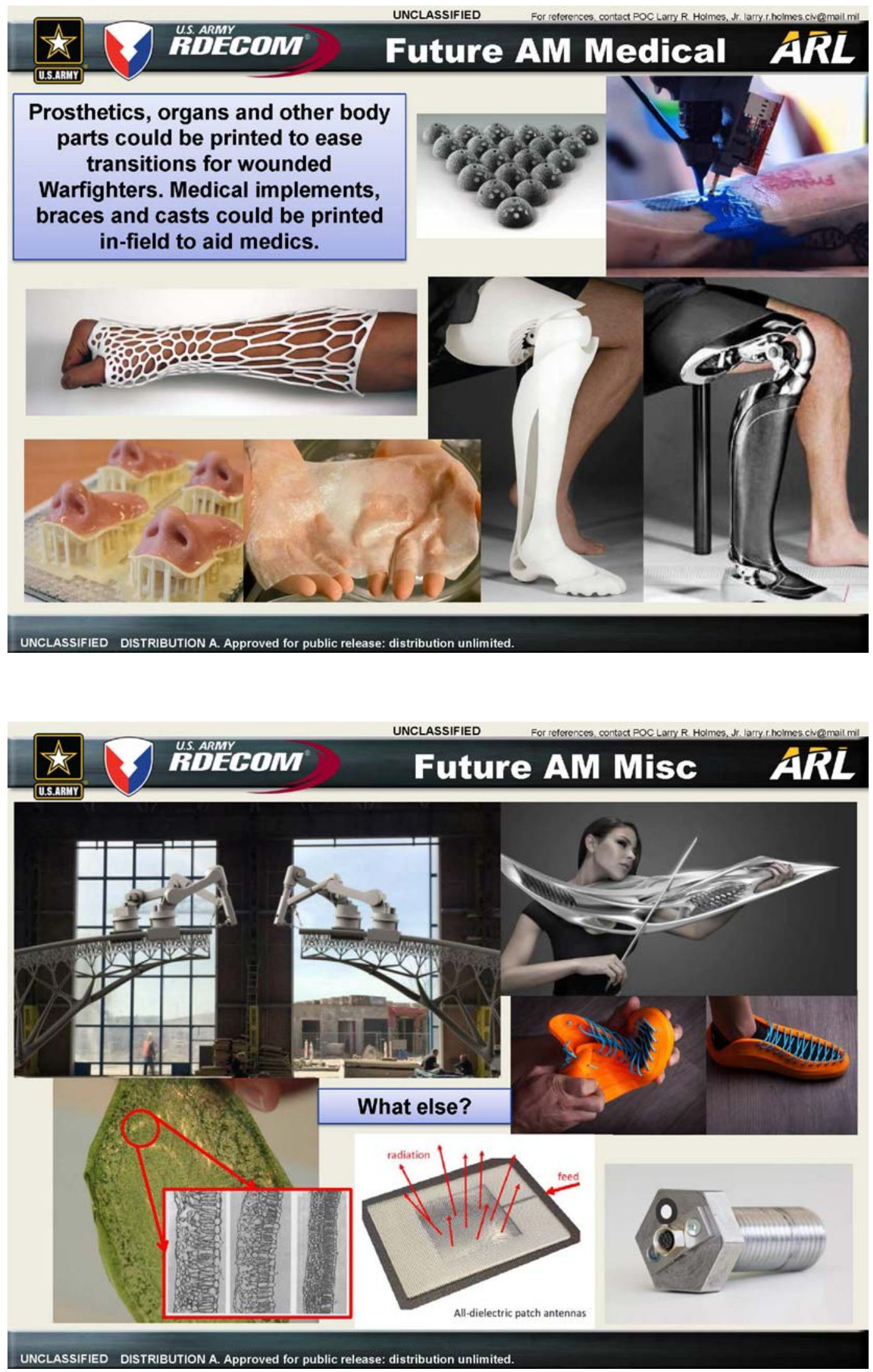

Approved for public release; distribution is unlimited. 

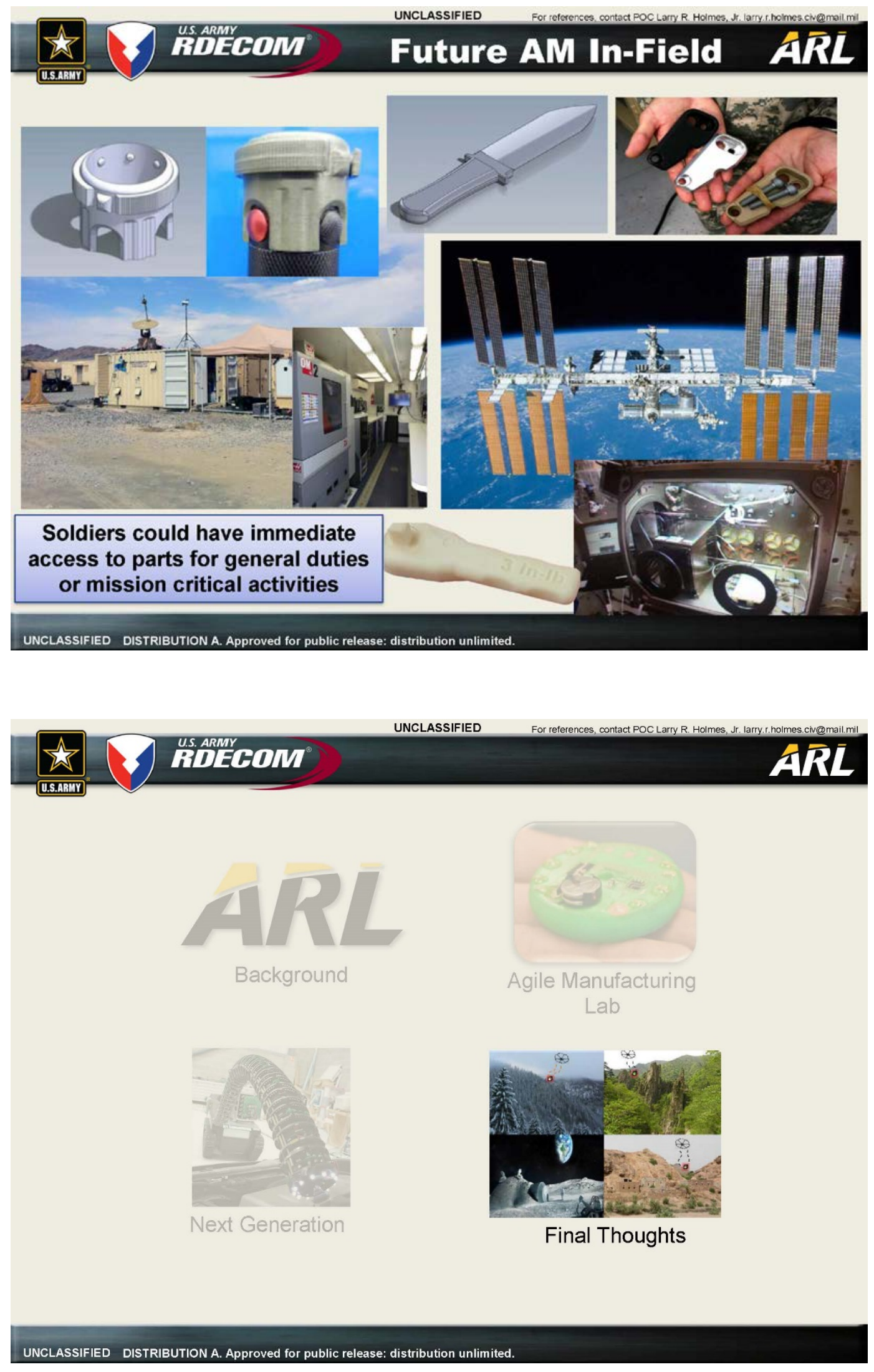

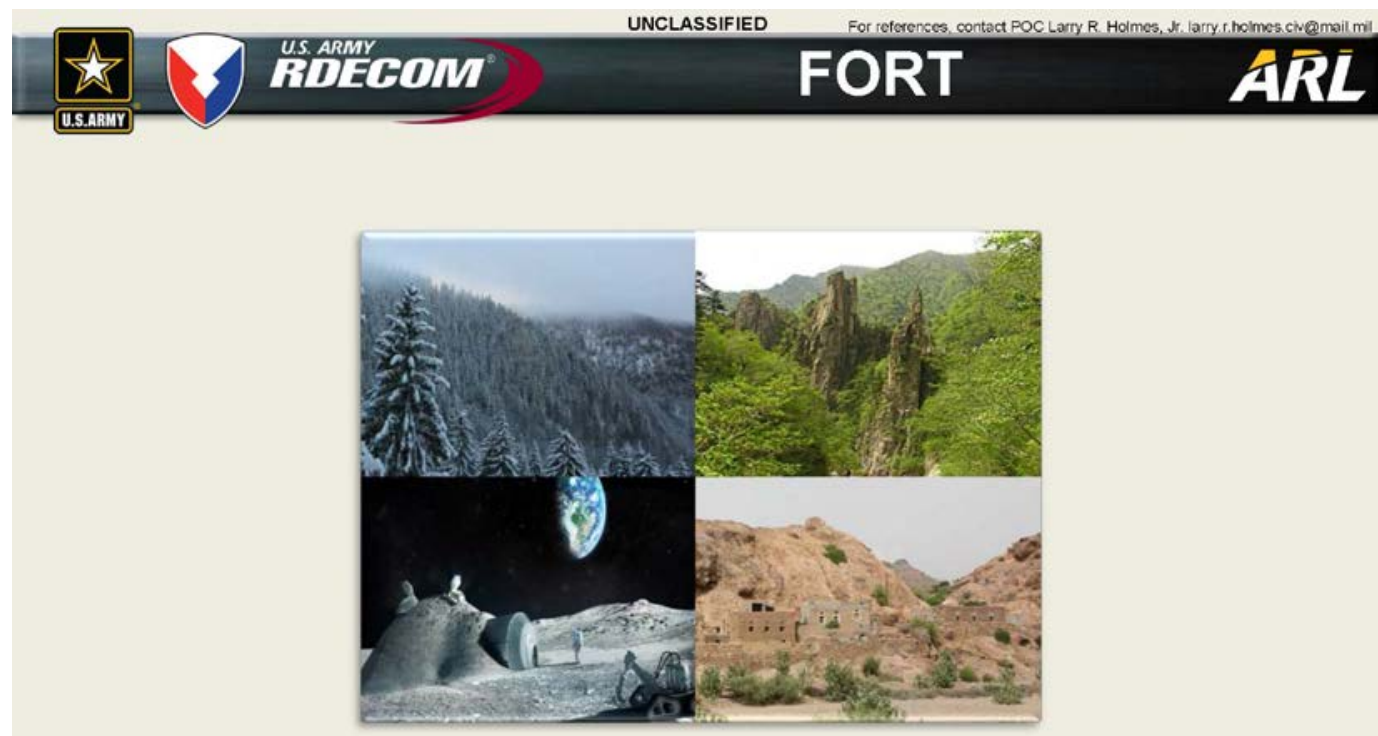

UNCLASSIFIED DISTRIBUTION A. Approved for public release: distribution unlimited.
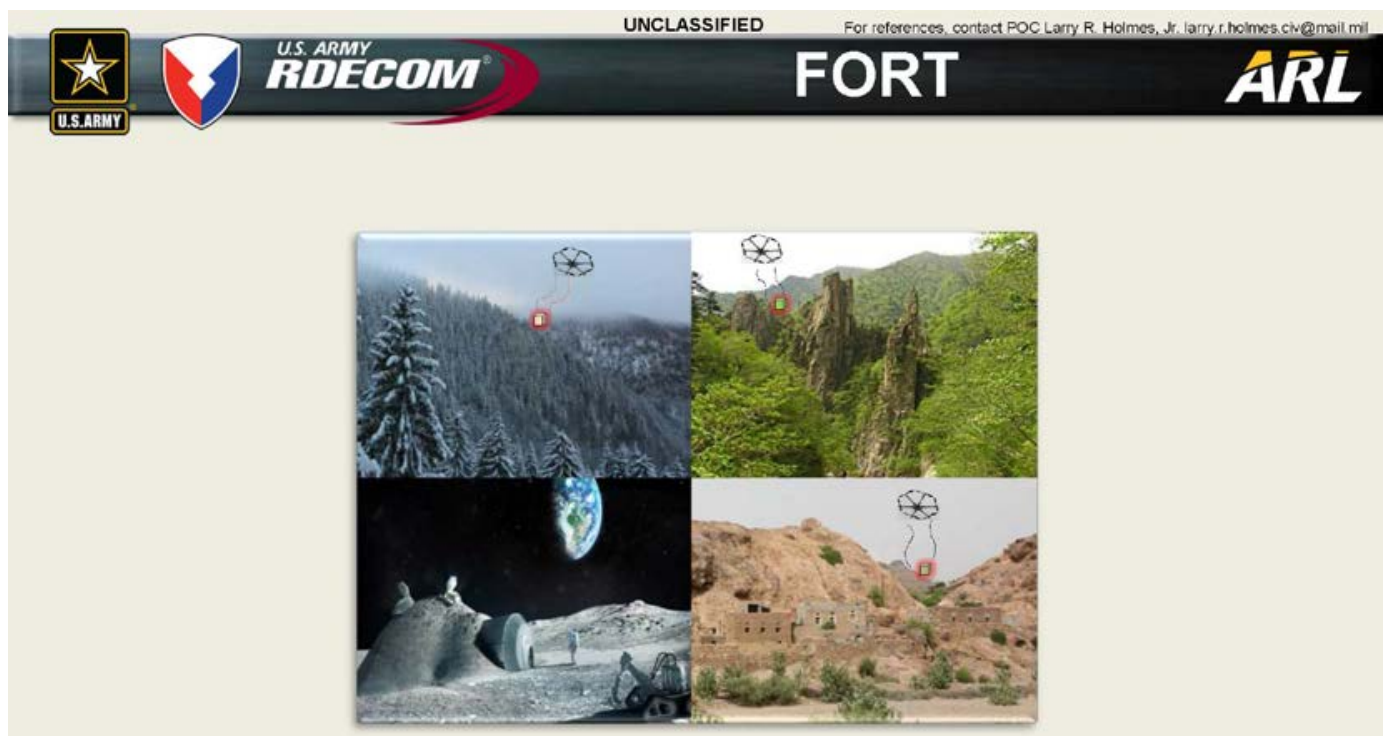

UNCLASSIFIED DISTRIBUTION A. Approved for public release: distribution unlimited.

Approved for public release; distribution is unlimited. 

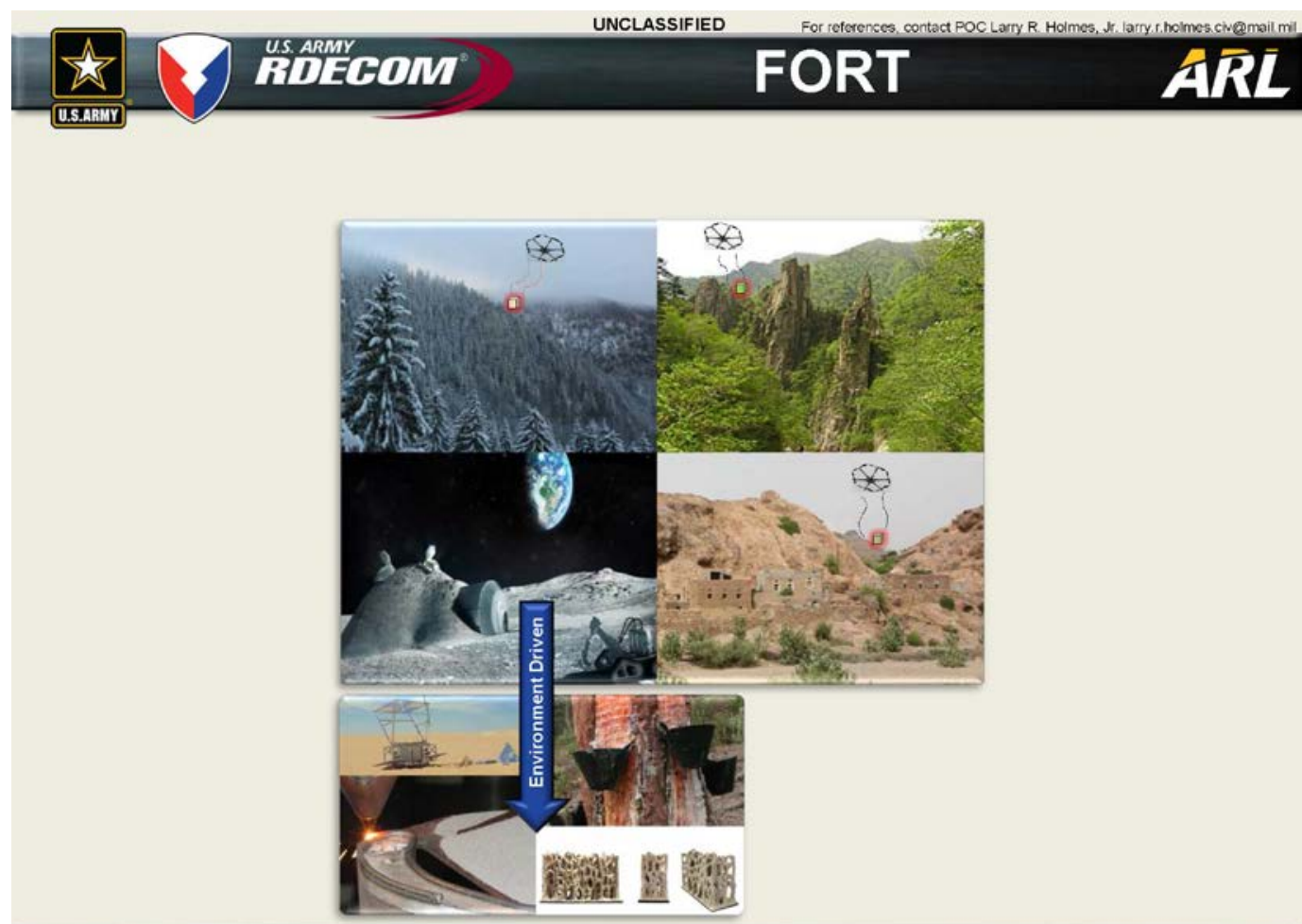

UNCLASSIFIED DISTRIBUTION A. Approved for public release: distribution unlimited.
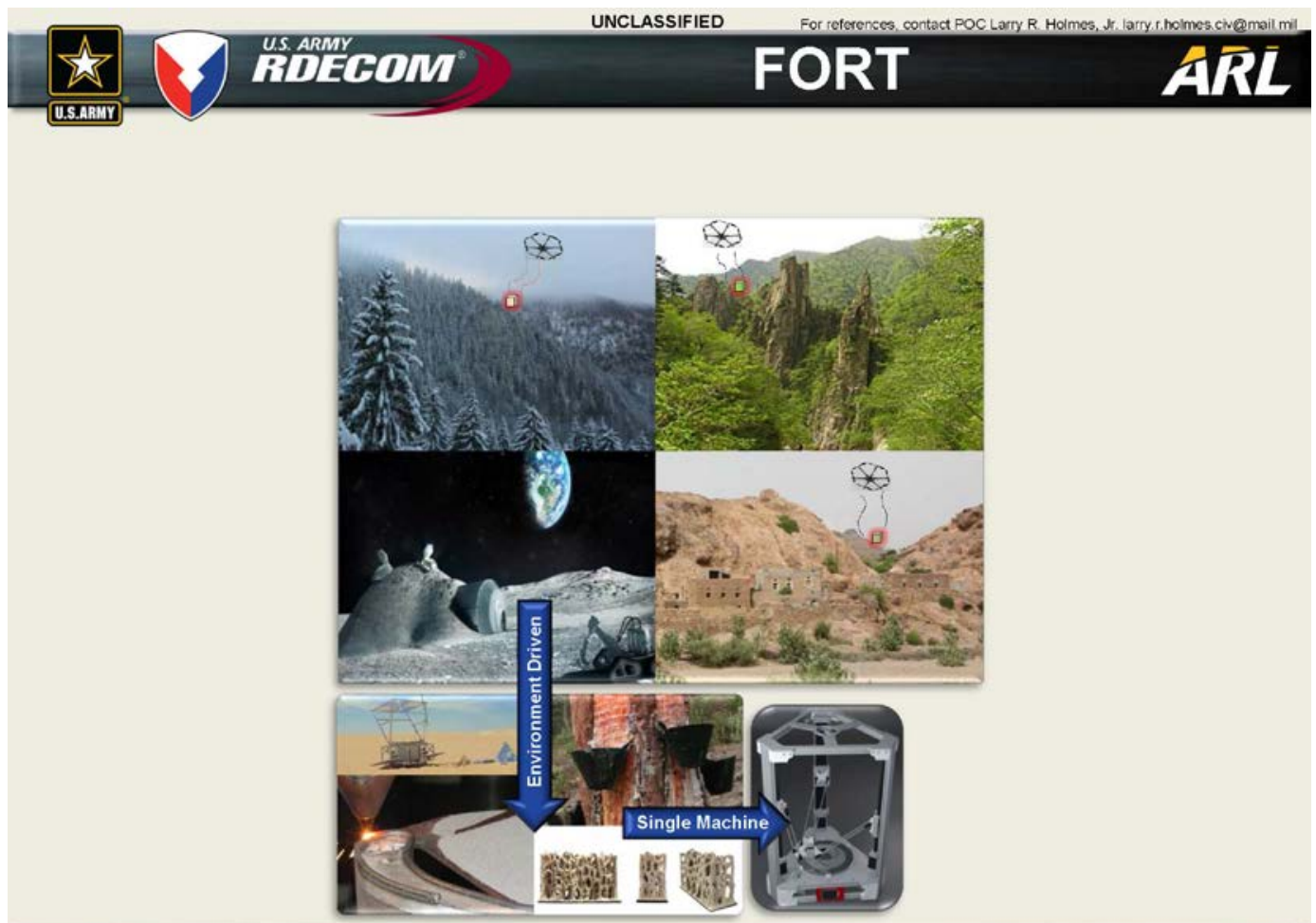

UNCLASSIFIED DISTRIBUTION A. Approved for public release: distribution unlimited. 

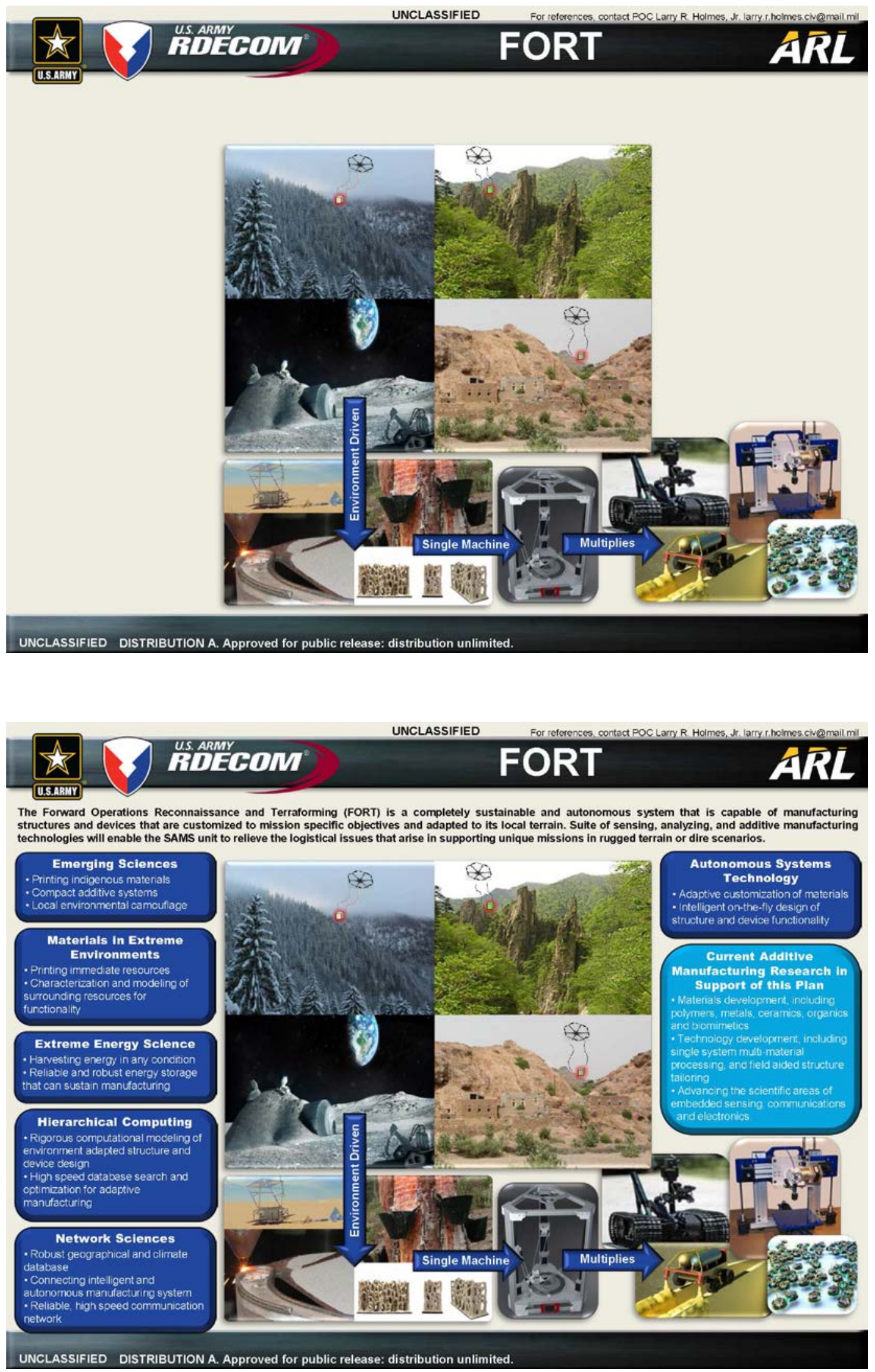

Approved for public release; distribution is unlimited. 

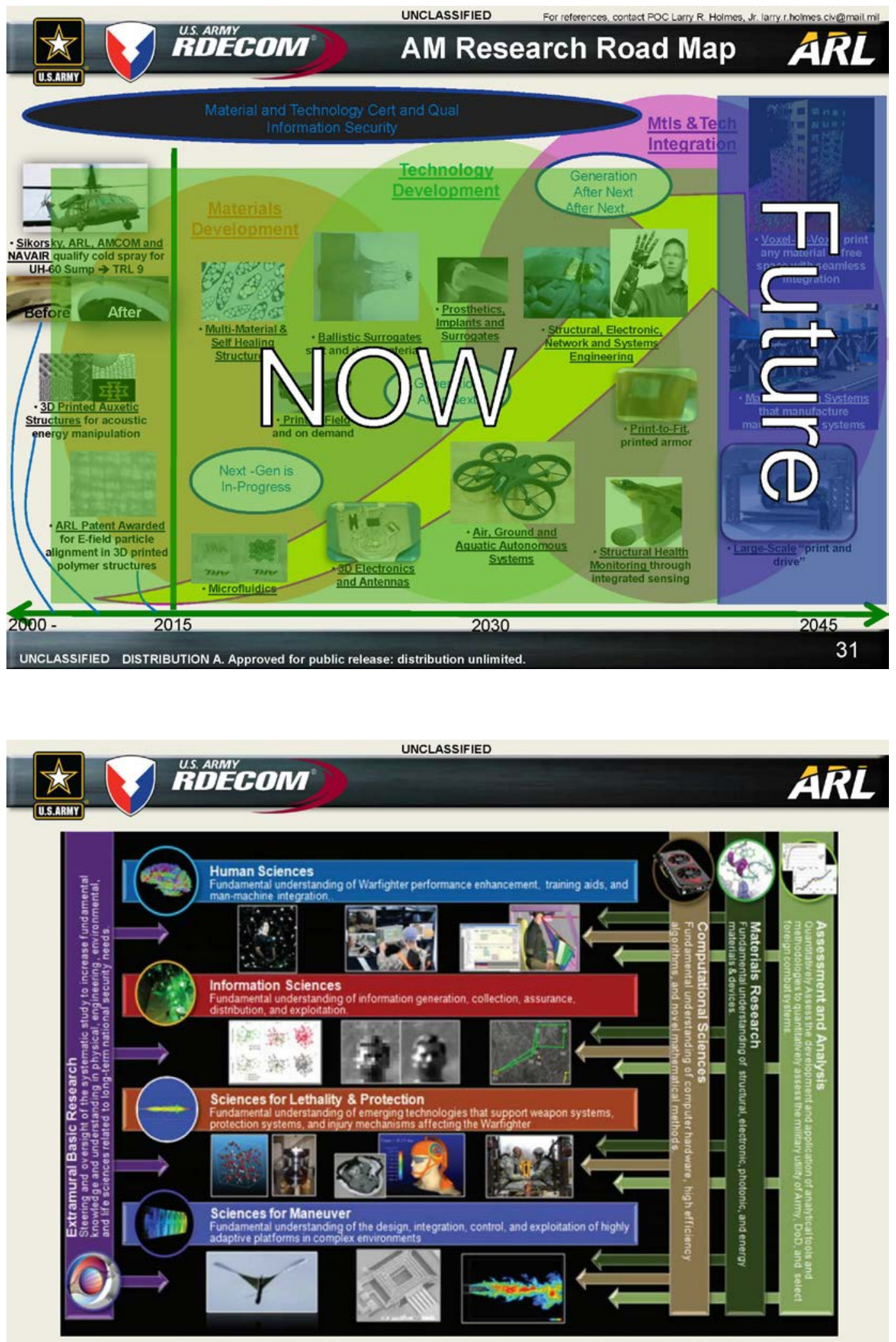


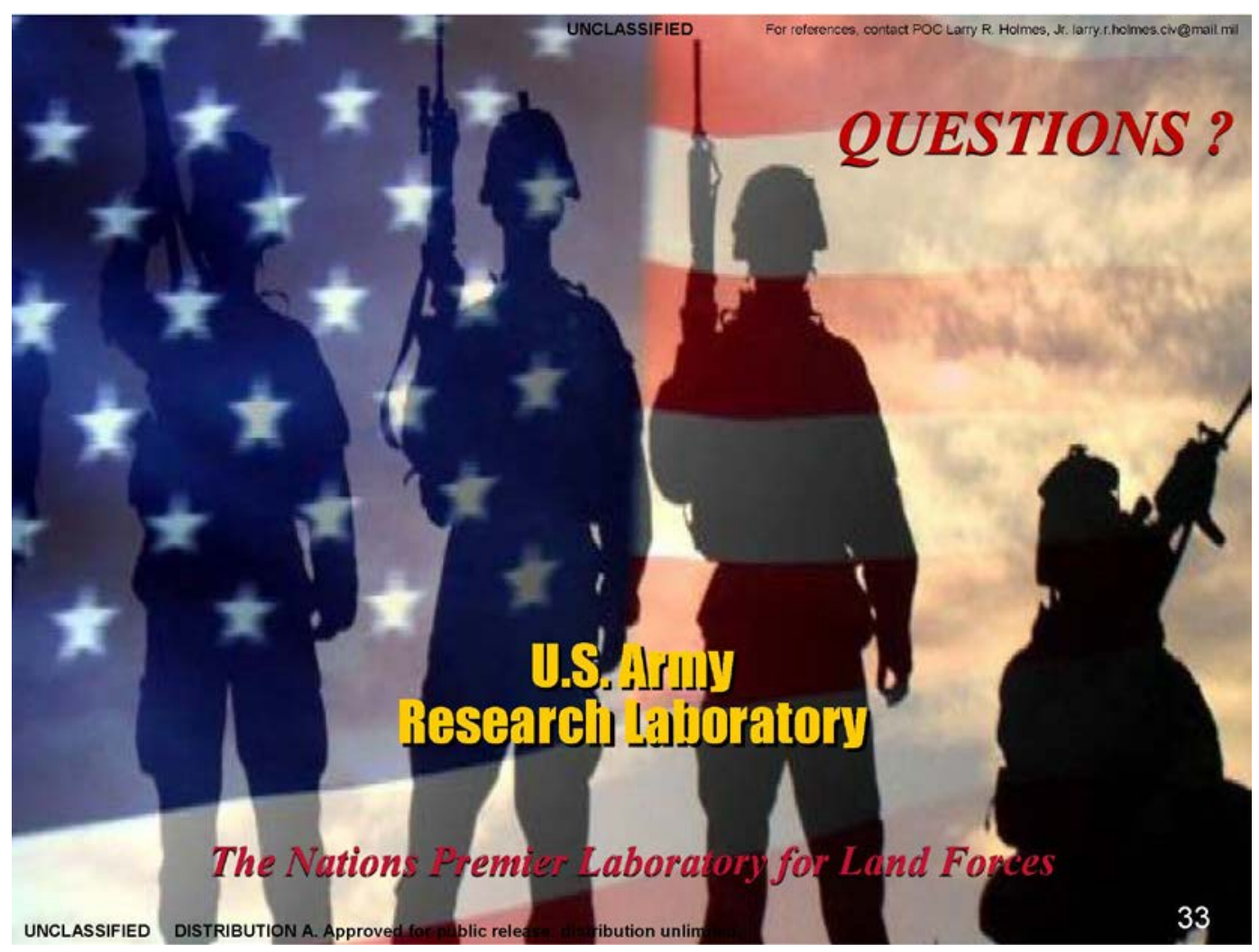




\section{List of Symbols, Abbreviations, and Acronyms}

3-D

AFRL

AM

ARL

CT

MFPT 3-dimensional

Air Force Research Laboratory

additive manufacturing

Army Research Laboratory

computed tomography

Machinery Failure Prevention Technology 


$\begin{array}{cl}1 & \text { DEFENSE TECHNICAL } \\ \text { (PDF) } & \text { INFORMATION CTR } \\ & \text { DTIC OCA } \\ 2 & \text { DIRECTOR } \\ \text { (PDF) } & \text { US ARMY RESEARCH LAB } \\ & \text { RDRL CIO L } \\ & \text { IMAL HRA MAIL \& RECORDS } \\ & \text { MGMT } \\ 1 & \text { GOVT PRINTG OFC } \\ \text { (PDF) } & \text { A MALHOTRA } \\ & \\ 1 & \text { PENN STATE UNIV } \\ \text { (PDF) } & \text { T PALMER } \\ & \text { AFRL } \\ \text { (PDF) } & \text { D BERRIGAN } \\ & \text { J MILLER } \\ 4 & \text { SOCIETY OF MFPT } \\ \text { (PDF) } & \text { C POMFRET } \\ & \text { R WADE } \\ & \text { A WYNN } \\ & \text { M GASSMAN } \\ 4 & \text { DIR USARL } \\ \text { (PDF) } & \text { RDRL WMM D } \\ & \text { M PEPI } \\ & \text { J SIETINS } \\ & \text { R RODRIGUEZ } \\ & \text { RDRL WMM G } \\ & \text { N ZANDER } \\ & \end{array}$

